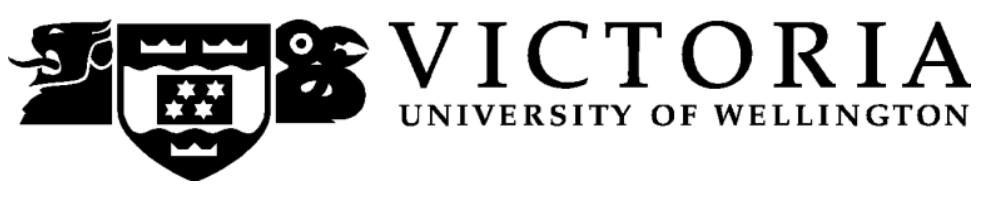

\title{
Managing risks in offshore outsourcing relationships with China: a relational view
}

\author{
By
}

\section{Yiying Zhang (Cindy)}

\begin{abstract}
A thesis submitted to the Victoria University of Wellington and the School of Marketing and International Business in fulfilment of the requirements for the degree of Master of Commerce and Administration in International Business
\end{abstract}

Victoria University of Wellington 


\begin{abstract}
Over the past two decades, offshore outsourcing to emerging economies, such as China, has been viewed by firms as an efficient way to gain competitive advantage. Literature indicates that offshore outsourcing can enhance firms' competitiveness and efficiency by reducing costs, expanding relational ties, freeing up scarce resources, and leveraging capabilities. However, the research relating to risk management of offshore outsourcing relationships has not been widely reflected in extant literature. This study addresses this research gap by developing a conceptual model that examines the association between management approaches and the risks in offshore outsourcing relationships. This study applies two types of risks being relational risk and performance risk, as dependent variables. Based on social exchange theory and transaction cost theory, this study proposes two management approaches to minimise risks in offshore outsourcing relationships, which are the relational approach and the transactional approach.
\end{abstract}

Empirical testing of the conceptual model employed a quantitative approach using an online survey of 41 managers from Australia and New Zealand. The survey data was analysed using a multiple regression technique, which revealed four valuable findings. Firstly, a higher level of relational risk leads to a higher level of performance risk. Secondly, the relational approach, based on interdependence of outsourcing exchange firms, can reduce performance risk. Thirdly, an increased level of relationship-specific investments contributes to the rise of performance risk. More importantly, the survey results show that relational risk plays a mediating role between relational factors and performance risk. This study recommends that offshore outsourcing firms employ the relational approach to manage performance risk. The mediating role of relational risk also indicates that firms should not just concentrate on minimising the performance risks of offshore outsourcing relationships, but should also manage relational risks due to uncooperative behaviours such as opportunism. 


\section{Acknowledgements}

I would like to thank all those who made it possible for me to complete this thesis. First and foremost, I would like to express my sincere gratitude to my supervisors, Dr Hongzhi Gao and Professor Val Lindsay, for their continuous support and guidance during this Masters research. Secondly, I would like to thank my former supervisor, Dr Audra Mockaitis, for contributing her time and ideas during her tenure at the School of Marketing and International Business.

I would also like to thank academic and professional staff at the School of Marketing and International Business for providing their support and advice during my research, particularly Dr Aaron Gazeley for his statistical insights, and Jacqui FitzGerald for her kind encouragement.

My sincere thanks also to the managers who kindly agreed to give up their valuable time to be surveyed for my research. I am grateful and impressed by their willingness to participate in this study.

Last but not least, I am thankful for the support, encouragement, and patience over the past two years of my dear friend Andrea Bates and my loving husband Damien Barthel.

Without the help of all these people this thesis would never have been possible. Thank you again. 


\section{Table of Contents}

Abstract ii

Acknowledgements iii

Chapter 1: Introduction ................................................... 1

1.1. Overview ...................................................... 1

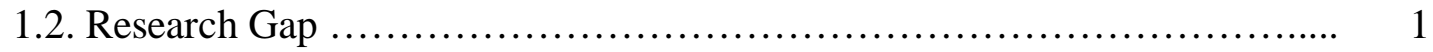

1.3. Research Objectives ............................................ 2

1.4. Research Contributions ............................................. 2

1.5. Research Questions ................................................ 4

1.6. Research Model .................................................. 4

1.7. Methodological Approach .......................................... 5

1.8. Outline of the Thesis .............................................. 5

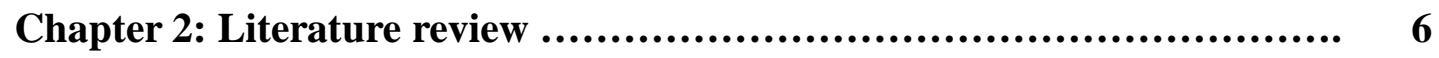

2.1. Offshore Outsourcing ............................................. 6

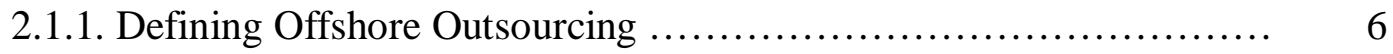

2.1.2. Motives for Offshore Outsourcing ........................... 7

2.2. Theoretical Underpinnings of Offshore Outsourcing .................... 9

2.2.1. Transaction Cost Theory ...................................... 9

2.2.1.1. Applying TCT to Outsourcing Relationship Management ....... 10

2.2.1.2. Applying TCT to Outsourcing Risks .......................... 12

2.2.2. Resource-Based View ......................................... 12

2.2.2.1. Applying RBV to Outsourcing Relationship Management ........ 12

2.2.2.2. Applying RBV to Outsourcing Risks ......................... 14

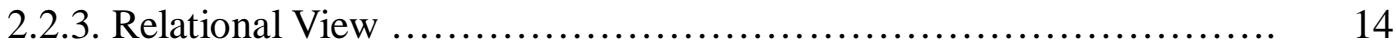

2.2.3.1. Social Exchange Theory $\ldots \ldots \ldots \ldots \ldots \ldots \ldots \ldots \ldots \ldots \ldots \ldots \ldots . \ldots . \ldots \ldots$ 
2.2.3.2. Apply SET to Outsourcing Risks .......................... 16

2.2.4. Comparing TCT with SET in Managing Outsourcing Relationships ... 17

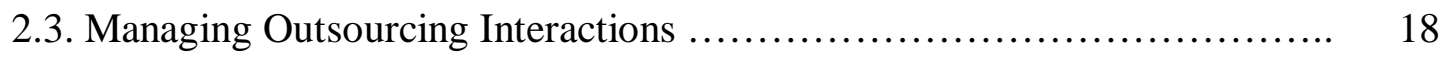

2.3.1 Existing Relationship Approaches ............................. 18

2.4. Outsourcing Risks .............................................. 18

2.4.1. Defining Risk ............................................. 20

2.4.2. Phases of Outsourcing Risk ..................................... 21

2.4.2.1. Risks in the Ex-ante Contract Phase ............................ 21

2.4.3. The Risks in Offshore Outsourcing Relationships ................. 22

2.4.4. Categorising Risks in Offshore Outsourcing Relationships ........... 24

2.4.4.1. Relational Risk .......................................... 24

2.4.4.2. Performance Risk ....................................... 25

2.5. Research Problem ................................................. 26

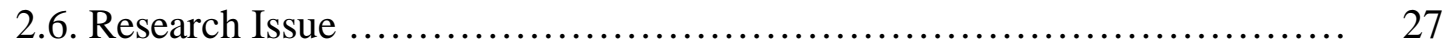

2.7. Chapter Summary ............................................ 28

Chapter 3: Conceptual Development ..................................... 29

3.1. Recapping Outsourcing Risk ...................................... 29

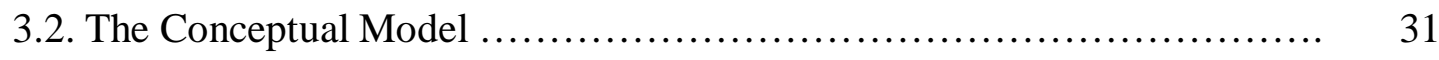

3.2.1. Relationship between Relational Risk and Performance Risk ......... 31

3.2.2. Key Influencing Factors in the Management of Outsourcing 32

Relationship Risks

3.2.2.1. Trust .................................................. 34

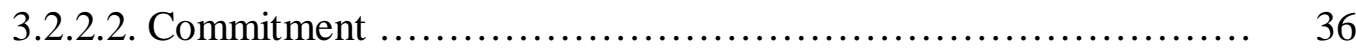

3.2.2.3. Information Sharing .................................... 36

3.2.2.4. Communication Quality .................................. 37

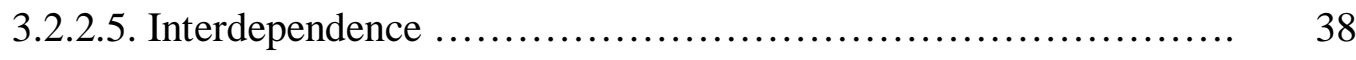

3.2.2.6. Guanxi ................................................ 39

3.2.2.7. Contractual Complexity ................................. 39

3.2.2.8. Asset Specificity ...................................... 40 
3.2.2.9. Indirect Effect of Relational Risk

3.2.3. Control Variable ............................................. 42

3.3. The Conceptual Model $\ldots \ldots \ldots \ldots \ldots \ldots \ldots \ldots \ldots \ldots \ldots \ldots \ldots \ldots \ldots \ldots \ldots \ldots . \quad 43$

3.4. Chapter Summary .............................................. 43

Chapter 4: Methodology .................................................. 44

4.1. Justification of Methodology Used ............................... 44

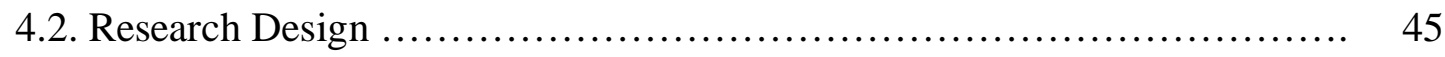

4.3. Survey Research ............................................ 46

4.3.1. Sampling and Data Collection ................................. 47

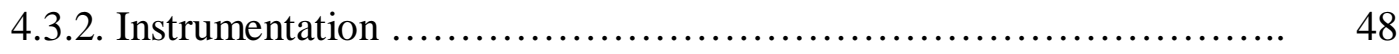

4.4. Validity and Reliability of the measurement instrument $\square \ldots \ldots \ldots \ldots \ldots \ldots .53$

4.5. Statistical Method ............................................... 54

4.6. Ethics ...................................................... 55

4.7. Chapter Summary ............................................... 55

Chapter 5: Survey Results ........................................... 56

5.1. Firm and Respondent Demographics ................................ 56

5.1.1. Firm Demographics ....................................... 56

5.1.2. Respondent Demographic ................................... 58

5.2. Reporting Firms' Outsourcing Experience ........................... 59

5.2.1. Firms' International Outsourcing Experience ...................... 59

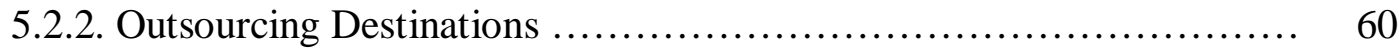

5.2.3. Outsourcing Motivations ....................................... 61

5.2.4. Outsourcing Experience in China ................................ 62

5.3. Results of Hypothesis Testing ................................... 63

5.3.1. Descriptive Results ............................................ 63

5.3.2. Regression Results .......................................... 64

5.3.2.1. Assumptions of Regression Analysis ......................... 65

5.3.2.2. Results of Regression Analysis ............................. 70

5.3.2.2.1. Testing the Indirect Effects of Relational Risk .............. 69 
5.3.2.2.2. Control Variable ....................................... 71

5.3.2.3. Summary of Hypotheses Testing Results ..................... 72

5.4. Chapter Summary ............................................... 73

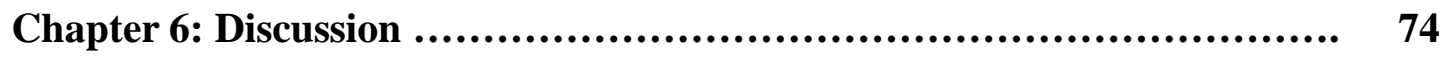

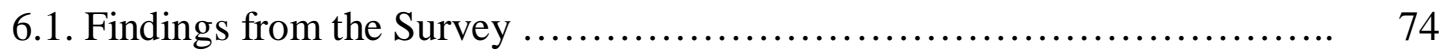

6.1.1. Discussion on Hypotheses Testing ............................. 74

6.1.1.1. Interactions between Relational Risk and Performance Risk ...... 75

6.1.1.2. Interactions between Relational Risk and Relational Factors ...... 76

6.1.1.3. Interactions between Performance Risk and Relational Factors .... 76

6.1.1.4. Interactions between Performance Risk and Transactional Factors.. 77

6.1.1.5. Interactions between Relational Risk and Transactional Factors ... 78

6.1.1.6. Indirect Effect of Relational Risk .......................... 78

6.1.1.7. The Role of Cultural Difference as Control Variable ............. 79

6.1.2. A Modified Research Model ..................................... 80

6.2. Research Contributions ......................................... 81

6.3. Chapter Summary .............................................. 82

Chapter 7: Conclusions ................................................ 83

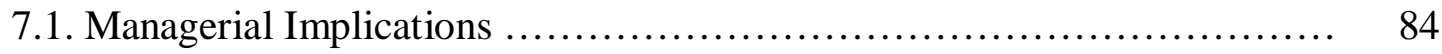

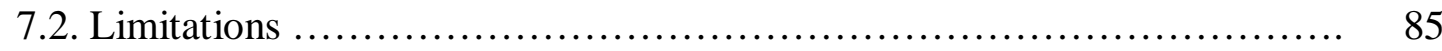

7.3. Recommendations for Future Research ............................. 86

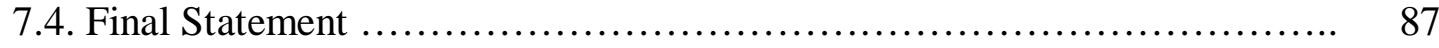

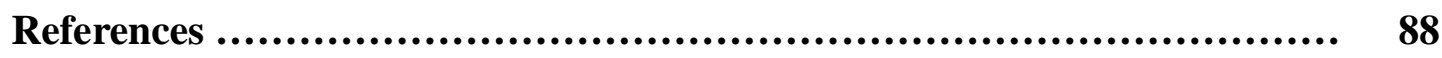

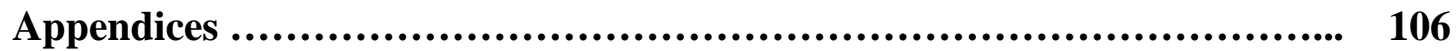

Appendix A: P-P Plot and scatterplot of equation 1 ...................... 106

Appendix B: P-P Plot and scatterplot of equation 2 ...................... 107

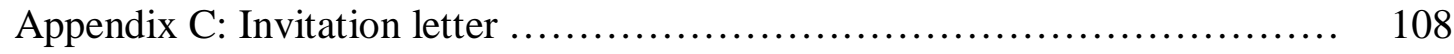

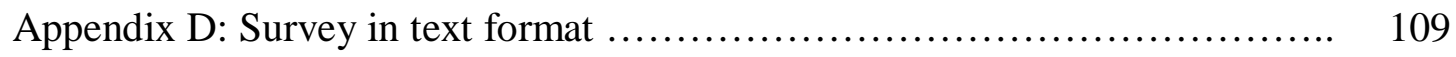




\section{List of Tables}

\begin{tabular}{|c|c|c|}
\hline Table & Description & Page \\
\hline Table 3.1 & $\begin{array}{l}\text { Key influencing factors in risk management of outsourcing } \\
\text { relationships }\end{array}$ & 32 \\
\hline Table 4.1 & Measurement items & 50 \\
\hline Table 4.2 & Results of Cronbach's alpha test & 53 \\
\hline Table 5.1 & Profile of responding firms & 57 \\
\hline Table 5.2 & Profile of respondents & 58 \\
\hline Table 5.3 & Firms' offshore outsourcing experience & 60 \\
\hline Table 5.4 & Outsourcing destination & 61 \\
\hline Table 5.5 & Firms' outsourcing motivations & 61 \\
\hline Table 5.6 & Years of outsourcing experience to China & 62 \\
\hline Table 5.7 & Outsourcing method in China & 62 \\
\hline Table 5.8 & Descriptive statistics and correlation matrix & 63 \\
\hline Table 5.9 & Correlated relationships between variables & 64 \\
\hline Table 5.10 & Results of Durbin-Watson test & 66 \\
\hline Table 5.11 & Assumption of regression analysis & 66 \\
\hline Table 5.12 & Results of multiple regression analysis & 67 \\
\hline Table 5.13 & The results of factor analysis & 69 \\
\hline Table 5.14 & Regression results for the indirect effects of relational risk & 70 \\
\hline Table 5.15 & Summary of hypothesis testing results & 72 \\
\hline
\end{tabular}




\section{List of Figures}

\begin{tabular}{|l|l|c|}
\hline Figure & Description & Page \\
\hline Figure 1.1 & $\begin{array}{l}\text { The basic model of managing risks in offshore outsourcing } \\
\text { relationships }\end{array}$ & 4 \\
\hline Figure 2.1 & Illustrating offshore outsourcing & 7 \\
\hline Figure 2.2 & $\begin{array}{l}\text { Conceptualising the link between management approaches and } \\
\text { risks in offshore outsourcing relationships }\end{array}$ & 27 \\
\hline Figure 3.1 & The conceptual model & 43 \\
\hline Figure 6.1 & The modified research model & 80 \\
\hline
\end{tabular}




\section{Chapter One: Introduction}

This chapter introduces the topic of interest for this study. Firstly, an initial overview describes the broad field of offshore outsourcing risks and relationship management. The second section provides a brief revision of the existing literature in the overall field, which leads into the research gap. It is followed by an outline of research objectives, contributions, and research questions. Finally, the last sections give an introductory overview of the research methodology and an outline of the sections covered in this thesis.

\subsection{Overview}

Offshore outsourcing to emerging economies has grown rapidly in recent years (Chadee \& Raman, 2009). It is suggested that outsourcing allows firms to improve their performance by reducing costs, increasing flexibility, accessing new capabilities and focusing on core business (Kotabe, 1992; Quinn and Hilmer, 1994; Di Gregorio et al., 2001; Tate et al., 2009). However, benefits from outsourcing cannot be achieved if the associated risks are not accurately identified and managed (Aron et al., 2005b). Oza and Hall (2005) argued that relationship management is a crucial factor in outsourcing success.

Offshore outsourcing research has established that developing a cooperative relationship based on trust, commitment, and information sharing is critical to outsourcing success (Lee \& Kim, 1999; Lee, 2001; Haried \& Ramamurthy, 2009). Kakabadse and Kakabadse (2005) point out that poor management of outsourcing relationships reduces opportunities for firms to gain competitive advantage. Hence, it is useful to examine the key risks in managing offshore outsourcing relationships and the mechanisms available for firms to control them.

\subsection{Research gap}

This study identified two research gaps relating to offshore outsourcing relationship management. Firstly, offshore outsourcing research has largely emphasised the 
benefits of outsourcing and how outsourcing can contribute to a firm's competitive advantage (Kotabe, 1992; Quinn and Hilmer, 1994; Di Gregorio et al., 2009). However, there is a lack of understanding of the risks in managing offshore outsourcing relationships. Secondly, a lot of research attention has been paid to examining the relationship between partnership quality and offshore outsourcing success (Grover et al., 1996; Lee \& Kim, 1999; Lee, 2001; Barthelemy, 2003b). In contrast, there is lack of research development on how and what kind of management approaches are used to effectively minimise the risks of offshore outsourcing relationships.

These findings are consistent with analysis by Chadee and Raman (2009). These authors pointed out that a significant amount of attention has been focussed on outsourcing management, particularly in forms of contracts and relationships. However, there is a lack of understanding of the possible risk factors in supplier relationship management and the types of management approaches that can effectively minimise risks of offshore outsourcing relationships.

\subsection{Research objective}

Based on the discussions of research gaps in the literature, the objective of this study is to determine whether management approaches can minimise risks in offshore outsourcing relationships. In order to fulfil this research objective, this study will firstly determine the risks relating to offshore outsourcing relationships and secondly, uncover management approaches that can reduce risks in offshore outsourcing relationships. Finally, the study will develop and test a research model that recognises the link between management approaches and risks in offshore outsourcing relationships.

\subsection{Research contributions}

Four important contributions have been made to the existing knowledge of offshore outsourcing.

Firstly, research relating to managing risks in offshore outsourcing relationships has 
not been adequately reflected in the literature. This study expands current literature by addressing this research gap. This study also applied social exchange theory and transactional cost theory to construct a conceptual model of risk management in offshore outsourcing relationships, which builds a theoretical foundation for future testing.

Secondly, this study operationalised relational risk and performance risk from a conceptual base (Das \& Teng, 1996) and applied it in the context of offshore outsourcing. In addition, empirically testing relational risk for a mediating effect in this study is a novel concept in offshore outsourcing literature. Furthermore, by employing a China-specific factor (guanxi), this study adds a 'cultural characteristic' to the investigation of offshore outsourcing relationships.

Thirdly, the quantitative survey result revealed that the relational risk in the offshore outsourcing relationship played a critical role as a mediator between relational factors and performance risk. The implication of this finding demonstrates the importance of minimising relational risk in managing offshore outsourcing relationships.

A final contribution is made to the contextual understanding of risk management in offshore outsourcing relationships. In comparison with Europe and North America, less offshore outsourcing research has focussed on outsourcing firms in New Zealand and Australia. It is useful to extend the existing research context by examining risks in offshore outsourcing relationships from New Zealand and Australian perspectives.

This study also chooses to focus on China as a study context for two reasons. Firstly, it is one of the fastest growing economies in the world (Buckley, 2007), which is valuable to study. Secondly, China is an important trading destination for Australian and New Zealand outsourcing firms (Australian Department of Affairs and Trade, 2010; New Zealand Ministry of Foreign Affairs and Trade, 2010). Thus, this study provides useful insights for Australian and New Zealand outsourcing firms into managing risks in offshore outsourcing relationships with China. 


\subsection{Research questions}

Based on the previous discussions, three research questions were formulated as follows:

1. What are the risks in managing offshore outsourcing relationships?

2. What are the effective management approaches in minimising the risks of offshore outsourcing relationships?

3. Is there a direct link between management approaches and offshore outsourcing supplier risks?

\subsection{Research model}

To examine the risks in offshore outsourcing relationships, this study introduced two types of risks: relational risk and performance risk (dependent variables) that have been conceptualised by Das and Teng (1996). Based on social exchange theory and transaction cost theory, this study proposes two management approaches to minimise outsourcing supplier risks: the relational approach and the transactional approach. The relationship between the management approaches and outsourcing supplier risks are illustrated in Figure 1.1 below:

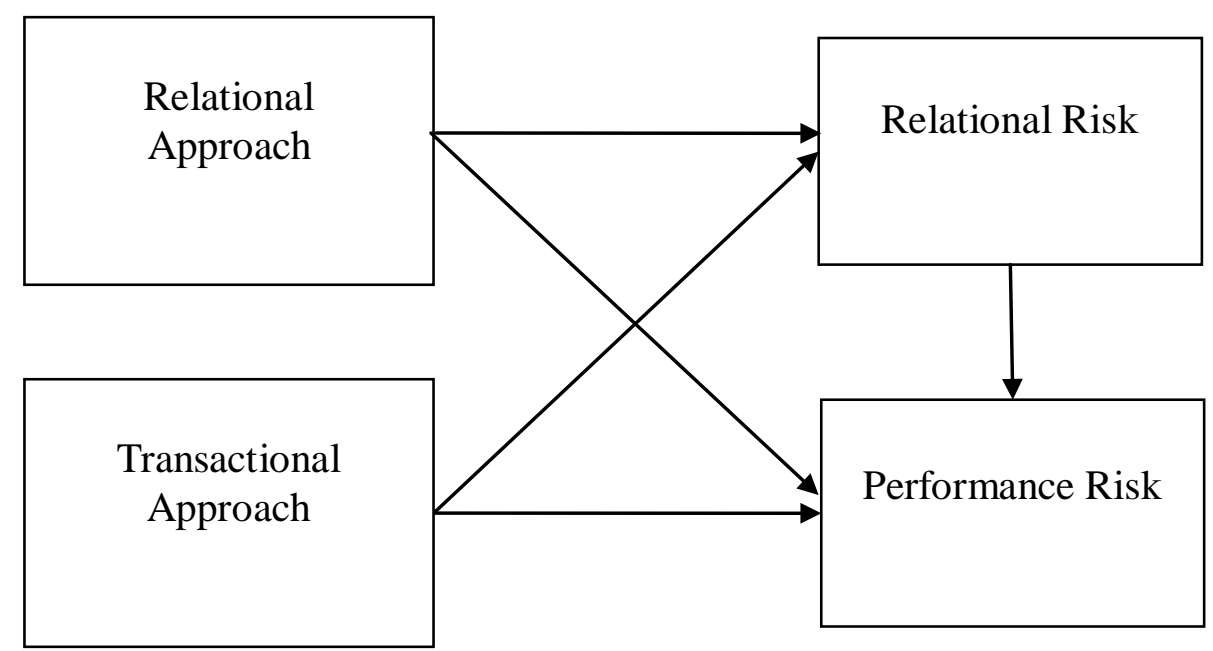

Figure 1.1: The basic model of managing offshore outsourcing supplier risks

It is assumed that a relational approach is best to manage relational risk; whereas, a 
transactional approach is more likely to be an effective management approach to reduce performance risk. This study also proposes that a higher level of relational risk can lead to a higher level of performance risk.

\subsection{Methodological approach}

In order to test the conceptual model and relevant hypotheses, a quantitative research method using an online survey was employed to test the role of relational and transactional approaches in managing the risks in offshore outsourcing relationships. The purpose of using a quantitative survey research method is to deductively test theories and establish specific relationship factors from a large representative sample of respondents (Bryman \& Bell, 2003; Hair et al., 2009). The survey data was analysed using SPSS version 18. Statistical procedures used in this study range from basic techniques such as descriptive and frequencies analysis, to more advanced techniques such as multiple regression analysis.

\subsection{Outline of the thesis}

This chapter provides a holistic view on the research topic of managing risks in offshore outsourcing relationships. The aim of Chapter 2 is to build a theoretical foundation by reviewing relevant literature to identify key research issues. Chapter 3 presents the development of a conceptual research model and pertinent hypotheses in an attempt to explain the relationship between outsourcing supplier risks and management approaches. Chapter 4 describes research design, the chosen methodology, data collection process, and statistical procedures for analysing the quantitative survey. Additionally, Chapter 4 presents the important results of the validity and reliability tests of this study. Chapter 5 shows the results obtained from the quantitative survey. Chapter 6 provides an in-depth discussion of the survey results and highlights the contributions of this study to the existing literature. Chapter 7 concludes the thesis by providing managerial implications, limitations of the research and suggestions for future research. 


\section{Chapter 2: Literature review}

This chapter will firstly present a broad review of the topic of offshore outsourcing. The second section reviews relevant management approaches to offshore outsourcing relationships. The third section focuses on the main risks associated with offshore outsourcing, with particular attention being paid to the risks in offshore outsourcing relationships. Lastly, this chapter determines some key research issues by identifying important gaps in offshore outsourcing literature. Furthermore, this chapter proposes a research problem that will guide this study in attempting to fill the gaps in extant literature.

\subsection{Offshore outsourcing}

The following sections provide some background information on offshore outsourcing including definitions, motives and theoretical underpinnings.

\subsubsection{Defining offshore outsourcing}

It is indicated by Mol et al. (2005) that offshore outsourcing has become an important topic in the international business (IB) literature. According to their investigation of published sources in the ProQuest database, the number of academic articles on (out)sourcing considerably increased between 1970 and 2000.

Numerous terms and definitions of offshore outsourcing are employed by academic researchers and practitioners, which often causes great confusion (Mol et al., 2005; Chadee \& Raman, 2009; Di Gregorio et al., 2009). The terms used include insourcing, outsourcing, offshore outsourcing and domestic outsourcing.

In particular, the terms offshoring and outsourcing are often confused. Offshoring refers to the process of sourcing products and services across national boundaries (Lewin et al., 2009). Offshoring may include both international in-house sourcing and international outsourcing. In comparison, outsourcing refers solely to the process of contracting out products or services that were provided internally (insourcing) to 
external providers (Sako, 2005). Outsourcing can be conducted domestically (onshore) and internationally (offshore). The distinctions between offshoring and outsourcing are clarified in Figure 2.1 as set out below.

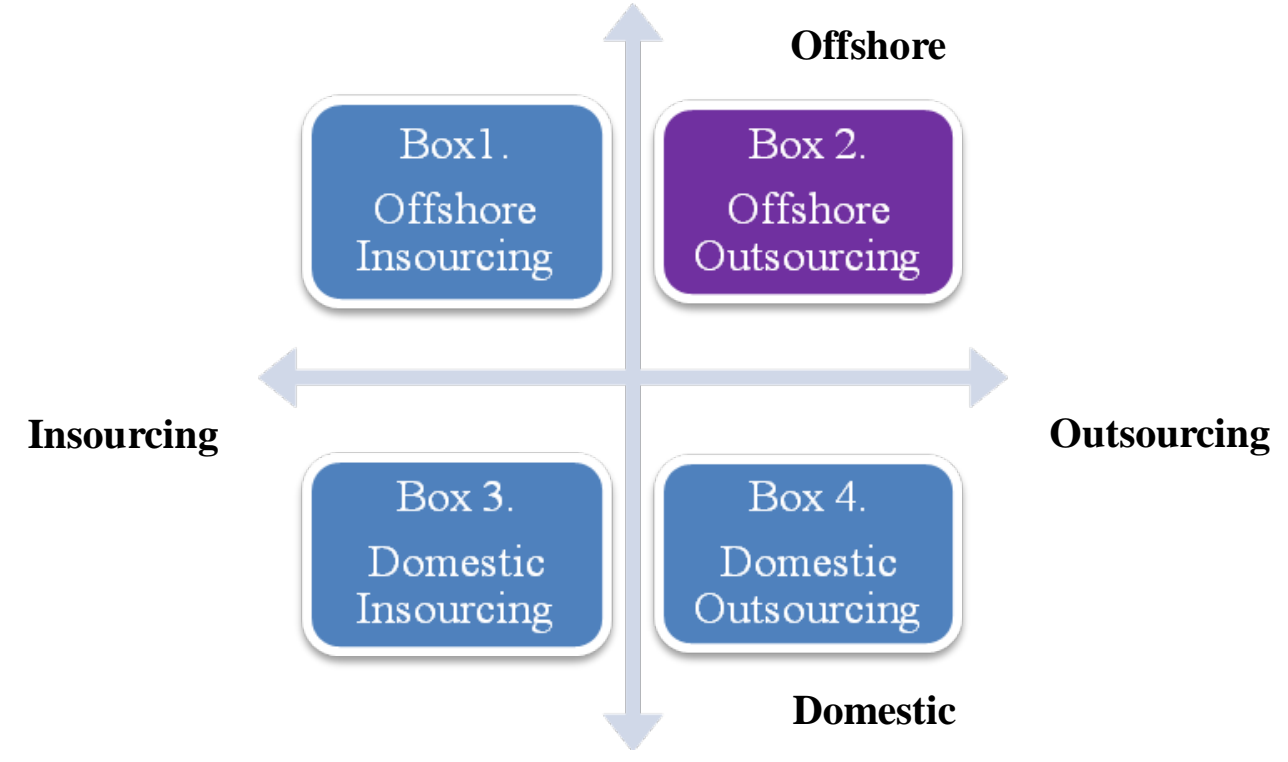

Figure 2.1: Illustrating Offshore Outsourcing adopted from Sako (2005)

Figure 2.1 indicates that insourcing of goods and services can be achieved through domestic insourcing (Box 3) and offshore insourcing (Box 1). Correspondingly, outsourcing of goods and services can be carried out either domestically (Box 4 domestic outsourcing) or internationally (Box 2 offshore outsourcing). It is also illustrated in Figure 2.1 that offshoring can be conducted in-house through foreign subsidiaries (Box 1 offshore insourcing) or contracted out to external foreign providers (Box 2 offshore outsourcing). The focus of this thesis is on offshore outsourcing $^{1}$ of the manufacturing function from New Zealand and Australia to China.

\subsubsection{Motives for offshore outsourcing}

Literature has revealed various rationales for firms' decisions to undertake outsourcing (Cavusgile et al., 1993; Kotabe \& Murray, 2004; Schniederjans \& Zuckweiler, 2004; Tate et al., 2009). Outsourcing is not just a straightforward financial or purchasing decision, but a complex strategic business decision (Costa,

\footnotetext{
${ }^{1}$ From this section onwards, this study refers to offshore outsourcing as outsourcing.
} 
2001). The motives for undertaking outsourcing vary, depending on each firm's individual circumstances. It is argued that outsourcing may not be appropriate for every firm. If a firm chooses the wrong reasons to outsource, it could suffer major setbacks, such as losing control over outsourced activities and losing core competencies (Gupta and Gupta, 1992; Bathelemy, 2001).

Seeking cost reduction is viewed as one of the main motives for outsourcing (Kakabadse \& Kakabadse, 2005; Farrell, 2005; Di Gregorio et al., 2009). Outsourcing allows firms to exploit cost advantages in less-developed countries such as cheaper labour, material, components, and transportation costs, which consequently reduces costs (Dunning, 1998). Farrell (2005) argues that savings from outsourcing can also be re-invested into new, higher value-added products, and then passed onto customers in the form of a better price.

Outsourcing literature also indicates that focusing on core competencies is regarded as one of the main motivations for outsourcing decisions (Saunders et al., 1997; Quinn \& Duhamel, 2003). A core competency is a special capability or expertise that determines whether a firm can sustain its competitive advantage (Prahalad \& Hamel, 1990). Outsourcing allows firms to concentrate their efforts on activities that drive competitive advantages while contracting out peripheral activities, enabling it to leverage the specialist skills of the supplier (Di Gregorio et al., 2009). It is indicated that some firms may not have the necessary skills or expertise to develop peripheral activities, due to a lack of resources and high costs (Costa, 2001). Outsourcing offers firms opportunities to gain relevant skills without encountering the difficulties of attracting and retaining highly-trained individuals (McFarlan and Nolan, 1995; Quinn, 1999). Gupta and Gupta (1992) further argue that by acquiring the specialised knowledge of others, firms would avoid the risks associated with building specialisation in-house. Thus the benefits of gaining specialised capability externally can add more value for firms and serve customers in a more efficient and low cost manner.

Outsourcing exposes firms to global talent and enables firms to select 'best-in-world' suppliers (Quinn and Hilmer, 1994). It is argued that accessing the new skills and technologies of foreign suppliers facilitates firms' achievement of competitive 
advantage and efficiency (Cavusgil et al., 1993). By taking advantage of suppliers' skills and expertise, firms are given more flexibility to experiment with new ideas and responses to market changes, such as intensified global competition, rapid diffusion of technology, reduced time-to-market and increasingly sophisticated consumers (Apte et al., 1997; McIvor, 2005).

Competitive pressure has also been identified as a key driver for firms' outsourcing decisions. The existing literature reveals that competitive pressure may arise from external pressure, strong supplier marketing efforts and management attitudes (Pinnington \& Woolcock, 1995; McFarlan \& Nolan, 1995). Firms can lower the risks of external competitive pressure by observing and imitating successful industry leaders (Tate et al., 2009).

\subsection{Theoretical underpinnings of offshore outsourcing}

Three theoretical perspectives are found to be most relevant to the purpose of this study. They are transaction cost theory (Coase, 1937; Williamson, 1975), the resourcebased view (Penrose, 1959; Wernerfeldt, 1989; Barney, 1991), and the relational view (Dryer \& Singh, 1998; Poppo and Zenger, 2002). The following sections will evaluate all three perspectives to gain a theoretical understanding in the areas of outsourcing decisions, outsourcing relationship management, and outsourcing risk management.

\subsubsection{Transaction cost theory}

Transaction cost theory (TCT) has been widely used to examine a firm's decision on outsourcing, or the 'make' or 'buy' options (Murray and Kotabe, 1999; Ellram et al, 2008; Tate et al., 2008, 2009), and assumes that a firm's outsourcing decision is based on economic rationales (Williamson, 1975).

Literature indicates three transaction cost variables may influence a firm's outsourcing decisions (Mahnke et al., 2005; McIvor, 2005). Firstly, asset specificity refers to the extent to which specific assets are required to support a particular activity (Williamson, 1975). Specific asset investment can be in the forms of (1) physical assets such as customised machinery or tools, (2) human assets including specialised 
skills and knowledge required in the activities, (3) site specificity, for example a natural resource available at a certain location, and (4) dedicated assets (Williamson, 1983). Secondly, uncertainty refers to the unanticipated changes in circumstances surrounding a transaction which includes behavioural and environmental uncertainties (Williamson, 1985). Finally, transaction frequency is viewed as the number of transactions (Williamson, 1985).

Although all three variables are considered important, asset specificity is regarded as the most crucial variable (Williamson 1981). A highly asset-specific investment requires costs that may not be re-deployed or transferred to another transaction (Williamson, 1975, 1985). Thus, the higher the asset specificity of a given transaction, the more likely a firm is to internalise its activity (Walker \& Weber, 1984). As asset specificity and uncertainty increase, the risk of opportunism increases as well. In response, firms are more likely to source internally. It is argued that high transaction frequencies will escalate costs (Williamson, 1985). In summary, firms should outsource activities when asset specificity is low, uncertainty is insignificant, and transactions are relatively infrequent.

While TCT provides a good theoretical basis for understanding firms' outsourcing decisions, it is limited because the rationale behind an outsourcing decision may vary with applications, industries and organisations (Costa, 2001). For example, some firms in technical service industries still choose to outsource specialised capabilities, even though the costs of acquiring externally are excessively high. Applying the logic of TCT, firms should develop the capabilities internally when the transaction costs of outsourcing specialised capabilities are high. However, Lewin et al (2009) found the reason behind firms' outsourcing decisions is to stay competitive by accessing global talent and innovation. Thus, the decision to outsource does not depend solely on economic rationales.

\subsubsection{Applying TCT to outsourcing relationship management}

When it comes to managing outsourcing relationships, TCT promotes the development and enforcement of formal contracts for safeguarding firms from any potential risks that might arise in the buyer-supplier relationships. Firms completely 
rely on formal agreements, such as a formal contract that carefully defines the nature of the activities, to resolve any unforeseeable outcomes (Williamson, 1985; Poppo \& Zenger, 2002). A detailed formal contract has been found to have a huge impact on the effective management of outsourcing relationships as it helps to protect the buyer firm from the potential opportunism of the supplier firm (Saunders et al., 1997; Barthelemy, 2001, 2003a).

According to TCT, factors including uncertainty, asset specificity, and measurement difficulties, contribute negatively to the management of outsourcing buyer-supplier relationships. Firstly, uncertainty can be in the form of a behaviour uncertainty and an environmental uncertainty. Opportunism is regarded as a behavioural uncertainty, referring to decision makers acting out of self-interest with guile (Williamson, 1985). The threat of opportunism requires outsourcing exchange firms to prepare highlydetailed formal contracts that will protect them against unforeseen events. A high level of environmental uncertainty in offshore outsourcing due to geographical and cultural differences increases the likelihood of a supplier firm's opportunism, as the buyer firm would find it difficult to monitor the behaviours of its supplier over the geographical separation (Tate \& Ellram, 2009). Consequently, a highly-specified formal contract can help the buyer firm to monitor a supplier firm’s behaviours (Poppo \& Zenger, 2002).

Secondly, a high level of asset specificity in outsourcing relationships may open the door to opportunistic behaviours (McIvor, 2009). In order to limit the threat of opportunism and encourage the longevity of buyer-supplier relationships, outsourcing exchange firms are expected to adopt formal contracts, not only specifying actions and the conditions of contractual breach, but also provisions for resolving unforeseen disputes (Poppo \& Zenger, 2002), since any failure and subsequent losses could be significant to both exchange firms.

Finally, difficulties in measuring the performance of outsourcing buyer firms may cause confusion about whether the supplier firm has fulfilled its obligations and delivered according to the prior agreement (Williamson, 1985). When the outsourcing supplier firm minimises its input towards fulfilling the agreement, the outsourcing buyer firm receives less value on already-paid-for products or services due to the 
inability to measure performance. In this case, outsourcing buyer firms are expected to develop better specifications and measurements within their formal contracts, allowing them to accurately monitor and evaluate performance.

\subsubsection{Applying TCT to outsourcing risks}

TCT is also useful when it comes to evaluating the various risks of outsourcing. Firms may encounter risks before (ex-ante) and after (ex-post) a contract is closed. In the exante contract phase, transaction cost theory provides the necessary tools for firms to determine whether it is feasible to outsource an activity by assessing macro risks in offshore outsourcing, such as political and cultural risks (McIvor, 2009). In the expost contract phase, a transactional management approach guided by TCT assists outsourcing firms in managing the risks in offshore outsourcing relationships. The transactional approach develops through the use of formal contract, in which rules are well-defined and any failure to deliver agreed products or services by either party will be resolved by litigation and the penalties in the contract (Henderson, 1990; Lee \& Kim, 1999). In the ex-post contract phase, outsourcing exchange firms may choose to minimise risks in offshore outsourcing through inter-firm cooperation. Cooperation between the firms can result in a high level of interdependence, which may open the door for opportunistic behaviours. Through the utilisation of formal contracts, the transactional approach can protect outsourcing exchange firms from potential opportunism.

\subsubsection{Resource-based view}

The resource-based view (RBV) is increasingly being considered as an alternative explanation for a firm's decision to outsource (Leiblein and Miller, 2003; Kotabe \& Murray, 2004; Doh, 2005; Tate et al., 2009). The RBV considers the firm as a unique bundle of assets and resources which, if managed in a distinctive way, can achieve competitive advantage (Wernerfelt, 1984; Barney, 1991). Resources that are valuable, rare, inimitable, and non-substitutable can contribute to firm-specific capabilities. The RBV argues firm-specific capabilities are inherently complex, causally ambiguous, and difficult to replicate (Barney, 1991; Conner \& Prahalad, 1996). This assumption implies that when a firm lacks capabilities in a certain area, it is more efficient to gain 
access to skills and capabilities in external markets.

Applying the RBV, outsourcing decisions are driven more by resource considerations and less by transaction cost factors. A firm will internalise its activities when possessing valuable strategic resources in order to exploit better future value than its competitors (Doh, 2005). On the other hand, when a firm has relatively fewer valuable and rare resources, outsourcing enables a firm to acquire complementary resources to fill the resource gaps and to develop new capabilities (Costa, 2001; Kotabe and Murray, 2004; Mahnke et al., 2005). In addition, Quinn and Hilmer (1994) argue that firms should concentrate on their core competencies while capitalising on the capabilities of others by contracting out peripheral activities. Accordingly, firms may improve flexibility and free up scarce resources for even greater value creation (Barney, 1991; Costa, 2001; Mahnke et al., 2005). However, Barthelemy (2001) indicated that outsourcing firms often found it hard to determine their core business function.

\subsubsection{Applying RBV to outsourcing relationship management}

Successfully managing the buyer-supplier relationship is crucial in the context of the RBV, since buyer firms rely on their supplier's superior skill and innovative technologies to achieve competitive advantage (Kotabe \& Murray, 2004; Doh, 2005). In addition, when competitors become more competent, it is necessary for buyer firms to recognise the need to access the supplier's complementary capabilities in order to close the gap with competitors (McIvor, 2009). On the other hand, supplier firms can better develop their core competencies through outsourcing exchanges with buyer firms. Therefore, it involves both firms mutually leveraging each other's resources and capabilities in order to derive competitive advantage. Consequently, it becomes necessary to accurately address the development of long-term relationships as the intensity of the relationship increases during the outsourcing venture (Mahnke et al., 2005). 


\subsubsection{Applying RBV to outsourcing risks}

In order to create competitive advantage, the RBV encourages outsourcing exchange firms to develop collaborative relationships as a means of reducing the risk of opportunism while acquiring expertise and technical resources externally (Duncan, 1998; McIvor, 2009). A collaborative relationship allows outsourcing exchange firms to obtain and maintain complementary capabilities where there are resource constraints (McIvor, 2009). Although the RBV contributes to the insights of managing risks in offshore outsourcing, the focus of the RBV is on the creation of competitive advantage through resource analysis, not on the minimisation of risks in offshore outsourcing relationships. Accordingly, the application of the RBV does not appear compatible with the purpose of this study, which is to determine the link between management approaches and risks in offshore outsourcing relationships.

\subsubsection{Relational view}

The relational view (RV) is often used to gain understanding of how firms can gain and sustain competitive advantage. This view is employed particularly in the area of inter-firm relationships. It has evolved from the limitations of TCT and the extended understanding of achieving competitive advantages offered by the RBV (Mclvor, 2009). The RBV claims that the firm must possess unique resources that enable the firm to achieve competitive advantage. The characteristics of these unique resources need to be valuable, rare, inimitable and non-substitutable, which are viewed as terms of specificity by the transaction cost perspective (Williamson, 1991). Therefore, when firms choose to outsource activities comprising unique resources, the firm's performance can be negatively affected by the risk of opportunism and the threat of contract termination (Klein et al., 1987). The RV argues that firms can develop critical resources by carefully managing relationships with external parties including suppliers, customers, and government agencies (Mahnke et al., 2005). Firms can gain and sustain competitive advantages by accessing these critical resources in a unique way that spans firms’ boundaries (Dryer \& Singh, 1998).

In addition, the RV expands the understanding of achieving competitive advantage offered by the RBV. The RBV sees competitive advantage arising from the remaining 
activities constituting core competences within the firm, whereas the RV considers the competitive advantage to be embedded in social relationships placed outside the firm, rather than arising through the remaining activities within the firm (Granovetter, 1985). Dryer and Singh (1998) argue that combined capabilities of exchange parties can create a relational rent, which is a supernormal profit jointly generated in a relationship. Furthermore, the relational rent-generating process cannot be achieved by either firm in isolation (Dryer \& Singh, 1998). In the case of offshore outsourcing, buyer and supplier firms may generate these supernormal profits by focusing on the relationship benefits, which require outsourcing exchange firms to share close interfirm relational ties involving trust and mutual commitment. In addition, such close relational ties provide outsourcing firms with safeguards from exchange hazards such as opportunistic behaviours (Haried \& Ramamurthy, 2009). The RV provides a broader concept from which social exchange theory (SET) derives; this study is only going to utilise SET for the operational part of this study.

\subsubsection{Social exchange theory}

Social exchange theory (SET) is closely associated with the relational view. It focuses on the social and behavioural perspective of the outsourcing relationship, whereas TCT concentrates primarily on economic aspects of the outsourcing relationship. Kern and Willcock (2000) point out that research in outsourcing draws heavily upon TCT for explanatory frameworks. The core view of TCT states that outsourcing firms do not interact with each other but directly with the market (Williamson 1985). However, SET considers that the outsourcing firms interact with each other as exchange actions contingent on rewarding reactions from others (Blau, 1964). Thus, it is argued that the understanding of the outsourcing relationship should not solely rely on an economic view but also on social views (Blau, 1964; Emerson, 1981; Cook, 2000).

SET was originally developed to examine interpersonal exchanges within a societal environment (Homans, 1958; Thibaut \& Kelley, 1959; Blau, 1964). The aim of SET is to understand the underlying social structures and behaviours of each actor that shape the exchange of resources and benefits (Cook, 1977; Emerson, 1976). SET has been increasingly employed in outsourcing to address the issue of managing inter-firm ties in outsourcing relationships (Lee \& Kim, 1999; Kern \& Willcocks, 2000; Gottschalk 
\& Solli-Sæther, 2005; Lai, 2009). SET suggests that the need for social exchange is initiated by the scarcity of resources, which motivate individuals to engage with each other to gain valuable inputs. The assumption of SET is that exchange firms are intending to gain benefits from the exchange relationship that would not be achievable on their own (Blau, 1964; Molm, 1997). This assumption requires outsourcing exchange firms to collaborate and cooperate with each other in order to obtain simultaneous benefits. Thus, outsourcing exchange firms will maintain an ongoing reciprocal relationship in which the benefits of continuing the relationship are more attractive than other alternatives (Blau, 1964).

It is also assumed by SET that firms evaluate the outcomes of exchange relationships based on cost and benefit analysis. Resources provided to negative outcomes of the exchange are considered as costs. Conversely, resources contributed to positive outcomes of the exchange are seen as benefits (Molm, 1997). Thus, SET requires exchange firms to behave in certain ways to maximise the benefits of the exchange and to minimise the costs since the negative outcome of the exchange would result in relationship termination (Molm, 1997).

\subsubsection{Applying SET to outsourcing risks}

SET offers important guidance on diminishing outsourcing risks, which suggests that the enforcement of obligations, promises and expectations occurs through social exchanges and that those social exchanges mitigate hazards associated with specific asset investments and uncertainty (Poppo \& Zenger, 2002). The expectation of relationship longevity encourages parties to protect exchange-specific investments in consideration of the mutually-imposed costs of termination (Blau, 1964). Outsourcing firms may encounter a high risk of free riding given that reciprocity in the exchange relationship is voluntary. Therefore, outsourcing buyer and supplier firms involved in exchange relationships have a high need for trust. Trust among outsourcing exchange firms reduces anxiety and allows reciprocity to take place over time.

According to SET, outsourcing firms promote more relational, informal safeguards like trust and commitment rather than having third party and formal safeguards such 
as legal contracts (Haried \& Ramamurthy, 2009). Informal safeguards provide the flexibility to manage any unforeseeable events and are considered to have a greater ability to minimise the costs of exchange hazards than that of formal contracts (Zaheer \& Venkatraman, 1995; Uzzi, 1997; Alder, 2001). SET argues that social capital such as trust and commitment also contribute to the prevention of transaction costs caused by opportunistic behaviours and conflict between partners (Uzzi, 1997; Kale et al., 2000; Alder, 2001).

\subsubsection{Comparing TCT with SET in managing offshore outsourcing relationships}

There are important differences between TCT and SET. TCT promotes the utilisation of detailed formal contracts that might provide opportunities for outsourcing firms to minimise exchange hazards. However, overly-specified contracts reduce flexibility between supplier and buyer firms (Mahnk et al., 2005). The focus of TCT is on single transactions as units of analysis, which assume no interactions between outsourcing parties but directly with the market. Therefore TCT fails to recognise that the development of collaborative behaviours require outsourcing parties to interact continually with each other (Doz \& Prahalad, 1991). Furthermore, explicit and detailed contracts specified according to TCT may also signal distrust, and hence aggravate opportunistic behaviours (Ghoshal \& Moran, 1996). In contrast, relational contracts based on mutual trust are regarded as substitutes (Uzzi, 1997; Alder, 2001) or complements for explicit contracts (Poppo \& Zenger, 2002). To conclude, TCTguided formal contracts are necessary but not sufficient when fully explaining outsourcing relationship management.

SET elements such as trust and commitment play an important role in successful infirm relationships, and they have been considered to be the key relationship norms of a variety of inter-firm relationships (Anderson \& Narus, 1990; Morgan \& Hunt, 1994; Wu \& Cavusgil, 2006; Kwon, 2008; Han et al., 2008). In contrast to managing relationships by formal contract guided by TCT, informal relational governance based on trust is argued to have the ability to discourage opportunistic behaviours, lower the need for monitoring and facilitate contractual adaptation (Gulati, 1995; Uzzi, 1997; Alder, 2001). 


\subsection{Managing outsourcing interactions}

The analysis of the four theoretical perspectives has provided an important understanding of how firms can achieve and sustain competitive advantage through outsourcing by reducing transaction costs, tapping into the capabilities of others, and managing relationships in a unique way. It has been argued that an outsourcing firm's ability to effectively manage inter-firm relationships with its foreign suppliers is a key determinant of outsourcing success (Grover et al., 1996; Lee \& Kim, 1999; Lee, 2001; Barthelemy, 2003; Feeny et al., 2005; Haried \& Ramamurthy, 2009). Successful relationships may assist firms in achieving performance objectives and mitigating the risks associated with offshore outsourcing. By employing astute relationship management approaches, it is possible for outsourcing firms to leverage the capabilities of suppliers in a more effective way than other competitors. However, failure of a buyer-supplier relationship can be very costly for both buyer and supplier firms (Aron et al., 2005; Herath \& Kishore, 2009). In practice, managing the outsourcing relationship requires a considerable amount of detailed administration, cooperation and coordination between buyer and supplier firms, which does not guarantee a desired outcome. Thus it becomes a significant challenge for many outsourcing firms to employ the appropriate management approach to facilitate the development of a successful relationship.

\subsubsection{Existing relationship approaches}

Research of the outsourcing literature revealed that firms can manage their relationships through a formal approach or an informal relational approach (Lee \& Kim, 1999; Barthelemy, 2003b). The formal approach of managing relationships is well grounded in TCT, which promotes the utilisation of an explicit and well-defined contract. A formal contract is critical in the outsourcing process as it defines the role, responsibilities, requirements and ongoing performance measurements (Poppo \& Zenger, 2002). A good quality contract protects the outsourcing firms from the potential risks arising during the exchange process. It also allows outsourcing exchange firms to set expectations and commit themselves to short and medium-term goals (Gulati, 1995). On the other hand, formal contracts cannot predict all the changes and future needs that lie ahead. The presence of incomplete contracts implies 
that firms' outsourcing goals may not be able to be met (Kern \& Willcock, 2000; Ellram et al., 2008). Thus, outsourcing firms are required to constantly add updates and changes to a contract, which entails additional transaction costs.

An informal relational approach is guided by SET, which involves a series of repeated exchanges that make the outsourcing buyer and the supplier firms interdependent, and so expects coordinated action and cooperation in order to achieve mutual benefits (Lee \& Kim, 1999). Hence, outsourcing firms are required to demonstrate their trustworthiness over time. In contrast to the formal approach of relationship exchange, the enforcement of obligations, responsibilities and expectations occurs through a social process that promotes norms such as trust, commitment, cooperation, and information sharing. These social norms offer flexibility, which facilitates adaptation to unforeseeable events and minimises the high costs of exchange hazards (Macaulay, 1963; Granovetter, 1985; Uzzi, 1997; Alder, 2001).

The management of the buyer-supplier relationship can be influenced by the objectives of the overall outsourcing strategy. Outsourcing firms may want to achieve tangible objectives including reduced costs, increased productivity, better service levels in the form of on-time deliveries and better quality (McIvor, 2005). In this case, a formal approach of relationship exchange will be more effective as it allows outsourcing firms to reduce transaction costs and in particular relationship-specific investments. On the other hand, outsourcing firms may aim to achieve a long-term objective such as developing complementary skills and capabilities in a particular process and developing more innovative capabilities (McIvor, 2005). In this case, an informal relational approach is more appropriate since the objective requires a more collaborative interaction with suppliers over time in order to leverage these suppliers' capabilities more fully.

The choice of management approach can also be influenced by the level of risks in the supply market (McIvor, 2005). Risks such as hidden costs and opportunistic behaviours can create difficulties in firms' abilities to sustain the long-term economic benefits of outsourcing. An explicit and well-specified contract provides the outsourcing firm with the chance to safeguard against potential opportunism and achieve short-term economic objectives. However, a formal contract cannot foresee 
all uncertainties and it is costly to design a quality contract to mitigate all opportunistic behaviour during the outsourcing process. An informal approach, on the other hand, proposes relationship-based exchange in the form of mutual understanding, which is advantageous for settling disputes arising from opportunistic behaviours (Macaulay, 1963; Ghoshal \& Moran, 1996). In addition, an informal relational approach is a more effective and less costly alternative to a formal contract because it is a self-enforcing safeguard. Outsourcing exchange firms are expected to understand their responsibilities and be willing to perform actions that result in positive outcomes (Blau, 1964; Granovetter, 1985). Thus, an informal approach provides flexibility for outsourcing exchange firms to adjust to unforeseen circumstances.

\subsection{Outsourcing risks}

Managing risks and uncertainties is one of the primary objectives of firms operating globally (Ghoshal, 1987). It is noted by scholars that there are many risks and challenges associated with offshore outsourcing (Earl, 1996; Barthelemy, 2001; Kliem, 2004; Rubin, 2009; Herath \& Kishore, 2009). Outsourcing risks such as loss of internal know-how (Willcocks et al., 2004), loss of control over suppliers (Quinn \& Hilmer, 1994), and reduced product quality (Kotabe and Murray, 2004) may lead to undesirable consequences. Therefore it is vital for firms to mitigate outsourcing risks and uncertainties in order to maximise returns on invested resources.

\subsubsection{Defining risk}

The concept of risk has been widely researched in various disciplines, such as economics, psychology, and healthcare. Each discipline interprets risk differently, depending on specific contexts and types (Ritchie and Marshall, 1993; Frosdick, 1997; Dhar \& Balakrishnan, 2006). This study explores the term risk in the supply chain management literature which is the broader domain of the offshore outsourcing literature. Li and Barnes (2008: 254) defined risk in the context of supply chain management as "the probability or likelihood of danger and disruption, under which events would obstruct a company in achieving its planned objective”. According to Levine and Schneider (1997: 38), risk is identified as “...events that, if they occur, represent a material threat to an entity's fortune”. These definitions are summarised 
into three dimensions by Ritchie and Brindley (2007: 305), which are "likelihood or probability of occurrence of a particular event or outcome; consequences due to occurrence of a particular event or outcome; and a 'causal pathway' effect due to the nature of a particular event and its sources and causes”. This study interprets offshore outsourcing risk as the probability that undesirable events occurring will potentially lead or expose businesses to adverse outcomes.

\subsubsection{Phases of outsourcing risks}

This study examines outsourcing risks in two phases of the outsourcing process. Firstly, the ex-ante contract phase where risks occur during decision making, supplier selection, and contract development stages. Secondly, risk factors in the ongoing outsourcing supplier management stage (the ex-post contract phase) will be discussed thoroughly in Section 2.4.3.

\subsubsection{Risks in the ex-ante contract phase}

In the ex-ante contract phase, firms need to assess risks in the supply market environment such as political risks, cultural risks, and economic risks. Political risks are a major concern for offshore outsourcing firms because political instability and unpredictable changes in labour and environmental laws and regulations may result in undesirable consequences (Graf \& Mudambi, 2005; Dhar \& Balakrishnan, 2006; Ellram et al., 2008). Cultural and language barriers also contribute to overall outsourcing risks. Language barriers make communication difficult between client and supplier, which may lead to delays, misunderstanding and conflicts (Schniederjans \& Zuckweiler, 2004; Kakumanu \& Portanova, 2006). Cultural differences such as religion, social norms, and decision making styles can prevent client and supplier firms from building the necessary trust, undermining any collaborative efforts made in the outsourcing process (Graf \& Mudambi, 2005; Dhar \& Balakrishnan, 2006). Economic risk arises from the variability in the inflation rate and currency exchange rate, which can contribute negatively to the financial performance of outsourcing firms (Schniederjans \& Zuckweiler, 2004; Dhar \& Balakrishnan, 2006). 
These macro environmental risks are perceived as exceptionally important when it comes to selecting an appropriate vendor in a certain location, and overall outsourcing considerations (Ellram et al., 2008; Herath \& Kishore, 2009). According to Barthelemy (2003b), constructing a good contract is crucial to outsourcing performance, since contracts facilitate the client and the supplier establishing a balance of power. It is also indicated that a contract is a vital governance tool for managing the outsourcing relationship and mitigating risk (Goo et al., 2009). Conversely, a poorly formulated contract could have a significant negative impact on the potential risk in the ex-post contract phase in terms of contractual conflicts, supplier's opportunistic behaviours and escalating costs (Bathelemy, 2003; Dhar \& Balakrishnan, 2006; Tate \& Ellram, 2009). The risks in offshore outsourcing relationships (the ex-post contract phase) is discussed in the next section.

\subsubsection{The risks in offshore outsourcing relationships (the ex-post contract phase)}

Managing outsourcing relationships involves managing contracts and suppliers. The risks could arise from mismanagement of a contract as well as suppliers. In the expost contract phase, supplier management is considered as the key aspect for outsourcing success (Lee \& Kim, 1999; Barthelemy, 2003b; Haried \& Ramamurthy, 2009). However, numerous risks lie within the supplier management stage. Firms may experience risks due to a lack of outsourcing expertise; a supplier's insufficient capability and opportunistic behaviours; high asset specificity; and conflicts and unintentional knowledge leakage.

Firstly, it is suggested that a firm's lack of outsourcing experience could cause unexpected transaction and management costs and loss of control over suppliers (Aubert et al., 1996; Bahili \& Rivard, 2003; Barthelemy, 2003a). Literature also indicates that a firm's strategic intent and motivation to outsource products and services is to save costs (Cavusgil et al, 1993; Costa, 2001; Kakabadse \& Kakabadse, 2005). However, the risk of escalating costs arising from unexpected transactions and management costs have also been well-established in the literature (Mahnke et al., 2005). When a firm suffers from a lack of outsourcing experience and expertise, it faces internal uncertainty due to unclear outsourcing requirements (Ellram et al., 2008). Consequently, it may be difficult for a firm to accurately specify the level of 
quality and performance required in the contract. Thus, firms are unlikely to foresee problems such as incomplete contract specifications, hidden costs, and management conflicts occurring in the future outsourcing operation (Earl, 1996; Aubert et al., 1996; Dhar \& Balakrishnan, 2006). Quinn and Hilmer (1994) also argued that unresolved conflicts in the outsourcing management stage may cause client firms to lose control of their suppliers.

Secondly, a supplier's lack of capability and their opportunistic behaviours can result in quality issues, a longer period of lead time, and delayed delivery, or no delivery at all (Kotabe and Murray, 2004; Herath \& Kishore, 2009; Barthelemy, 2003a; Enderwick, 2008). A supplier’s opportunistic behaviour is a deliberate action taken by the supplier in order to maximise their own profits (Aron et al., 2005). This kind of behaviour is not caused by the supplier's lack of capability but by a wrong selection choice made by the buyer firm (Barthelemy, 2003a). Both issues impact negatively on outsourcing management.

Thirdly, asset specificity refers to the level of customisation associated with the exchange (Williamson, 1985). Managing outsourcing relationships may require significant relationship-specific investments including physical and human assets (McIvor, 2009). Firms could possibly find themselves in a 'lock-in' situation due to asset specificity, when there are only a small number of qualified and available suppliers (Herath \& Kishore, 2009). An increase in transaction costs from switching and transferring to another supplier also contributes to the risk of escalating costs in outsourcing management.

Fourthly, as mentioned previously, firms' inexperience and lack of expertise in outsourcing operations may create conflicts between client firms and their suppliers. According to inter-firm relationship management literature, many factors could trigger conflicts between the client firm and supplier, namely miscommunication, unbalanced information, lack of trust and commitment (Mohr \& Spekman, 1994; Wu \& Cavusgil, 2006; Tate \& Ellram, 2009; Haried \& Ramanurthy, 2009). Morgan and Hunt (1994) argue that if conflicts are not resolved amicably, the results could lead to destructive outcomes including relationship termination. 
Finally, the risk of an unintended knowledge leak is a major concern in outsourcing (Quinn \& Hilmer, 1994; Kakumanu \& Portanova, 2006). Suppliers may attempt to misuse or steal proprietary knowledge for secondary purposes, such as reverse engineering or selling to competitors (Aron et al., 2005).

\subsubsection{Categorising risks in offshore outsourcing relationships}

Based on the revision of risks in offshore outsourcing relationships, this study adopts categorisation ideas from Das and Teng (1996) to analyse the risks in offshore outsourcing buyer-supplier relationships. These are relational risk and performance risk.

\subsubsection{Relational risk}

Relational risk is defined as the possibility and the consequence that the partners in inter-firm alliances do not fully commit themselves to a joint goal (Das \& Teng, 1996). A successful outsourcing buyer-supplier relationship depends on effective cooperation between partners, since the intention of engaging each other is to exploit the benefits of cooperation. If one outsourcing partner fails to comply with cooperation, the level of confidence in a good working relationship will reduce (Das \& Teng, 1996). Thus, the perceived relational risk increases. It is indicated by economists that outsourcing firms are always seeking self-interested benefits to maximise their own gain (Williamson, 1983, 1985). Opportunistic behaviours of outsourcing exchange firms are viewed as a typical source of relational risk, which includes secretly extorting or misusing a partner's skills and knowledge to maximise their own benefits (Barthelemy, 2003a; Ellram et al., 2008; Harried \& Ramamurthy, 2009). Conflicts due to buyer firms' inexperience, miscommunication and unbalanced information are also regarded as sources of relational risk, which could potentially lead to a loss of suppliers and termination of relationships.

Das and Teng (1996) acknowledged that the degree of perceived relational risk is closely related to trust. According to MacAllister (1995), there are two forms of trust: cognition-based trust and affect-based trust. Cognition-based trust arises not only from an accumulated knowledge of performance, but also accomplishments resulting 
from direct interactions with a partner that allow others to have confidence in this partner to make reliable and competent choices. The author also indicated that a focal partner needs to display evidence of trustworthiness. Scholars such as Ring and Van de Ven (1994) and Williamson (1993) viewed cognitive trust as a calculated risk since a partner's future actions can be predicted by an accumulated knowledge of previous performance. Consequently, firms can minimise the probability of uncertainties by careful calculations. This study acknowledges the concept of cognitive trust, but disagrees with the description of trust as a type of risk.

In contrast, affect-based trust is built on social and emotional bonds between partners which go beyond a regular business relationship. MacAllister (1995) indicated that partners in an exchange relationship make emotional investments and express genuine feelings and concerns for the welfare of partners. Thus, the emotional bond between partners provides the basis of trust. As the emotional bond deepens, trust in a partner may go beyond accumulated knowledge. The emotionally-motivated nature of affectbased trust makes the relationship less transparent to the objective risk assessments perceived by economists (Johnson \& Grayson, 2005). Affect-based trust encourages partners to interact on a personal level, which is greatly endorsed by social exchange theory. This study supports trust as an important element of social exchange theory, which can be utilised as an informal relational approach to managing risks in outsourcing relationships.

\subsubsection{Performance risk}

Performance risk addresses the possibility that the strategic objectives of partners are not successfully achieved, despite adequate cooperation being made by both partners (Das \& Teng, 1996), and the subsequent consequences. Relational risk is viewed as an inter-firm phenomenon. Performance risk, on the other hand, includes all kinds of risks except those factors related to cooperation. There are various factors contributing to performance risk in managing outsourcing relationships, all of which can lead to the failure of a partnership or the decline of firm performance. Some factors that contribute to performance risk include supplier's lack of capability and incomplete contractual specifications. As discussed in the previous section, a supplier's lack of capabilities can result in a longer period of lead time, delayed, or no 
delivery, and a reduction of quality level (Barthelemy, 2003a; Dhar \& Balakrishnan, 2006; Herath \& Kishore, 2009). The choice that an outsourcing firm makes during the supplier selection process could be wrong due to a lack of experience or a lack of choices caused by a minimal number of available suppliers in the market. Thus, it becomes challenging for the outsourcing firm to monitor their outsourcing performance. In addition, incomplete contractual specifications due to a lack of experience and expertise with contract management will lead the buyer firm to cost escalation (Ellram et al., 2008). It is stressed that a good contract must be precise, complete and balanced (Barthelemy, 2003b). However, there is no such thing as a completed contract, due to constant changes occurring during the outsourcing process. Hence, the risk of incomplete contractual specifications can disrupt a firm's overall outsourcing strategic objectives.

\subsection{Research problem}

This review of the literature has found that research on outsourcing supplier management has suffered from two main problems. Firstly, research has largely focused on the benefits of outsourcing and how outsourcing can contribute to a firm's competitive advantage. There is a lack of understanding of the possible risk factors in different stages of the outsourcing process, particularly in supplier relationship management. Secondly, much attention has been paid to examining the relationship between partnership quality and offshore outsourcing success (Grover et al., 1996; Lee \& Kim, 1999; Lee, 2001; Barthelemy, 2003b). In comparison, there has been limited research on how relationship management strategies can effectively minimise the risks in offshore outsourcing relationships, and what types of strategies these actually are. These findings are consistent with those of Chadee and Raman (2009). They point out a significant amount of research effort has been placed on outsourcing management, particularly in the form of contracts and relationships. However, there is a lack of understanding of the possible risk factors in supplier relationship management and the types of management strategies that can effectively minimise these risks. This study will address the research gap by investigating the interaction between firms' management approaches and risks in offshore outsourcing relationships. 


\subsection{Research issue}

In order to fulfil the research gap discussed above, this study introduces two types of risks that are conceptualised by Das and Teng (1996). They are relational risk and performance risk. Based on SET and TCT, two management approaches are proposed to minimise the risks in offshore outsourcing relationships: a relational approach and a transactional approach. Figure 2.2 demonstrates the link between the two management approaches and the risks in offshore outsourcing relationships.

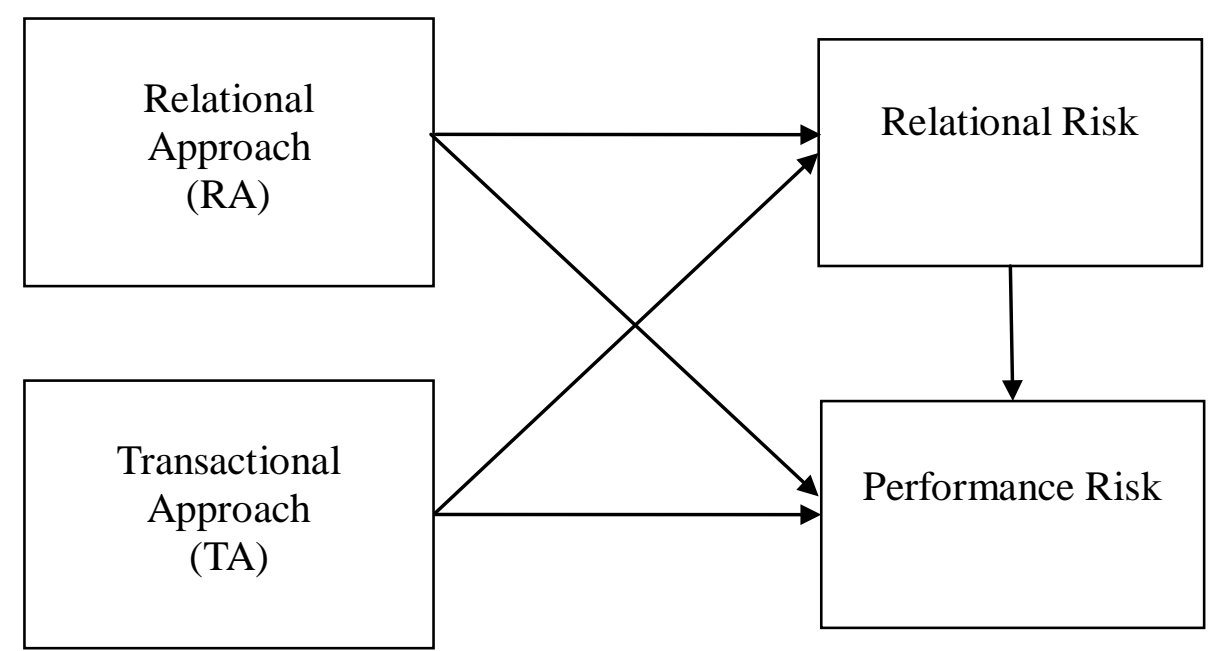

Figure 2.2: Conceptualising the link between management approaches and risks in offshore outsourcing relationships

Relational risk is associated with the probability that outsourcing buyer and supplier firms do not comply with the spirit of cooperation. A relational approach (RA) is guided by SET which regards the development of the outsourcing relationship as a dynamic process through repeated exchanges. The RA requires outsourcing buyer and supplier firms to collaborate and cooperate in order to achieve the mutual benefits of the exchange relationship (Blau, 1964; Granovetter, 1985). The RA also encourages outsourcing buyer and supplier firms to develop relationships based on social norms, such as trust and commitment, to overcome outsourcing relational risks caused by uncooperative behaviours such as opportunism. Thus, this study proposes that a relational approach is best to minimise relational risks.

Performance risk addresses the possibility and consequences of not achieving 
outsourcing objectives, despite a satisfactory cooperation between outsourcing buyer and supplier firms. A transactional approach (TA) grounded in TCT indicates that outsourcing firms can develop and enforce formal contracts to resolve outsourcing performance risk, such as low quality and late delivery, caused by not achieving strategic objectives. Hence, TA is more likely to be an effective management approach to diminish performance risk. This study also proposes that a high level of relational risk can lead to a high level of performance risk, based on the rationale that when the supplier firm behaves opportunistically, the likelihood of having late delivery and low quality products also tends to be high.

\subsection{Chapter summary}

This chapter provides an overview of literature on offshore outsourcing. The focus of this study is to examine the effects of management approaches on risks in offshore outsourcing relationships. A range of theoretical perspectives were discussed and evaluated for the purpose of this research. Based on the conceptualisation from Das and Teng (1996), two risks of offshore outsourcing relationships were introduced: relational risk and performance risk. This study proposes a relational approach, based on the theoretical understanding of social exchange theory for minimising relational risk. In addition, a transactional approach based on transaction cost theory is put forward to diminish the performance risk in offshore outsourcing relationships. Chapter 3 describes the development of a conceptual model that illustrates the association between the two management approaches and the two risks in offshore outsourcing relationships. 


\section{Chapter 3: Conceptual development}

After the presentation of the literature review in Chapter 2, the aim of this chapter is to describe the development of a conceptual model. This chapter starts by recapping outsourcing risks as the dependent variables of this study. Then, a conceptual model is presented in an attempt to explain the link between firms' management approaches and the risks in offshore outsourcing relationships.

\subsection{Recapping outsourcing risk (dependent variable)}

Outsourcing literature discussed in Chapter 2 revealed that risks associated with using external suppliers may result in undesirable outcomes. Hence outsourcing buyer firms may find it difficult to achieve their outsourcing goals and maximise returns on invested resources. As a result, it is critical for outsourcing buyer firms to reduce the level of exposure to the risks in offshore outsourcing relationships. This study categorises the risks in offshore outsourcing relationships into relational risks and performance risks, as conceptualised by Das and Teng (1996). Relational risk focuses on the probability and consequences of outsourcing exchange firms not having satisfactory cooperation towards a joint goal (Das \& Teng, 1996). On the other hand, performance risk refers to the probability and consequences of not achieving outsourcing objectives, despite satisfactory cooperation between outsourcing exchange firms (Das \& Teng, 1996). In order to ensure firms' outsourcing success, this study proposes two management approaches to reduce the risks in offshore outsourcing relationships: the relational approach and the transactional approach.

The relational approach is guided by SET (Blau, 1964; Emerson, 1976; Cook, 1977), which encourages outsourcing buyer and supplier firms to collaborate and cooperate based on shared norms, values and goals to achieve mutual benefits in the exchange relationship. Given the mutual benefits and reciprocity that are achieved through repeated exchanges, outsourcing exchange firms are required to demonstrate their trustworthiness over time. The trustworthiness between outsourcing buyer and supplier firms reduces uncooperative behaviours such as opportunism (Zaheer \& Venkatraman, 1995) and allows reciprocity to happen continuously. The benefit of 
reciprocity is also encapsulated in the cultural concept of guanxi among the Chinese communities, which has influenced business relationships in the context of Asia (Lee et al., 2010). In addition, it is argued through SET (Blau, 1964; Emerson, 1976; Cook, 1977), outsourcing exchange firms can obtain benefits that would not be achievable on their own, by establishing, developing, and growing exchange relationships. This study argues that the relational approach is an effective method for managing the relational risk in offshore outsourcing relationships. Because the relational risk is associated with outsourcing exchange firms not complying with the spirit of cooperation, the relational approaches requires exchange firms to collaborate and cooperate in order to achieve mutual benefits and to overcome the relational risks caused by uncooperative behaviours.

The transactional approach is derived from TCT (Williamson, 1985), which emphasises the establishment and utilisation of formal rules and controls to monitor, regulate and reward desirable outsourcing performance. The transactional approach employs formal contracts as a means to control uncooperative behaviours (relational risk), such as opportunism. However, the utilisation of formal contracts may not be effective for resolving relational risks, due to the high costs of contractual renegotiations and amendments. Furthermore, social scholars such as Gulati (1995a), Ghoshal and Moran (1996), and Uzzi (1997) argue that the use of formal contracts has a negative effect on cooperation between exchange parties. They assert that a highlyspecified contract signals distrust by exchange parties, which encourages opportunistic behaviour. On the other hand, this study argues that the transactional approach is a better tool for diminishing performance risks. Performance risk is concerned with the possibility and consequences of not achieving outsourcing objectives, despite satisfactory cooperation between firms. The transactional approach supports the use of formal contracts. A complex formal contract defines the roles and responsibilities to be performed and, more importantly, it determines outcomes or output to be delivered. The formal contract gives outsourcing buyer firms the abilities to penalise and punish outsourcing supplier firms if they fail to achieve the outsourcing objective. Therefore, the transactional approach is more likely to be an effective management approach to reduce performance risks such as low quality level and late delivery, caused by not achieving strategic objectives. 


\subsection{The conceptual model}

Two arguments are proposed in Section 3.1, explaining the link between outsourcing risks and relationship management approaches. In order to understand this focal research issue, this section begins with an examination of the relationship between the two dependent variables, relational risk and performance risk. Based on SET and TCT, two sets of independent variables are found to be critical to explain the dependent variables. A number of hypotheses are developed to illustrate the relations between the dependent variables and independent variables.

\subsubsection{Relationship between relational risk and performance risk}

In the context of offshore outsourcing, the relational risk and performance risk in offshore outsourcing relationships can be interconnected. According to TCT (Williamson, 1991), outsourcing exchange firms may be required to invest relationship-specific assets to support their outsourcing activities, which cannot be used or transferred into other applications. Thus the outsourcing buyer firms could develop a high level of dependence on the supplier firms, and the outsourcing supplier firms could then become opportunistic (relational risk). When the outsourcing suppliers are opportunistic, they will limit their efforts toward fulfilling the outsourcing objectives, which can be reflected in the form of increase in prices, longer lead times and reduction of service levels (performance risk). In this situation, a high relational risk can lead to a high performance risk. In addition, difficulty in measuring performance may result in incomplete outsourcing contracts, which can cause confusion about whether the supplier has fulfilled its obligations and delivered the quality level of products and services specified in the contract. Due to differences in interpretation of contracts, incompletion of outsourcing contracts can become a source of conflicts (relational risk) in outsourcing buyer-supplier relationships. When the conflicts between the buyer firm and the supplier firm are high, the outsourcing exchange parties tend to lack motivation for achieving outsourcing objectives, which may result in a disappointing outsourcing performance (performance risk). In this case, a high level of relational risk in offshore outsourcing relationships is associated with a high level of performance risk. Therefore: 
Hypothesis 1: Relational risk is positively related to performance risk

\subsubsection{Key influencing factors in the management of outsourcing relationship risks (independent variables)}

The main arguments of this research assume that the relational approach is an effective method to minimise relational risk, whereas the transactional approach is considered more useful to diminish performance risk. Accordingly, this study separates influencing factors into relational factors and transactional factors which are illustrated in Table 3.1.

Table 3.1: Key influencing factors in risk management of outsourcing relationships

\begin{tabular}{|c|c|c|}
\hline & Factors & Sources \\
\hline \multirow{6}{*}{ 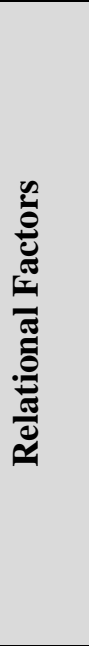 } & Trust & $\begin{array}{l}\text { Mao et al., 2008; Haried \& Ramamurthy, 2009; Mohr \& Spekman, 1994; Heide } \\
\text { et al., 2007; Zaheer \& Venkatraman, 1995; Kern \& Willcocks, 2000; Poppo \& } \\
\text { Zenger, 2002; Anderson \& Narus, 1990; Morgan \& Hunt, 1994; Larson, 1992; } \\
\text { Doney \& Cannon, 1997; Parkhe, 1998. }\end{array}$ \\
\hline & Commitment & $\begin{array}{l}\text { Mohr \& Spekman, 1994; Heide et al., 2007; Morgan \& Hunt, 1994; Haried \& } \\
\text { Ramamurthy, 2009; Heide \& John, 1992; Henderson, 1990; Cook \& Emerson, } \\
1978 .\end{array}$ \\
\hline & Information sharing & $\begin{array}{l}\text { Mao et al., 2008; Haried \& Ramamurthy, 2009; Mohr \& Spekman, 1994; Poppo } \\
\text { \& Zenger, 2002; Kern \& Blois, 2002; Lee \& Kim, 1999; Morgan \& Hunt, } \\
\text { 1994; Oliver, 1990; Han et al., 2008. }\end{array}$ \\
\hline & Communication quality & $\begin{array}{l}\text { Mao et al., 2008; Mohr \& Spekman, 1994; Poppo \& Zenger, 2002; Lee \& Kim, } \\
\text { 1999; Anderson \& Narus, 1990; Sarkar et al., 1997; Han et al., } 2008 .\end{array}$ \\
\hline & Interdependence & $\begin{array}{l}\text { Mohr \& Spekman, 1994; Heide et al., 2007; Bensaou \& Venkatraman, 1995; } \\
\text { Anderson \& Narus, 1990; Herderson, } 1990 .\end{array}$ \\
\hline & Guanxi & Luo, 1997; Yang, 1994; Park \& Luo, 2001; Gu et al., 2008; Coleman, 1990. \\
\hline \multirow{2}{*}{ 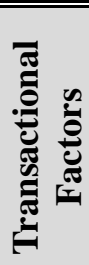 } & Contractual complexity & $\begin{array}{l}\text { Poppo \& Zenger, 2002; Lai, 2009; Barthelemy, 2003b; Zaheer \& Venkatraman, } \\
\text { 1995; Li et al., 2008; Haried \& Ramamurthy, 2009; Zhang et al., 2003; Cannon } \\
\text { \& Perreault, 1999. }\end{array}$ \\
\hline & Asset specificity & $\begin{array}{l}\text { Poppo \& Zenger, 2002; Zaheer \& Venkatraman, 1995; Ellram et al., 2008; } \\
\text { Haried \& Ramamurthy, } 2009 .\end{array}$ \\
\hline
\end{tabular}

Literature in marketing, sociology and outsourcing management has identified a number of factors that indicate a firm's effort in managing inter-firm relations and enhance exchange performance (Anderson \& Narus, 1990; Heide \& John, 1992; Lee \& Kim 1999; Poppo \& Zenger, 2002; Barthelemy, 2003b). This study divides the 
factors into relational factors ${ }^{2}$ (based on the relational approach argument) and transactional factors (based on the transactional approach argument). This study has selected eight factors (six relational factors and two transactional factors) that are considered most relevant to the purpose of this research as shown in Table 3.1. The relational factors include trust, commitment, information sharing, communication quality, interdependence and guanxi. The transactional factors are contractual complexity and asset specificity.

This study argues the relational approach that derives from SET (Homans, 1958; Thibaut \& Kelly, 1959; Blau, 1964) is an effective way to minimise relational risk, because this approach is characterised by the relational factors that promote cooperation and the joint benefits of exchange relationships. Social scholars claim that the relational factors can function as an effective management alternative to the transactional approach via formal contracts (Macaulay, 1963; Granovetter 1985; Alder, 2001). Relational factors such as trust and commitment can align the interests of exchange parties and restrict opportunistic behaviour (Heide \& John, 1992; Larson, 1992; Uzzi, 1997; Alder, 2001). Consequently, relational factors may offer an efficient way to reduce relational risk caused by uncooperative behaviours like opportunism. In addition, it is indicated that relational factors contribute to increased performance (Kalwani \& Narayandas, 1995; Bello \& Gilliland, 1997; Skarmeas \& Katsikeas, 2001). Larson (1994) found that the level of buyer-supplier cooperation is positively related to product quality and lower transaction costs. Therefore, the cooperation promoted by relational factors encourages outsourcing buyer and supplier firms to work towards mutual goals and thus achieve the joint benefits of exchange relationships, which reduces performance risk in offshore outsourcing relationships.

This study also argues the transactional approach grounded in TCT (Williamson, 1975; 1981; 1985), serves as an efficient response to safeguard performance risk, because this approach is characterised by transactional factors that specify clear rules and guidelines to monitor, control, and assess the partner's behaviours, and also determine the outcomes to be delivered. When outsourcing supplier firms fail to deliver expected

\footnotetext{
${ }^{2}$ There are many other relational factors indicated in the literature. Examples are joint action, risks and benefits sharing, and cooperation. This study acknowledges there are other relational factors, but the six relational factors chosen are the most relevant factors to this study.
} 
performance such as quality and quantity, transactional factors can provide useful procedures for resolving unforeseen disputes. Consequently, transactional factors are beneficial for reducing performance risk in offshore outsourcing relationships. In contrast, transactional factors may not be successful at reducing relational risk, due to dissatisfaction with the cooperation between exchange parties. Social theorists such as Gulaiti (1995) and Uzzi (1997) assert that cooperation among exchange parties cannot be regulated by formal rules and procedures since it is embedded in exchange relationships. In addition, transactional factors emphasise that the rational, calculative nature of the exchange relationship can discourage the formation of cooperative behaviours between exchange parties (Macaulay, 1963; Ghoshal \& Moran, 1996). Berheim and Whinston (1998) contend that highly complex formal contracts could encourage opportunistic behaviour regarding actions that cannot be specified within contracts. Consequently, transactional factors may cause relational risk in outsourcing relationships to escalate. Therefore, these arguments lead to the development of the hypotheses below:

Hypothesis 2: Relational factors are negatively related to the relational risk.

Hypothesis 3: Relational factors are negatively related to the performance risk.

Hypothesis 4: Transactional factors are negatively related to the performance risk.

Hypothesis 5: Transactional factors are positively related to the relational risk.

\subsubsection{Trust}

According to SET, trust is regarded as one of the key social components in developing successful inter-firm relationships (Mogan \& Hunt, 1994; Alder, 2001). Empirical research has revealed that trust can improve inter-firm exchanges (Heide \& John, 1990, 1992; Mohr \& Spekman, 1994; Zaheer \& Venkatraman, 1995). However, a significant number of debates exist about the mechanism behind trust. Economists tend to emphasise the rational and calculative origin of trust. Williamson (1993) claims that the term trust is misleading. In contrast, sociologists such as Uzzi (1997) argue that trust is embedded in social relationship exchanges. When one party trusts the other, there is little need to control all circumstances through complex contracts, and thus transaction costs are reduced by removal of costly contractual renegotiation and amendments (Zaheer \& Venkatraman, 1995). Zhang et al (2003:554) defines trust 
as "the confidence that exchange partners have for each other's reliability and integrity”.

This study acknowledges that the term trust is a complex and multidimensional concept, and agrees with the definition of Zhang et al (2003), which captures the behavioural dimension of trust that is particularly important to the management of outsourcing exchange relationships.

Trust is an important factor of the outsourcing relational approach, because trust provides a context in which partners share critical information and exert efforts to achieve individual and joint goals (Anderson \& Narus, 1990). In the context of offshore outsourcing, the outsourcing buyer firms are challenged by huge geographical distances, and they have to trust that their counterpart is acting in ways beneficial to the relationship. Anderson and Narus (1990) asserts that once trust is formed, exchange firms will discover that joint efforts lead to outcomes that exceed what one party would achieve solely in its own interests. Additionally, Parkhe (1998) claims a mutual trust between exchange parties may weaken the need to control all circumstances through formal contracts and thus deter opportunistic behaviours. In other words, when the outsourcing buyer firms believe that their suppliers will replace short-term opportunistic behaviour with long-term shared values, the buyer firms will pay less attention to cooperation and thereby lower the perceived level of relational risk. Furthermore, when mutual trust reduces the monitoring efforts of outsourcing buyer firms, the buyer firms may concentrate more of their efforts towards their suppliers on activities that enhance performance. Therefore, a high level of trust between outsourcing buyer and supplier firms reduces the perceived level of performance risk. These arguments are formalised in the hypotheses below:

Hypothesis 2a: Trust is negatively related to the relational risk.

Hypothesis 3a: Trust is negatively related to the performance risk. 


\subsubsection{Commitment}

Commitment is viewed as a crucial relational component in building long-term business relationships (Morgan and Hunt, 1994; Mohr \& Spekman, 1994; Lee \& Kim, 1999; Lee 2001). Drawing on the relational perspective (Anderson \& Weitz, 1992; Han et al, 2008; Kwon, 2008), when outsourcing buyer and supplier firms are committed to a relationship, they should demonstrate a willingness to make short-term sacrifices, with the aim of maintaining a long-term relationship. A high level of commitment encourages outsourcing buyer and supplier firms to interact beyond what is defined in formal contracts, and thus encourages cooperative behaviours. Additionally, a mutual commitment promotes exchange parties to achieve individual and joint goals without raising the presence of opportunistic behaviours (Cumming, 1984). Therefore, a high level of commitment is likely to reduce relational risk in offshore outsourcing relationships. The definition of commitment implies future orientation in which outsourcing buyer and supplier firms are willing to build and sustain long-term relationships that can resolve unforeseen disturbances. Furthermore, when outsourcing buyer and supplier firms are highly committed to a relationship, they will utilise maximum efforts to achieve joint goals. Consequently, highly committed outsourcing exchange relationships will lower the perception of performance risk caused by issues such as low quality level, late delivery and longer lead time. The above arguments support the following hypotheses:

Hypothesis 2b: Commitment is negatively related to the relational risk.

Hypothesis 3b: Commitment is negatively related to the performance risk.

\subsubsection{Information sharing}

Information sharing is defined as a bilateral expectation that exchange parties will proactively provide critical and proprietary information to each other (Mohr and Spekman, 1994; Zhang et al., 2003). Lee (2001) found a more frequent and relevant exchange of information leads to closer relationships. Haried and Ramamurthy (2009) assert that effective information sharing has the ability to foster commitment, instil trust, and rapidly resolve any conflicts as they emerge. It is argued that trust and commitment discourages opportunistic behaviours and prevents conflicts between 
partners (Heide \& John, 1994; Adler, 2001). As a result, a high level of information exchange can reduce the perception of relational risk that is caused by opportunism and relationship conflicts. In addition, information sharing allows outsourcing buyer and supplier firms to assign and complete tasks more efficiently, which leads to a more satisfying cooperation between the buyer and supplier firms. Consequently, cooperation encourages outsourcing buyer and supplier firms to work towards mutual goals, with the intention of achieving the joint benefits of the exchange relationship, which reduces performance risk due to non-accomplishment of outsourcing objectives. These arguments lead to the development of the following hypotheses:

Hypothesis 2c: Information sharing is negatively related to the relational risk.

Hypothesis 3c: Information sharing is negatively related to the performance risk.

\subsubsection{Communication quality}

According to the social exchange literature (Thibaut \& Kelley, 1959), effective communication between partners is essential in order to achieve the intended objective (Anderson \& Narus, 1990). Communication quality involves sharing significant and meaningful information in both informal and formal situations that are accurate, timeless, adequate, and credible (Anderson \& Narus, 1990; Mohr \& Spekman, 1994). In the context of offshore outsourcing, timely, accurate, and relevant communication between buyer firms and supplier firms allows exchange firms to be better informed of each other's progress and development. Consequently, quality communication facilitates a better understanding and improves the confidence of collaboration between outsourcing buyer and supplier firms, which in turn enhances mutual commitment and trust between exchange firms. It is confirmed by Sarkar et al., (1997) that communication quality is associated with a mutual trust and commitment and this mutual trust and commitment deters opportunistic behaviours (Cumming, 1984; Heide \& John, 1992; Parkhe, 1998). Furthermore, it is evident that a high level of communication exerts a positive impact on relationship satisfaction between exchange parties (Mohr \& Spekman, 1994). Therefore, communication quality can reduce relational risk caused by dissatisfaction in exchange relationships. When outsourcing buyer and supplier firms are communicating in an accurate, timely and relevant manner, the misunderstandings and flawed expectations caused by 
miscommunication diminish, which helps outsourcing buyer firms to reduce transaction costs and thus better manage the performance risk in offshore outsourcing relationships. Based on the above arguments, it is hypothesised:

Hypothesis 2d: Communication quality is negatively related to the relational risk.

Hypothesis 3d: Communication quality is negatively related to the performance risk.

\subsubsection{Interdependence}

Interdependence derives from the social exchange perspective, which requires members of exchange relationships to join forces to achieve mutually beneficial goals (Homan, 1958; Blau, 1964; Kelly \& Thibaut, 1978). In the context of offshore outsourcing, when buyer and supplier firms are working towards mutual goals, the benefits of exchange relationships will be greater than either firm could achieve in isolation. Thus, the interdependence between outsourcing buyer and supplier firms will be motivated to maintain the relationship since any loss of autonomy will be equally compensated through mutual gains. Consequently, the interdependence of outsourcing exchange parties creates an increased willingness for closer cooperation and stronger outsourcing buyer supplier relationships, which in turn reduces relational risk caused by unsatisfactory cooperation, such as opportunism. In contrast, interdependence requires members of exchange relationships to rely on each other to achieve mutual benefits from joint goals. If one of the members fails to embrace the spirit of the exchange relationship, the failure of the relationship will be directly translated into an escalation of transaction costs. Therefore, outsourcing buyer and supplier firms will be more likely to maximise the benefits of the exchange relationship and minimise the mutually-imposed costs of termination. As a result, interdependence between outsourcing exchange parties diminishes performance risk due to unachieved outsourcing objectives. The above arguments are demonstrated in the hypotheses below:

Hypothesis 2e: Interdependence is negatively related to the relational risk.

Hypothesis 3e: Interdependence is negatively related to the performance risk. 


\subsubsection{Guanxi}

The word guanxi is translated as relationship (Hwang, 1987). It is embedded in every part of social life in China and is considered to be a specific mechanism of Chinese social governance (Park \& Luo, 2001). Guanxi refers to relationships or social connections that bond exchange parties through the reciprocal exchange of favours to obtain resources (Gu et al., 2008). At a firm level, guanxi builds trust and facilitates the exchange of favours for organisational purposes (Gu et al., 2008). In addition, a good personal relationship with Chinese supplier firms would assist the flow of quality communication and information exchange, and thus encourages better cooperation between outsourcing buyer and supplier firms. Consequently, when the buyer firm is involved in a close guanxi with the supplier firm, the buyer firm would believe that the supplier firm intends to develop a long-term relationship that will achieve mutual benefits in the future. Coleman (1990) contends the norms of reciprocity in guanxi establish a social constraint that prevents exchange parties from self-seeking opportunism. Therefore, guanxi may reduce the relational risk perceived by outsourcing buyer firms. Park and Luo (2001) found that the development of a guanxi relationship leads to lower transaction costs and higher firm performance. Consequently, establishing a guanxi relationship can reduce the performance risk caused by not achieving outsourcing objectives. This leads to the development of the hypotheses below:

Hypothesis 2f: Guanxi is negatively related to the relational risk.

Hypothesis 3f: Guanxi is negatively related to the performance risk.

\subsubsection{Contractual complexity}

A complex contract carefully defines the roles and responsibilities to be performed, and specifies procedures for non-compliance (Poppo \& Zenger, 2002). In the context of offshore outsourcing, when an outsourcing supplier firm fails to achieve the expected quality level or perform delivery on time, a buyer firm has the ability to resolve these non-performance issues by including stringent rules and conditions in the contract and applying penalties to mitigate such risks. In addition, when problems arise due to unforeseeable changes, outsourcing buyer firms can add clauses and 
procedures that facilitate negotiations. Thus, a complex contractual agreement serves as an effective mechanism for resolving performance risks such as late delivery time, low product quality and escalating costs of outsourcing activities. According to transactional cost theory, a complex contract enhances an outsourcing buyer firm's ability to detect suppliers' opportunism and also offers the buyer firm appropriate controls to mitigate the opportunistic behaviours of suppliers. However, empirical evidence suggests an opposing outcome. Murry and Heide (1998) find a formal control through the use of complex contracts undermines the cooperation of exchange relationships. It is evident that a complex contract may signal distrust and create defensive attitudes and behaviours of the exchange partners that are characteristically opportunistic in nature (Deci et al., 1999). Therefore, a high level of contractual complexity is likely to encourage relational risk in outsourcing relationships. This leads to the development of hypotheses below:

Hypothesis 4a: Contractual complexity is negatively related to the performance risk. Hypothesis 5a: Contractual complexity is positively related to the relational risk.

\subsubsection{Asset specificity}

Asset specificity requires specific assets that are specialised and unique to support a particular activity (Williamson, 1983). Highly asset-specific investments in the forms of human assets, physical assets, and company-specific routines create great costs that may not be re-deployable to other activities. In the context of offshore outsourcing relationships, both buyer firms and supplier firms are expected to interact, which forms some kind of dependence caused by relationship-specific assets. Relationshipspecific assets build on a substantial exchange of information, joint adaptations to each other's business routines and work flows. Since a high level of relationshipspecific asset investments impose mutually high costs of termination, outsourcing exchange firms tend to safeguard these investments. Hence outsourcing firms are likely to work towards a mutual objective that may increase performance. In contrast, when the level of relationship-specific assets increases, the outsourcing buyer firm could develop a high level of dependence on the supplier. The dependence on the supplier may encourage the supplier to behave opportunistically and be less motivated to resolve differences relating to cooperation. Therefore, a high level of asset 
specificity tends to increase the relational risks in offshore outsourcing relationships. Following on from the above arguments, hypotheses are formed as below:

Hypothesis 4b: Asset specificity is negatively related to the performance risk.

Hypothesis 5b: Asset specificity is positively related to the relational risk.

\subsubsection{The indirect effect of relational risk}

Social scholars argue that relational factors promote cooperation and the joint benefits of exchange relationships (Homans, 1958; Thibaut \& Kelly, 1959; Blau, 1964). The cooperation promoted by relational factors encourages outsourcing buyer and supplier firms to work towards mutual goals, which in turn increase outsourcing performance. It is well-grounded in social exchange theory that the use of relational factors contributes to increased performance (Kalwani \& Narayandas, 1995; Bello \& Gilliland, 1997; Skarmeas \& Katsikeas, 2001). For example, Larson (1994) found that the level of buyer-supplier cooperation is positively related to product quality and lower transaction costs. Consequently, it is established that social factors can reduce the performance risk in offshore outsourcing relationships.

Social scholars also argue that relational factors such as trust and commitment discourage opportunistic behaviour (Heide \& John, 1992; Larson, 1992; Uzzi, 1997; Alder, 2001). Consequently, relational factors can reduce relational risk caused by uncooperative behaviours, such as opportunism.

Furthermore, Hypothesis 1 argues that when the outsourcing suppliers are opportunistic, they will limit their efforts toward fulfilling the outsourcing objectives, which can be reflected in forms of increasing prices, longer lead time and reducing product quality. Thus, a high level of relational risk can lead to a high level of performance risk.

The above arguments can be understood as relational factors facilitating a cooperative relationship between outsourcing buyer and supplier firms, which reduce opportunistic behaviours (relational factors lower the relational risk). In addition, the cooperation between outsourcing buyer and supplier firms allows the two parties to 
work towards mutual outsourcing objectives (relational factors lower performance risk). Furthermore, a higher relational risk can result in a higher performance risk. Therefore, it is logical to assume relational risk may have an indirect effect on the relationship between relational factors and performance risk. In order to determine the indirect effect of relational risk, this study hypothesises as below:

Hypothesis 6: Relational risk indirectly affects the relationship between relational factors and performance risk.

Hypothesis 6a: Relational risk moderates the relationship between relational factors and performance risk.

Hypothesis 6b: Relational risk mediates the relationship between relational factors and performance risk.

\subsubsection{Control variable (cultural difference)}

Cultural differences such as language, values and attitude play a powerful role when firms outsource offshore. Cultural differences can create difficulties and cause misunderstandings between outsourcing supplier and buyer firms. Differences in management styles, problem resolution practices and work ethics are shaped by an outsourcing firm's national culture. It has also been found that exchange parties with similar national cultures indicated greater levels of trust and commitment with each other than parties with dissimilar national cultures (Mehta et al., 2006). Therefore, cultural difference can influence the perception of outsourcing risks and thus it should be controlled for. 


\subsection{The conceptual model}

The conceptual model of this study is presented as below:

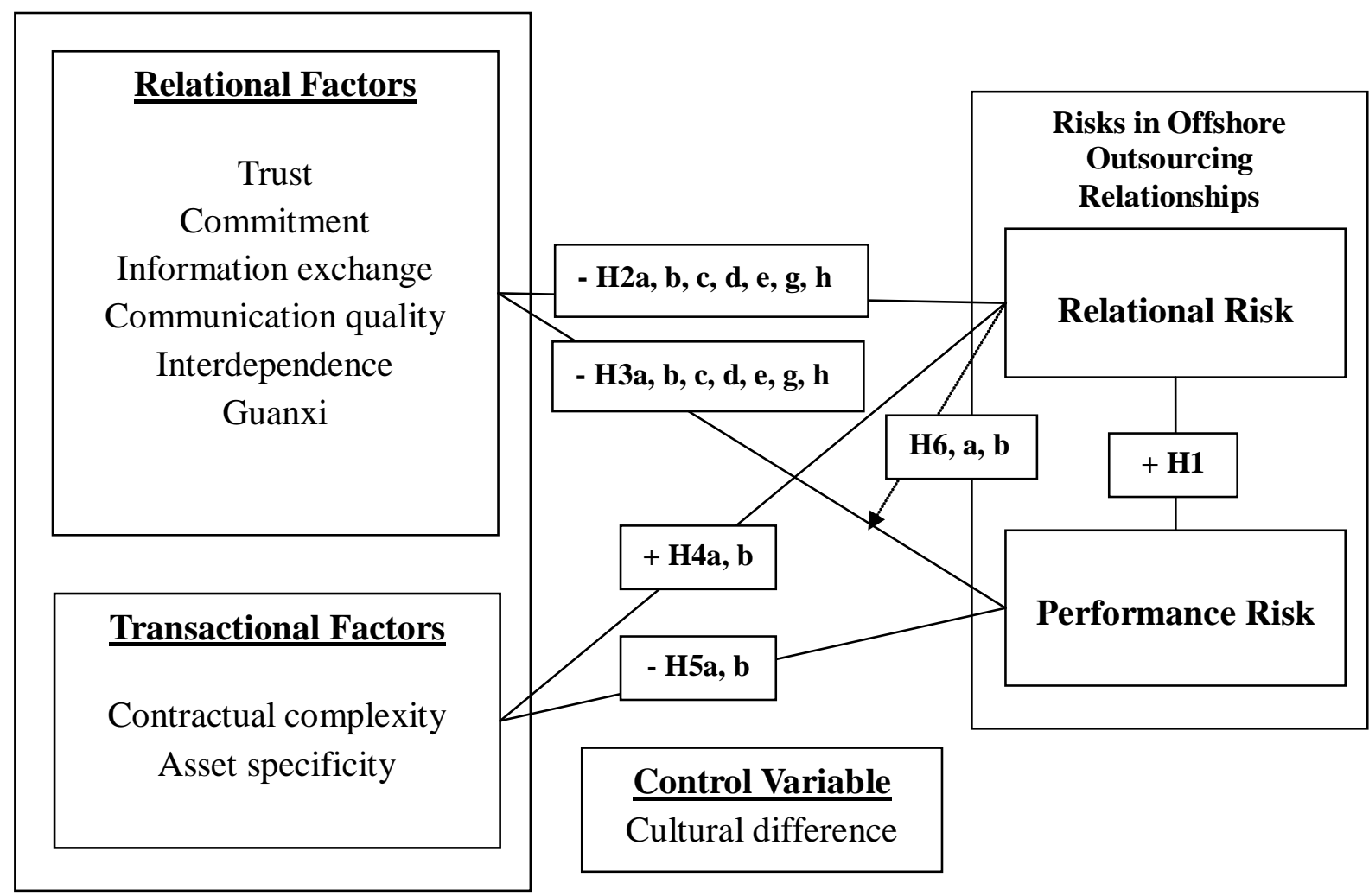

Figure 3.1: The conceptual model

\subsection{Chapter summary}

In this chapter, a conceptual model has been developed to examine the interactions between management approaches and risks in offshore outsourcing relationships. The model incorporates a theoretical understanding from the risk perspective, relational perspective, and transaction cost perspective. The dependent variables of this study are relational risk and performance risk. The independent variables are separated into relational factors (based on the understanding of relational perspective) and transactional factors (based on the understanding of transactional cost perspective). The relational factors include trust, commitment, information sharing, communication quality, interdependence and guanxi. The transactional factors include contract complexity and asset specificity. The control variable considered in this study is cultural difference. Chapter 4 of this study describes the methodology used to collect data. 


\section{Chapter 4: Methodology}

The previous chapter discussed the development of a conceptual model and the pertinent hypotheses. The purpose of this chapter is to describe the method used to measure and validate the role of different management approaches on the risks of offshore outsourcing relationships. This chapter will first present the justification for choosing a quantitative research methodology. It is followed by detailed descriptions of survey design, data collection process, and survey instrument. Finally, this chapter addresses the validity issue, statistical method, and ethical issues.

\subsection{Justification of methodology used}

Quantitative research method reflects the positivist paradigm, which is most useful in testing theories (Creswell, 2009). The main goals of quantitative research are to make accurate predictions about the relationships pertaining to a specific phenomena, gaining meaningful insights of the phenomena, validating the relationships and testing theories and models that explains the relationships between the phenomena (Hair et al., 2009). A quantitative research method allows researchers to develop and employ model and pertinent hypotheses to test existing theories. The utilisation of numerical data and statistics collected from participants provides researchers with exact and quantifiable answers to prove or refute the hypotheses pertaining to the phenomena (Creswell, 2009). The quantitative research technique is found to be most appropriate for this study because it permits the researcher to obtain accurate results about the research problem, which intend to examine the relationships between management approaches and the risks of offshore outsourcing relationships, by testing and validating hypotheses derived from it.

A conceptual model is presented in Chapter 3, drawing on social exchange perspective, transaction cost perspective, and risk management literature to investigate the research problem. In order to gain a better understanding of managing risks in offshore outsourcing relationships in this study, it is important to test and establish relationships in the conceptual model. As applied to this study, the quantitative research method enables the researcher to employ statistical analysis of data to confirm or disconfirm the research assumptions (Creswell, 2009). In addition, the 
quantitative approach allows the researcher to identify the best predicting factors on risks in outsourcing relationships.

\subsection{Research design}

A quantitative research design, using an online survey to collect data, was used as the preferred research technique. A survey design is a research procedure, which involves investigators distributing questionnaires to a sample of a particular population and generalising a quantitative or numeric description of trends, attitudes, behaviours or opinions from analysis of that particular population (Creswell, 2009). In the present case, the purpose of this survey study is to test the interaction between management approaches and outsourcing risks among New Zealand and Australian manufacturing firms that outsource to China, because there are fewer research-represented perspectives from New Zealand and Australian outsourcing firms. The dependent variables are the risks in offshore outsourcing relationships, which categorise into relational risk and performance risk as conceptualised by Das and Teng (1996). Relational risk is defined as the probability and consequences of outsourcing exchange firms not having satisfactory cooperation towards a joint goal (Das \& Teng, 1996). Performance risk refers to the possibility and the consequence that the strategic objectives of outsourcing exchange firms are not successfully achieved, despite an adequate cooperation (Das \& Teng, 1996).

In Chapter 2, two management approaches (the relational approach and the transactional approach) were proposed to minimise the risks in offshore outsourcing relationships. The independent variables were developed based on an understanding of the two management approaches. The relational approach guided by SET regards the development of outsourcing relationships as a dynamic process through specific sequential interactions in which exchange parties are expected to understand their responsibilities and are willing to perform actions that result in positive outcomes (Blau, 1964; Granovetter, 1985). The factors related to relational approach were trust, commitment, information sharing, communication quality, interdependence, and guanxi. On the other hand, the transactional approach grounded by TCT is an effective tool for minimising risks related to performance, as it is characterised by transactional factors that specify clear rules and guidelines to monitor, control, and assess the 
partner's behaviours, and also determines the outcomes to be delivered. When outsourcing supplier firms fail to deliver expected performance such as quality and quantity, transactional factors can provide useful procedures for resolving unforeseen disputes and in turn achieve outsourcing objectives. The transactional factors selected for this study are contractual complexity and assets specificity.

Cultural difference was added as the control for possible influence on the dependent variables. Culture difference can create difficulties and cause misunderstandings between outsourcing supplier and buyer firms if cultural factors such as language, values, and attitude are mismanaged during outsourcing relationship development (Mehta et al., 2006). The effect of cultural difference playing a contributing role to outsourcing supplier risks was, therefore, investigated.

\subsection{Survey research}

This study employed a survey research method using an online questionnaire to collect data from outsourcing managers of New Zealand and Australia. The online questionnaire approach is considered one the most efficient ways of collecting primary data (Bryman \& Bell, 2003). This approach invites prospective respondents to visit a website at which the questionnaire can be found and complete it online (Bryman \& Bell, 2003). There are several advantages associated with using online questionnaires. Firstly, the administrative cost of online questionnaires is much cheaper for researchers than mail questionnaires as costs of postage, paper, and envelope are saved. Secondly, online questionnaires allow a faster response time since mail questionnaires would take a longer delivery time. Thirdly, online questionnaires save respondents valuable time by making it easy to select choices in drop down menus and adding automatic skipping functions (Bryman \& Bell, 2003). Finally, respondents' answers can be automatically stored in a database, thus eliminating data entry time and errors. It is also acknowledged in literature that using online questionnaires may have some problems such as low response rates, restricted online population, multiple replies, and confidentiality and anonymity issues (Hair et al., 2009; Bryman \& Bell, 2003). However, using online questionnaires in this study provided the researcher with efficiencies such as faster response time, lower administrative costs, and easy comparison and analysis of data. Thus, the online 
questionnaire is a versatile, economical and efficient research tool for gathering data for this research.

\subsubsection{Sampling and data collection}

The purpose of this study is to examine the relationship between firms' management approaches and risks in offshore outsourcing relationships. Thus it is important to gain understanding how outsourcing risks can be managed through relational factors and transactional factors on a firm level. Thus the unit of analysis is the firm.

This research focuses on New Zealand and Australian firms which outsource manufacturing activities to China. A large number of empirical studies of offshore outsourcing have concentrated on the information service sector and took place in the United State of America (USA) and Europe (EU) since there is a larger pool of outsourcing firms located in the USA and EU (Grover etl., 1996; Barthelemy, 2003a, b; Gregorio et al., 2009). In comparison, fewer empirical researches on offshore outsourcing to China have taken place in New Zealand and Australia. It is useful to extend the existing research context by examining risks in offshore outsourcing relationships from New Zealand and Australian perspectives. This study also chooses to focus on China as a study context as China is one of the fastest growing economies in the world (Buckley, 2007) and also an important trading destination for Australian and New Zealand outsourcing firms (Australian Department of Affairs and Trade, 2010; New Zealand Ministry of Foreign Affairs and Trade, 2010). Thus, this study can provide useful insights for Australian and New Zealand outsourcing firms into how to manage risks in offshore outsourcing relationship with China.

New Zealand and Australian outsourcing firms were searched in the Kompass database, New Zealand Export Directory, the New Zealand Trade and Enterprise (NZTE) website and international databases such as Dun \& Bradstreet. The databases contained a large number of manufacturing firms. However, the number of firms that perform outsourcing to China was unable to be established. In the end, this study chose to use the data from Dun \& Bradstreet, because it is a Fortune 500 company, with access to information about more than 140 million companies worldwide (Dun \& Bradstreet, 2010). In order to narrow down the search of outsourcing firms, this study 
employed the Australian and New Zealand Standard Industrial Classification (ANZSIC), which is developed by the New Zealand and Australian Bureau of Statistics to improve the ability of industry statistics to be compared between the two countries and with the rest of the world (Statistics New Zealand, 2010). The ANZSIC was also employed to classify companies in the database of Dun \& Bradstreet. A total of 433 firms were randomly selected in the categories of manufacturing including apparel and other unfinished products, textile mill products, leather products and other textile products, comprising of 322 Australian firms and 111 New Zealand firms.

In order to fulfil the research objective, an investigation of the behaviour and experience of outsourcing managers was required. This study adopted a systematic random sampling approach that allows sample elements to be selected extremely precisely, making it easier to guarantee respect for criteria such as homogeneity (Bryman \& Bell, 2003). The sample of 322 Australian firms and 111 New Zealand firms was drawn from 15 percent of a total target population of 2146 Australian and 740 New Zealand firms using ANZSIC industry classification. In the case of this study, the systematic sampling method provides a relatively easy way to draw a sample while ensuring randomness (Hair et al., 2009). The sample of 322 Australian and 111 New Zealand manufacturing firms was then investigated through websites and telephone communication to determine whether they perform outsourcing functions to China. Within the sample, 117 (56 Australian firms and 61 New Zealand firms) firms were found to conduct outsourcing activities to China. Thus, the online survey was sent to senior managers of those 117 manufacturing firms inviting them to participate. Forty-eight responses (25 New Zealand firms and 23 Australian firms) were received over the period of October and November (41 percent response rate). From those, the results of 41 completed responses were analysed for the purpose of this study.

\subsubsection{Instrumentation}

The data was collected through the application of an observation technique involving a structured survey. An observation technique is used to collect primary data about human behaviours and marketing phenomena, which enables researchers to capture the real behaviours of an individual in a natural setting (Hair et al., 2009). In addition, 
this technique reduces recall error and response bias, and observer errors (Hair et al., 2009). More importantly, data can be collected in less time and at a lower cost. Therefore, the observation technique is an appropriate method to use. The survey of this study used the existing measures from previous validated empirical researches, as well as developing new measures based on interpretation of the constructs from the outsourcing literature (see Table 4.1). This study's initial survey was designed in a text format prior to Human Ethics Consent approval of online applications. Later, the survey was transformed into an online questionnaire using Qualtrics. Qualtrics is webbased survey software that allows researchers to build, distribute and analyse surveys.

A critical stage in the use of survey-based research is the design of the survey (Fowler, 1993). After thorough examinations of extant outsourcing literature, the survey developed 28 questions, which were grouped into six sections in order to examine the interaction between management approaches and risks in offshore outsourcing relationships (see Appendix D).

Section 1 was comprised of five questions that focused on general company information, including headquarters location, year of establishment, foreign ownership, operating industry, and annual sales revenue.

Section 2 was comprised of eight questions that were designed to determine how much outsourcing experience companies have internationally. Respondents were asked to indicate their firms' outsourcing experience, main outsourcing activity, percentage of outsourcing, those countries most important to their companies and the main reasons for conducting outsourcing offshore.

Section 3 included six questions relating to companies' outsourcing experience to China, since China is the main focus of this study. Respondents were asked to indicate the number of years that their companies have been involved in outsourcing to China, the number of suppliers and intermediate parties involved in outsourcing activities, and cultural differences they experienced during outsourcing to China in terms of culture, religion, people's thinking, business practices, language, and macroenvironment, which were obtained from Lee \& Kim (1999), Tihanyi et al., (2005), Mao et al., (2008). The main purpose of this section was to determine the experience 
that outsourcing companies had in China. Thus, the background information about outsourcing to China in Section 3 facilitated an understanding of the companies' overall relationship building approaches in China.

Section 4 of the survey comprised of 26 statements concerned with companies' outsourcing relations with Chinese suppliers. Based on social exchange theory, six relational factors were developed including trust, commitment, information exchange, communication quality, interdependence and guanxi. The measurement items were extracted from the existing literature. As illustrated in Table 4.1, four items were used to measure trust and guanxi, whereas three items were employed to examine commitment, information sharing, communication quality and interdependence. The transactional factors derived from transaction cost theory and comprised of contractual complexity and asset specificity, which were measured based on three items.

Table 4.1: Measurement items

\begin{tabular}{|c|c|}
\hline Constructs and measures & Source \\
\hline $\begin{array}{l}\text { Trust (TR) } \\
\text { TR1: We trust that this supplier makes beneficial decisions for us under } \\
\quad \text { any circumstances. } \\
\text { TR2: This supplier is willing to provide assistance to us without } \\
\text { exception. } \\
\text { TR3: We are generally sceptical of the information provided to us by this } \\
\quad \text { foreign supplier. } \\
\text { TR4: Without monitoring, this foreign supplier would fulfil his } \\
\text { obligations. }\end{array}$ & $\begin{array}{l}\text { Lee\&Kim, 1999; } \\
\text { Han et al., 2008; } \\
\text { Li et al., } 2008\end{array}$ \\
\hline $\begin{array}{l}\text { Commitment (CM) } \\
\text { CM1: We and this supplier are willing to devote all resources needed for } \\
\text { the relationship. } \\
\text { CM2: We would not drop this supplier even if another supplier offers us } \\
\text { better terms. } \\
\text { CM3: We are fully committed to helping this supplier in the long term. }\end{array}$ & $\begin{array}{l}\text { Lai, 2009; } \\
\text { Heide et al. } 2007\end{array}$ \\
\hline $\begin{array}{l}\text { Information sharing (IS) } \\
\text { IS1: We share mutual information with this supplier regarding the } \\
\text { business environment and technical change that affects each } \\
\text { other's businesses. } \\
\text { IS2: We mutually share proprietary information with this supplier. } \\
\text { IS3: We only provide information to this supplier according to a pre- } \\
\text { specified agreement. }\end{array}$ & $\begin{array}{l}\text { Mohr\&Spekman, } \\
\text { 1994; } \\
\text { Lee\&Kim, } 2005\end{array}$ \\
\hline $\begin{array}{l}\text { Communication quality (CQ) } \\
\text { CQ1: This supplier lets us know as soon as possible about any unexpected } \\
\text { problems. } \\
\text { CQ2: The communication between us and this supplier is complete and }\end{array}$ & $\begin{array}{l}\text { Anderson\&Narus, } \\
\text { 1990; } \\
\text { Mao et al., } 2008\end{array}$ \\
\hline
\end{tabular}




\begin{tabular}{|c|c|}
\hline $\begin{array}{l}\text { thorough. } \\
\text { CQ3: There is no language barrier between us and this supplier. }\end{array}$ & \\
\hline $\begin{array}{l}\text { Interdependence (ID) } \\
\text { ID1: We have made significant investments for this supplier (e.g. } \\
\text { upgraded production systems). } \\
\text { ID2: If we wanted to, we could switch to another supplier quite easily. } \\
\text { ID3: If this supplier wanted to, they could easily switch to another client. }\end{array}$ & $\begin{array}{l}\text { Mohr\&Spekman, } \\
\text { 1994; } \\
\text { Heide et al., } 2007\end{array}$ \\
\hline $\begin{array}{l}\text { Guanxi (GX) } \\
\text { GX1: Our senior manager has extensive personal relationships with this } \\
\text { supplier. } \\
\text { GX2: Based upon our senior manager's personal relationship with this } \\
\text { supplier, our company was able to gain privileges. } \\
\text { GX3: Our senior manager was able to obtain valuable and important } \\
\text { information based on his/her personal relationship with this } \\
\text { supplier. } \\
\text { GX4: When problem arises, our senior manager contacts this supplier for } \\
\text { resolutions based on their personal relationship. }\end{array}$ & $\begin{array}{l}\text { Su et al., 2009; } \\
\text { Lee\&Dawn, } 2005\end{array}$ \\
\hline $\begin{array}{l}\text { Contractual complexity (CC) } \\
\text { CC1: Our outsourcing contract with this supplier is highly customised and } \\
\text { required considerable legal work. } \\
\text { CC2: We believe a detailed contract is the most important tool for } \\
\text { regulating the behaviour of this supplier. } \\
\text { CC3: When it comes to disputes and arbitration concerning the products } \\
\text { and services with this supplier, we always follow the terms of the } \\
\text { contract }\end{array}$ & $\begin{array}{l}\text { Poppo\&Zenger, 2002; } \\
\text { Lai, 2009; } \\
\text { Heide et al., } 2007\end{array}$ \\
\hline $\begin{array}{l}\text { Asset specificity (AS) } \\
\text { AP1: Our company-specific routines and workflows are customised to } \\
\quad \text { this supplier. } \\
\text { AP2: We invested a significant amount of time in developing the skill } \\
\quad \text { level of our employees to suit this supplier. } \\
\text { AP3: It's very costly for us to switch from this supplier. }\end{array}$ & $\begin{array}{l}\text { Poppo\&Zenger, 2002; } \\
\text { Zaheer\&Venkatraman, } \\
1995\end{array}$ \\
\hline $\begin{array}{l}\text { Relational risk (RR) } \\
\text { RR1: The probability of this supplier acting opportunistically is high. } \\
\text { RR2: The potential for conflicts regarding the way we do business with } \\
\text { this supplier is high. } \\
\text { RR3: The likelihood of this supplier acquiring useful technological } \\
\text { information from us for their own benefit is high. }\end{array}$ & $\begin{array}{l}\text { Cavusgil et al., 2004; } \\
\text { Herath\&Kishore, } \\
\text { 2009; Aron et al., } \\
\text { 2005; } \\
\text { Dhar\&Balakrishnan, } \\
2006\end{array}$ \\
\hline $\begin{array}{l}\text { Performance risk (PR) } \\
\text { PR1: The likelihood of unexpected costs in this working relationship is } \\
\text { high. } \\
\text { PR2: This supplier has a tendency of requiring longer lead time than } \\
\text { others in the past. } \\
\text { PR3: This supplier has a tendency of late delivery issues in the past. } \\
\text { PR4: This supplier has a tendency of quality issues in the past. } \\
\text { PR5: Our contract with this supplier suffers from lack of detail about } \\
\text { project scope. } \\
\text { PR6: Our contract with this supplier suffers from lack of detail about the } \\
\text { project compliance. } \\
\text { PR7: Our contract with this supplier suffers from lack of detail about } \\
\text { penalty clauses. }\end{array}$ & $\begin{array}{l}\text { Barthelemy, 2003a; } \\
\text { Aron et al., 2005; } \\
\text { Dhar\&Balakrishnan, } \\
\text { 2006; } \\
\text { Ellram et al., 2008; } \\
\text { Li \& Barnes, 2008; } \\
\text { Herath\&Kishore, } \\
2009\end{array}$ \\
\hline
\end{tabular}

Section 5 included ten statements, which were designed to understand an outsourcing manager's perception of the probability of outsourcing supplier risk occurring in the future. The related measurement items are illustrated in Table 4.1. The outsourcing 
supplier risk was divided into factors concerning relational risk and performance risk. The measurement items were developed based on careful investigation of risk factors within extant outsourcing literature. The relational risk was measured in three items; whereas seven items were used to measure the performance risk. In addition, particular attention was paid to the wording of the items used to measure outsourcing supplier risks, as the definition of relational risk and performance risk reflected the outsourcing manager’s future prediction based on current experience.

The last section of the survey had six questions, which required information regarding respondents' current position, job title, gender, working experience and their involvement in outsourcing decisions. In addition, a text box was also provided for any other comments respondents wished to make.

This online questionnaire used a seven-point Likert scale ranging from 1 as 'Completely disagree' to 7 as 'Completely agree' in Sections 4 and 5. The Likert scaling provided a simple and effective means of quantifying the data and obtaining a summated value (Alreck \& Settle, 1995). To ensure the accuracy of constructs measurement, the formulations of measurement items in the outsourcing relations section were adopted from previously-tested empirical research, including Anderson and Narus (1990), Mohr and Spekman (1994), Poppo and Zenger (2002), Lai (2009), Lee and Kim (1999, 2005). The measurements of dependent variables were formulated based on the conceptual understanding of the Das and Teng (1996) paper, as well as careful examination of risk factors within extant outsourcing literature (refer to Table 4.1).

Testing and improving the survey was achieved through three stages. In the initial stage, the text-formatted survey was tested by a number of academic peers within the school. The peers, including members of academic staff and fellow $\mathrm{PhD}$ students, were asked to comment on clarity, relevance, specificity and readability of the survey. Several improvements to the relevance of the questions and the clarity of the contents were made during numerous discussions with the academic peers. In the second stage, the text-formatted survey was transformed into an online survey and was then sent to non-academics, such as friends and family, for testing usability and functionality. Several other improvements were made to the skip function of the online survey. In 
the final stage, the online survey was emailed to three New Zealand outsourcing managers for pre-test purposes. Based on their experiences, corrections were made to the contents and language of the survey.

\subsection{Validity and reliability of the measurement instrument}

In social science it is argued that measurement can be defined as the process that enables researchers to establish a relationship between abstract concepts and empirical indicators (Camines and Zeller, 1990). It is crucial for researchers to ensure the data they plan to collect in the field relates as closely as possible to the reality they hope to study. Thus, empirical studies need to take into account whether measurements are valid and reliable.

Reliability is concerned with the extent to which a measuring instrument offers consistent results on a repeated basis across time, which is particularly at issue in connection with quantitative research (Hair et al., 2009). Internal consistency method was developed to measure reliability, which relies on Cronbach's alpha (Thietart et al., 2001). Thus, Cronbach’s alpha test (Cronbach, 2004) was calculated to assess the reliability of each construct in SPSS reliability programme. According to Hair, Bush, and Ortinau (2009), the Cronbach's alpha value may range from 0 to 1 , and a value of less than 0.6 would typically indicate a satisfactory internal consistency. The alpha scores for each construct fall above the accepted threshold of 0.6. As reported in Table 4.2, all measurement items of variables have achieved an accepted level.

Table 4.2: Results of Cronbach's alpha test

\begin{tabular}{l|c|c}
\hline \multicolumn{1}{c|}{ Variables } & Number of items & Reliability (Cronbach's alpha) \\
\hline 1.Trust & 4 & .702 \\
\hline 2.Commitment & 3 & .886 \\
\hline 3.Information sharing & 3 & .788 \\
\hline 4.Communication quality & 3 & .709 \\
\hline 5.Interdependence & 3 & .695 \\
\hline 6.Guanxi & 4 & .736 \\
\hline 7.Contractual complexity & 3 & .771 \\
\hline 8.Asset specificity & 3 & .725 \\
\hline 9.Relational risk & 3 & .707 \\
\hline 10.Performance risk & 7 & .689 \\
\hline 11.Culture difference & 16 & .834 \\
\hline
\end{tabular}


Validity is concerned with the integrity of the conclusions that are generated from a piece of research (Bryman \& Bell, 2003). This study assessed construct, content, as well as external validity.

The construct validity refers to the extent to which the variables under investigation are completely and accurately identified before any relationship was hypothesised (Hair et al., 2009: 283). This study addressed this validity by adopting constructs from empirical research that had been already used and validated by other scholars (see Table 4.1), except the items of the dependent variables. On the other hand, the constructs of the two dependent variables were developed based on careful examination of risk factors within extant outsourcing literature (also refer to Table 4.1). Therefore, the construct validity of this study is assured by empirical and theoretical support.

Content validity is sometimes referred to as face validity, which examines how well a construct's measurable components represent that construct (Hair et al., 2009: 337). The measurement items of the survey instrument were drawn up through a thorough examination of the offshore outsourcing domain. The content validity of the survey instrument was reviewed by a panel of academic peers for possible improvements to the measurement items of the survey, and non-academic respondents were employed in a pilot test for feedback on the clarity of the survey questions and contents.

\subsection{Statistical method}

The response data was analysed using SPSS version 18, which allowed this study to examine the links between management approaches and risks in offshore outsourcing relationships. The statistical methods used in this research range from basic techniques, such as calculating descriptive and frequency statistics, to more advanced techniques, such as regression analysis. The descriptive and frequency statistics are useful procedures for describing and summarising information about variables (Field, 2005). A correlation analysis is used to measure the degree of a supposed linear association between two or more variables (Field, 2005). This study employed the Pearson's correlation to access association between two interval variables. A regression analysis is a technique used for discovering the best linear prediction of a 
dependent variable from a set of predictor variables (Bryman \& Bell, 2003). This study employed a multiple regression analysis to test hypotheses proposed in Chapter 3. This procedure allows the researcher to examine the effects of relational factors and transactional factors (independent variables) on relational risk and performance risk (dependent variables) and obtain the statistical significance of the coefficients corresponding to the hypotheses. In addition, this study used data analysis procedures developed by Baron and Kenney (1986) to determine the moderating and mediating effects of relation risk on interactions between relational factors and performance risk.

\subsection{Ethics}

Following strict procedures for research involving human subjects at Victoria University of Wellington, this study has been assessed and approved by the Faculty of Commerce and Administration's Human Ethics Committee. In accordance with the Victoria University of Wellington Ethics Guidelines, the voluntary respondents were notified the purpose of the research, the confidentiality and rights to withdraw by invitation letters emailed to them (see Appendix C). It was assumed that, by completing the online survey, respondents' consents were granted. The data collected from the research participants was analysed in an aggregated form for research purposes only and was not distributed to any third parties.

\subsection{Chapter summary}

This chapter described the research method used to collect the primary data. A quantitative research design using an online survey was employed to investigate the effects of management approaches on risks in offshore outsourcing relationships. An invitation email, along with a link to the online survey, was sent to 117 Australian and New Zealand firms who perform outsourcing functions to China. Follow-up phone calls were also made to improve the response rate. A total of 48 responses were received (41 percent response rate). From these, the results of 41 completed responses were analysed for the purpose of this study. The reliability of the survey measures was conducted through a pilot test on a panel of academic peers and industry experts. The validity of the survey measurement was tested using the results of Cronbach's alph. The next chapter reveals the results of the survey data. 


\section{Chapter 5: Survey results}

The previous section outlines the methods used to measure and validate the conceptual model through data collection of an online survey. The aim of this chapter is to reveal the results of the quantitative survey. This chapter separates the survey results responses into three sections. The first section presents demographic data about the participating firms and respondents. The second section provides descriptive data relating to the participating firms' outsourcing experience. The last section summarises the findings of the research hypotheses that describe the relationships among relational factors, transactional factors and risks of offshore outsourcing relationships.

\subsection{Firm and respondent demographics}

The following two sections describe the demographic information about the participating firms and respondents.

\subsubsection{Firm demographics}

Firm demography statistics provide a snapshot of the characteristics of New Zealand (NZ) and Australian (AUS) businesses in the current study. Table 5.1 summarises the responses from NZ and AUS firms, which are engaged in offshore outsourcing production of goods and services to China. 
Table 5.1: Profile of responding firms

\begin{tabular}{|c|c|c|}
\hline Range & $\begin{array}{c}\text { Frequency } \\
\mathrm{N}=41\end{array}$ & Percent \\
\hline \multicolumn{3}{|l|}{ (a) Country of origin } \\
\hline Australia & 20 & 48.8 \\
\hline New Zealand & 21 & 51.2 \\
\hline Total & 41 & 100.0 \\
\hline \multicolumn{3}{|c|}{ (b) Total number of employees ${ }^{3}$} \\
\hline $0-5$ & 7 & 17.1 \\
\hline $6-20$ & 17 & 41.5 \\
\hline $21-50$ & 5 & 12.2 \\
\hline $51-100$ & 2 & 4.9 \\
\hline $101-200$ & 4 & 9.8 \\
\hline 200 or more & 6 & 14.6 \\
\hline Total & 41 & 100.0 \\
\hline \multicolumn{3}{|l|}{ (c) Industry } \\
\hline Manufacturing & 12 & 29.3 \\
\hline Wholesale Trade & 20 & 48.8 \\
\hline Retail Trade & 9 & 21.9 \\
\hline Total & 41 & 100.0 \\
\hline \multicolumn{3}{|l|}{ (d) Sales revenue ${ }^{4}$} \\
\hline$\$ 250,001-\$ 500,000$ & 3 & 7.3 \\
\hline$\$ 500,001-\$ 1,000,000$ & 2 & 4.9 \\
\hline$\$ 1,000,001-\$ 5,000,000$ & 13 & 31.7 \\
\hline$\$ 5,000,001-\$ 10,000,000$ & 5 & 12.2 \\
\hline$\$ 10,000,001-\$ 20,000,000$ & 7 & 17.1 \\
\hline$\$ 20,000,001$ and over & 8 & 19.5 \\
\hline Unanswered & 3 & 7.3 \\
\hline Total & 41 & 100.0 \\
\hline \multicolumn{3}{|l|}{ (e) Foreign ownership } \\
\hline Domestically owned & 39 & 95.1 \\
\hline Some foreign ownership & 2 & 4.9 \\
\hline Total & 41 & 100.0 \\
\hline
\end{tabular}

Part (a) of the table indicates that there are 20 AUS firms (48.8\%) and 21 NZ firms (51.2\%). According to the survey results, the earliest establishment among all responding firms was in 1950, while the most recent establishment was in 2007. Part

\footnotetext{
${ }^{3}$ The total number of employees was estimated by managers as the end of 2009. The categorisation of employee numbers is in accordance with Statistics New Zealand (SNZ) and Australian Bureau of Statistics (ABS).

${ }^{4}$ Sales revenue as at the end of 2009 and dollars as in firm's own country currency
} 
(b) shows the total number of employees of responding NZ and AUS firms as at the end of 2009. The largest proportion of firms had six to 20 employees, which includes 17 firms, giving it a percentage of 41.5. Only six large firms ${ }^{5}$, a percentage of 14.6, employed more than 200 staffs. According to part (c) of the table, wholesale trade was the leading industry, consisting of 20 firms (48.8\%). The second largest industry was manufacturing, consisting of 12 firms (29.3\%). It was followed by retail trade with nine firms (21.9 percent). Part (d) shows the sales revenue of responding firms as the end of 2009, which indicates that the majority of the firms were placed between the one million and five million dollar categories (31.7\%). Part (e) reveals that the majority of firms surveyed were domestically owned, which comprises 95.1 percent of returned data.

\subsubsection{Respondent demographics}

This section provides descriptive data about the respondents in the survey research. Table 5.2 illustrates the general characteristics of responding NZ and AUS firm managers.

Table 5.2: Profile of respondents

\begin{tabular}{lcc}
\hline Range & $\begin{array}{c}\text { Frequency } \\
\text { N=41 }\end{array}$ & Percent \\
\hline (f) Decision maker & 35 & 85.4 \\
Directly involved in outsourcing & 6 & 14.6 \\
Indirectly involved in outsourcing & 41 & 100.0 \\
Total & & \\
(g)Gender & 21 & 51.2 \\
Female & 20 & 48.8 \\
Male & 41 & 100.0 \\
Total & & \\
& 9 & \\
(h) Working experience in offshore outsourcing & 21.9 \\
1-5 years & 9 & 24.4 \\
6- 10 years & 10 & 48.8 \\
10 plus years & 20 & 4.9 \\
Unknown & 2 & 100.0 \\
Total & 41 & \\
\hline
\end{tabular}

\footnotetext{
${ }^{5}$ Statistics New Zealand and Australian Bureau of Statistics categorise firms that employ more 200 employees as large businesses.
} 
The results of the survey were measured based on mid-level firm managers from NZ and AUS. According to part (f) of the table, 85.4 percent of managers were directly involved in outsourcing decision making. The other 14.6 percent of managers were indirectly involved in the firm's outsourcing decisions. Within the managers surveyed in this research 21 were female managers (51.2\%) and 20 were male managers (48.8). Part (h) of the table shows the majority of firm managers had more than ten years' experience working in offshore outsourcing (48.8\%). Only a small number of managers had less than five years of experience (21.9\%). The results of the survey reveal that the managers of NZ and AUS firms have an impressive average outsourcing experience of more than ten years among a total of 39 managers (two other managers did not answer this particular question).

\subsection{Reporting firms' outsourcing experience}

The following sections describe firms' outsourcing experience internationally as well as experience in relation to China.

\subsubsection{Firms' international outsourcing experience}

Participants reported that manufacturing activities were their firm's primary activity. Table 5.3 below has summarised responding firms' overall experience of outsourcing manufacturing activities to foreign countries. 
Table 5.3: Firms' international outsourcing experience

\begin{tabular}{lcc}
\hline Range & $\begin{array}{c}\text { Frequency } \\
\text { N=41 }\end{array}$ & Percent \\
\hline (i) Outsourcing experience to foreign countries & \\
0-1 years & 0 & 0.0 \\
2-3 years & 1 & 2.4 \\
4-5 years & 11 & 26.8 \\
6-9 years & 9 & 22.0 \\
10-15 years & 14 & 34.1 \\
Over 15 years & 6 & 14.6 \\
Total & 41 & 100.0 \\
(j) Percentage of outsourcing business & & \\
5-10\% & 1 & 2.4 \\
10-20\% & 1 & 2.4 \\
20-30\% & 3 & 7.3 \\
30-50\% & 3 & 7.3 \\
50\% and over & 31 & 75.6 \\
Unknown & 2 & 4.9 \\
Total & 41 & 100.0 \\
\hline
\end{tabular}

Part (i) demonstrates the number of years the NZ and AUS firms have been performing offshore outsourcing internationally. Of the 41 who responded, a large majority $\left(48.7 \%{ }^{6}\right)$ has been outsourcing internationally for ten years or more. This is followed by 29.2 percent $^{7}$ of firms that performed outsourcing internationally for five years or less. The results in the table also reveal that no firm was involved in outsourcing activities to foreign countries for less than one year. Part (j) of the table reports a firm's total percentage of outsourcing business. A large proportion (75.6\%) of firms was outsourcing 50 percent or more activities in foreign countries. Only eight firms outsourced less than 50 percent of their business overseas.

\subsubsection{Outsourcing destinations}

Participants were asked to report their most important and second most important outsourcing destinations. Table 5.4 shows 39 firms revealed China as their most important destination. The other two firms considered China as their second most important destination.

\footnotetext{
${ }^{6}$ The percentage was calculated by adding 34.1\% (10-15 years) and $14.6 \%$ (over 15 years) together

${ }^{7}$ The percentage was calculated by adding $2.4 \%$ (2-3 years) and 26.8\% (4-5 years) together
} 
Table 5.4: Outsourcing destination

\begin{tabular}{lcc}
\hline Outsourcing destination-China & Frequency \\
& $\mathbf{N = 4 1}$ & Percent \\
\hline Main destination & 39 & 95.1 \\
$2^{\text {nd }}$ destination & 2 & 4.9 \\
Total & 41 & 100.0 \\
\hline
\end{tabular}

Additional popular outsourcing destinations given by firms that are not shown in the table were mostly located in the south and southeast of Asia including India, Philippines, Vietnam, Indonesia, Thailand and Hong Kong.

\subsubsection{Outsourcing motivations}

Respondents were asked to rate the main motivations for outsourcing on a scale of 1 to 7 , where 1 equalled completely unimportant and 7 equalled extremely important. Eight different choices of outsourcing motivations are listed in Table 5.5.

Table 5.5: Firms' outsourcing motivations

\begin{tabular}{lcc}
\hline Outsourcing motivations & $\begin{array}{c}\text { Mean } \\
\text { N=41 }\end{array}$ & Std. Deviation \\
\hline 1. Seeking low costs & 6.39 & 1.046 \\
2. Improving production flows & 5.90 & 1.081 \\
3. Serving customers more effectively & 5.85 & 1.329 \\
4. Seeking skilled labour & 5.13 & 1.472 \\
5. Accessing new skills and technologies from & 5.05 & 1.499 \\
foreign suppliers & & \\
6. Exploiting technological capabilities & 4.97 & 1.967 \\
7. Focusing on core business & 4.97 & 1.404 \\
8. Following industry competitors & 4.68 & 1.738 \\
\hline
\end{tabular}

The results of the survey reveal that the main motivation for firms to outsource production is seeking low costs. This is followed by the firm's intentions of improving production flows and serving customers more effectively. The motivation of following industry competitors was regarded as the least popular reason for firms to perform outsourcing activities. 


\subsubsection{Outsourcing experience in China}

Participants were asked to specify the year their firms commenced outsourcing activities to China. It is revealed that the earliest outsourcing activities to China by a firm was in 1980 and the latest activity commenced by a firm was in 2008 . Table 5.6 reveals the average years of outsourcing experience performed by NZ and AUS firms to China.

Table 5.6: Years of outsourcing experience to China

\begin{tabular}{lll}
\hline Range & N & Mean \\
\hline Years of outsourcing to China & 38 & 10.6 \\
\hline
\end{tabular}

As indicated in Table 5.6, a total of 38 participants answered this particular question. The average number of years that the firms have performed outsourcing to China is more than ten.

Participants were asked their method of conducting outsourcing activities in China. The results are illustrated in Table 5.7.

Table 5.7: Outsourcing method in China

\begin{tabular}{lcc}
\hline Range & $\begin{array}{c}\text { Frequency } \\
\text { N=41 }\end{array}$ & Percent \\
\hline (k) Outsourcing method in China & 24 & 58.5 \\
Working with suppliers directly & 4 & 9.8 \\
Working with intermediate parties & 13 & 31.7 \\
Working with both independent & & \\
suppliers and intermediate parties & 41 & 100.0 \\
Total & & \\
\hline
\end{tabular}

A majority of firms (58.5\%) chose to work with independent Chinese suppliers directly. This is followed by 31.7 percent of firms using both independent suppliers and intermediate parties. Only 9.8 percent of firms were working with intermediate parties alone. 


\subsection{Results of hypothesis testing}

The following sections illustrate the survey results from analysis of Pearson's correlation and multiple regressions.

\subsubsection{Descriptive results}

A correlation is a measure of the linear relationship between variables (Field, 2005). There are different ways in which two variables could be related. They could be positively or negatively related. However, correlation between two variables does not imply the direction of causality. This study used the Pearson's correlation to find correlation between two continuous variables. Table 5.8 gives an overview of the correlations between the variables in this study.

Table 5.8: Descriptive statistics and correlation matrix

\begin{tabular}{|c|c|c|c|c|c|c|c|c|c|c|c|}
\hline Variables & 1 & 2 & 3 & 4 & 5 & 6 & 7 & 8 & 9 & 10 & 11 \\
\hline 1.Trust & 1 & & & & & & & & & & \\
\hline 2.Commitment & $.486 * * *$ & 1 & & & & & & & & & \\
\hline 3.Information sharing & .028 & $.478^{* *}$ & 1 & & & & & & & & \\
\hline 4.Communication quality & $.500 * * *$ & $.378^{*}$ & .071 & 1 & & & & & & & \\
\hline 5.Interdependence & .283 & .308 & .001 & .261 & 1 & & & & & & \\
\hline 6.Guanxi & $.323^{*}$ & $.542 * * *$ & $.347 *$ & $.369 *$ & $.389 *$ & 1 & & & & & \\
\hline 7.Contractual complexity & .170 & .027 & -.237 & $.481^{* *}$ & .151 & .271 & 1 & & & & \\
\hline 8.Asset specificity & -.027 & .189 & .102 & -.064 & .234 & $.353 *$ & .128 & 1 & & & \\
\hline 9.Relational risk & -.199 & -.190 & -.157 & $-.318 *$ & -.168 & -.187 & -.016 & .185 & 1 & & \\
\hline 10.Performance risk & -.280 & -.280 & -.209 & $-.401 * *$ & $-.461 * *$ & -.168 & -.094 & .153 & $.657 * * *$ & 1 & \\
\hline 11. Cultural difference & -.083 & .188 & .023 & .050 & -.059 & $.309 *$ & .025 & .105 & .072 & .105 & 1 \\
\hline Mean values & 5.0061 & 5.3333 & 4.8659 & 4.9878 & 3.4837 & 4.9035 & 3.4708 & 4.5813 & 3.9573 & 4.1443 & 5.0244 \\
\hline Standard deviation & .94660 & 1.1199 & .99598 & 1.1465 & 1.0781 & 1.0117 & 1.3052 & 1.1378 & .99358 & .86642 & .72077 \\
\hline
\end{tabular}

For the purpose of easier reading, Table 5.9 below summarises the correlated relationships between variables at three different significant levels in this study. 
Table 5.9: Correlated relationships between variables

\begin{tabular}{ll}
\hline Level of significance & Existing links \\
\hline \multirow{2}{*}{ Correlation at a $\mathbf{0 . 0 0 1}$ significant level: } & 1.Trust and commitment \\
& 2.Trust and communication quality \\
& 3.Commitment and guanxi \\
& 4.Relational risk and performance risk \\
Correlation at a $\mathbf{0 . 0 1}$ significant level: & 1.Commitment and information sharing \\
& 2.Communication quality and contractual complexity \\
& 3.Communication quality and performance risk (negative) \\
& 4.Interdependence and performance risk (negative) \\
Correlation at a $\mathbf{0 . 0 5}$ significant level: & 1.Commitment and communication quality \\
& 2.Guanxi and trust \\
& 3.Guanxi and information sharing \\
& 4.Guanxi and communication quality \\
& 6.Guanxi and interdependence \\
& 7.Guanxi and asset specificity \\
& 8.Guanxi and cultural difference \\
\hline
\end{tabular}

At a significant level of 0.001 , it is revealed that trust is positively linked with several variables including commitment and communication quality. Commitment is positively linked to guanxi. In addition, it is important to notice that the main dependent variables, relational risk and performance risk, are positively linked at a high correlation level. At a significant level of 0.01 , it is observed commitment is positively linked to information sharing and communication quality is positively linked to contractual complexity. It is worth highlighting that performance risk is found to be negatively linked to both communication quality and interdependence in the results of Pearson's correlation analysis. At a significant level of 0.05, it is noted that guanxi is correlated to six variables including trust, information exchange, communication quality, interdependence, asset specificity and cultural difference. Lastly, commitment is found to be correlated to communication quality at significant levels of 0.05 .

\subsubsection{Regression results}

Regression analysis is used when independent variables are correlated with one another and with the dependent variable (Field, 2005). Multiple regression statistics testing is an extension of correlation analysis. The result of regression is an equation that represents the best prediction of a dependent variable from several independent variables (Field, 2005). This study employed simple and multiple regression analyses 
to explore the relationships among the dependent variable and independent variables.

The regression equations of this study are formulated below.

\section{Regression equation 1:}

$\mathrm{RR}=\mathrm{a}+\mathrm{b}_{1}$ TRU $+\mathrm{b}_{2}$ COMMT $+\mathrm{b}_{3}$ INFOSHR $+\mathrm{b}_{4}$ CMMQUAL $+\mathrm{b}_{5}$ INTDEP + $\mathrm{b}_{6} \mathrm{GUXI}+\mathrm{b}_{7}$ CONTRPLX $+\mathrm{b}_{8}$ ASSTSPEF + control variable $+\mathrm{e}$

\section{Regression equation 2:}

$\mathrm{PR}=\mathrm{a}+\mathrm{b}_{1}$ TRU $+\mathrm{b}_{2}$ COMMT $+\mathrm{b}_{3}$ INFOSHR $+\mathrm{b}_{4}$ CMMQUAL $+\mathrm{b}_{5}$ INTDEP + $\mathrm{b}_{6} \mathrm{GUXI}+\mathrm{b}_{7}$ CONTRPLX $+\mathrm{b}_{8}$ ASSTSPEF + control variable $+\mathrm{e}$

Where: $\quad$ RR stands for relational risk PR stands for performance risk

TRU stands for trust COMMT stands for commitment

INFOSHR stands for information sharing

CMMQUAL stands for communication quality

INTDEP stands for interdependence

GUXI stands for guanxi

CONTRPLX stands for contractual complexity

ASSTSPEF stands for asset specificity

\subsubsection{Assumptions of regression analysis}

There are several important assumptions underlying regression analysis. This study has tested assumptions including independent errors (Durbin-Watson test), no multicollinearity (variance inflation factor figure), normality of residuals, residual outliers, homoscedasticity and linearity. If any of these assumptions are violated, this can considerably lower the reliability of outcomes or make regression analysis impossible to use. Thus it is critical to conduct various procedures to prove that the results of regression in this study are reliable.

The Durbin-Watson test is designed to examine serial correlations between errors in regression models, which specifically tests whether adjacent residuals are correlated (Field, 2005). It is noted that values less than 1 or greater than 3 are cause for concern and the closer to 2 that the value is, the better (Durbin \& Watson, 1952). 
Table 5.10: Result of Durbin-Watson test

\begin{tabular}{lll}
\hline & M 1 & M 2 \\
\hline Durbin-Watson test & 1.924 & 1.878 \\
\hline
\end{tabular}

Table 5.10 showed the figures produced by the Durbin-Watson test is between 1 and 3 . Model 1 in the form of regression equation 1 reveals value of 1.924. Model 2 in the form of regression equation 2 shows a value of 1.878 . Both values are close to 2 , which indicate that there is no serial correlation found among residuals and the assumption has been met.

Variance inflation factor (VIF) is a measure of multi-collinearity. The VIF shows whether a predictor has a strong linear relationship with the other predictors (Field, 2005).

\section{Table 5.11: Assumptions of regression analysis}

\begin{tabular}{l|c}
\hline Variables & VIF \\
\hline 1.Trust & 1.764 \\
2.Commitment & 2.065 \\
3.Information sharing & 1.657 \\
4.Communication quality & 2.144 \\
5.Interdependence & 1.544 \\
6.Guanxi & 2.496 \\
7.Contractual complexity & 1.634 \\
8.Asset specificity & 1.580 \\
9.Cultural difference & 1.228 \\
\hline
\end{tabular}

According to Myers (1990), a VIF value less than 10 is acceptable. In Table 5.11, all of the VIF values are less than 10, which indicate that there is no linear relationship between two or more of the predictors and the assumption has been met.

In the analysis, the regression assumptions including normality of residuals, homoscedasticity and linearity by examining the P-P plot and scatterplot were checked (see Apendix A). The P-P plot reports whether the data set is following normal distribution (Field, 2005). A scatterplot is used to determine homoscedasticity and linearity, which requires the residuals at each level of the predictor to have the same variance and linear relationship (Field, 2005). The results of these tests indicate 
none of the assumptions are violated ${ }^{8}$ in the analysis.

\subsubsection{Results of regression analysis}

Table 5.12 reports the results of multiple regression analysis for outsourcing supplier risks. In the table, Model 1 reveals an ANOVA sig value of .475 ( $p>.05)$, which implies Model 1 is not a good fit. The value of $\mathrm{R}^{2}$ is 22.7 percent, which indicates 22.7 percent of variation in outsourcing relational risk is explained by six relational factors, two transactional factors and cultural difference.

Model 2 achieved an ANOVA sig value of .012 $(p<.05)$, which indicates Model 2, overall, predicts performance risk significantly well. The $\mathrm{R}^{2}$ value of Model 2 is 47 percent, which means the predictors, comprising of six relational factors, two transactional factors and cultural difference, accounts for 47 percent of the variation in outsourcing performance risk.

Table 5.12: Results of multiple regression analysis

\begin{tabular}{|c|c|c|c|c|c|c|}
\hline \multirow[t]{2}{*}{ Variables } & \multicolumn{3}{|c|}{ M 1 - Relational Risk } & \multicolumn{3}{|c|}{ M 2 - Performance risk } \\
\hline & UnStand.B & t-value & Sig. & UnStand.B & t-value & Sig. \\
\hline \multicolumn{7}{|c|}{ Independent variables } \\
\hline Trust & .032 & .147 & .884 & .030 & .194 & .847 \\
\hline Commitment & -.034 & -.165 & .870 & -.078 & -.543 & .591 \\
\hline $\begin{array}{l}\text { Information } \\
\text { sharing }\end{array}$ & -.083 & -.408 & .686 & -.219 & -1.534 & .136 \\
\hline $\begin{array}{l}\text { Communication } \\
\text { quality }\end{array}$ & -.233 & -1.203 & .238 & -.197 & -1.448 & .158 \\
\hline Interdependence & -.039 & -.215 & .831 & -.311 & -2.454 & $.020 *$ \\
\hline Guanxi & -.256 & -1.054 & .300 & -.014 & -.080 & .937 \\
\hline $\begin{array}{l}\text { Contractual } \\
\text { complexity }\end{array}$ & .094 & .603 & .551 & -.007 & -.064 & .950 \\
\hline Asset specificity & .273 & 1.612 & .117 & .276 & 2.324 & $.027 *$ \\
\hline \multicolumn{7}{|l|}{ Control variables: } \\
\hline Cultural difference & .101 & .401 & .691 & -.023 & -.132 & .896 \\
\hline \multicolumn{7}{|c|}{ Dependent variables: } \\
\hline Relational risk & - & - & - & .573 & 5.439 & $.000 * * *$ \\
\hline Performance risk & .753 & 5.439 & $.000 * * *$ & - & - & - \\
\hline$R^{2}$ & \multicolumn{3}{|c|}{.227} & \multicolumn{3}{|c|}{.470} \\
\hline ANOVA Sig & \multicolumn{3}{|c|}{.475} & \multicolumn{3}{|c|}{$.012 *$} \\
\hline F value & \multicolumn{3}{|c|}{.981} & \multicolumn{3}{|c|}{2.953} \\
\hline
\end{tabular}

\footnotetext{
${ }^{8}$ Results of the P-P plot and scatterplot are included in the appendix.
} 
$\mathrm{N}=40$. Significance level: ${ }^{*} \mathrm{p}<.05 ; * * \mathrm{p}<.01 ; * * \mathrm{p}<.001$.

Hypothesis 1 predicts there is a positive relationship between relational and performance risk. The result of regression analysis shows a highly significant relationship between relational risk and performance risk $(\mathrm{t}=5.439, p<0.001)$. Furthermore, the b-value of un-standardised coefficients is positive, implying a positive relationship between relational risk and performance risk ( $b=.573 \sim .753$ ). Thus Hypothesis 1 is supported.

Hypotheses 2, 2a, 2b, 2c, 2d, 2e and 2f predict there are negative relationships between relational risk (dependent variable) and relational factors including trust, commitment, information sharing, communication quality, interdependence and guanxi. The results of multiple regression analysis find no significant connections between relational risk as a dependent variable and all relational factors $(\mathrm{t}=-1.203$ $\sim .147, p=.238 \sim .884)$. Thus hypotheses 2, 2a, 2b, 2c, 2d, 2e and $2 \mathrm{f}$ are rejected.

Hypotheses 3, 3a, 3b, 3c, 3d, 3e and 3f argue that performance risk (dependent variable) would negatively impact on all relational factors including trust, commitment, information sharing, communication quality, interdependence and guanxi. However, the only significant correlation revealed by regression analysis results is between performance risk and interdependence $(\mathrm{t}=-2.454, p<0.05)$. The $\mathrm{b}$ value shows a negative coefficient, which indicates a negative relationship between performance risk and interdependence $(\mathrm{b}=$-.311). Thus Hypothesis 3e is supported. In contrast, no sufficient evidence is found between performance risk (dependent variable) and the five other relational factors: trust, commitment, information sharing, communication quality, and guanxi $(\mathrm{t}=-2.454 \sim .194, p=.136 \sim .847)$. Accordingly, there is only partial support for Hypothesis 3.

Hypotheses 4, 4a and 4b predict negative relationships between performance risk (dependent variable) and all transactional factors including contractual complexity and asset specificity. The results of regression analysis revealed no support for Hypothesis 4a $(\mathrm{b}=-.007, \mathrm{t}=-.064, p=.950)$. However, the result in Table 5.13 reveals a positive relationship between asset specificity and performance $(b=.276, t=2.324$, $p<0.05$ ), which implies a high level of asset specificity among outsourcing firms leads 
to higher performance risk. Therefore, none of the hypotheses are supported by the survey results.

Hypotheses 5, 5a and 5b predict relational risk (dependent variable) is positively correlated to transactional factors, including contractual complexity and asset specificity. The results of regression analysis show insufficient evidence to support Hypotheses 5, 5a and 5b (b=.094 .273, $\mathrm{t}=.603 \sim .1 .612, p=.117 \sim .551)$.

\subsection{Testing the indirect effects of relational risk (Hypotheses 6, 6a and 6b)}

The results of multiple regression analysis in Table 5.12 reveal that relational risk is not significantly correlated with relational factors and transactional factors. In this study, it is also hypothesised that relational risk may have an indirect effect on the relationship between relational factors and performance risk. Thus, relational risk is tested for moderating and mediating effects. Due to the number of independent variables involved, this study used factor analysis to examine whether these variables belong in the same group or different groups of variables. In Table 5.13, the results of the factor analysis suggest the six relational factors only reflect a single variable (Eigen value $>1$, all six factor loadings $>0.5$ ). Similarly, the factor analysis results indicated the two transactional factors also reflect one factor (Eigen value $>1$, both factor loadings $>0.5$ ). Accordingly, two variables were obtained by averaging all scores for six relational factors and two transactional factors. These variables are aggregate relational factors (ARF) and aggregate transactional factors (ATF).

Table 5.13: The results of factor analysis

\begin{tabular}{l|c|c}
\hline $\begin{array}{l}\text { Variables } \\
\mathrm{N}=41 .\end{array}$ & $\begin{array}{c}\text { Relational variables } \\
\text { Factor 1 }\end{array}$ & $\begin{array}{c}\text { Transactional variables } \\
\text { Factor 1 }\end{array}$ \\
\hline Trust & .727 & - \\
\hline Commitment & .818 & - \\
\hline Information exchange & .520 & - \\
\hline Communication quality & .649 & - \\
\hline Interdependence & .530 & .751 \\
\hline Guanxi & .752 & .751 \\
\hline Contractual complexity & - & 1.128 \\
\hline Asset specificity & - & - \\
\hline Eigen value & 2.734 & - \\
\hline
\end{tabular}


In general, the moderating effects are indicated by the interaction between the dependent variable and the moderating variable (Baron \& Kenny, 1986). To become a moderating variable, the variable should not be correlated with the independent variable (Baron \& Kenny, 1986). In Table 5.14, Model 2 shows relational risk (RR) as the moderating variable is significantly correlated with aggregate relational factors (ARF), implying the rule of being a moderator is violated. Model 3 reveals RR has no direct effect on independent variables (ARF and ATF) and the interaction effects (ARF $x$ RR and ATF $x$ RR). Therefore, the regression results suggest RR does not play a moderating role between relational factors and performance risk, indicating a lack of support for Hypothesis 6a.

Table 5.14: Regression results for the indirect effects of relational risk

\begin{tabular}{|c|c|c|c|c|c|c|c|c|c|}
\hline \multirow{3}{*}{$\begin{array}{l}\text { Dependent } \\
\text { Variables }\end{array}$} & \multirow{2}{*}{\multicolumn{3}{|c|}{$\begin{array}{c}\text { Relational Risk } \\
\text { M1 } \\
\end{array}$}} & \multicolumn{6}{|c|}{ Performance Risk } \\
\hline & & & & \multicolumn{3}{|c|}{ M2 } & \multicolumn{3}{|c|}{ M3 } \\
\hline & UnStand.B & t-value & Sig. & UnStand.B & t-value & Sig. & UnStand.B & t-value & Sig. \\
\hline \multicolumn{10}{|c|}{ Independent variables } \\
\hline ATF & .146 & 1.044 & .303 & .041 & .351 & .727 & -.251 & -.506 & .616 \\
\hline \multicolumn{10}{|c|}{ Variable of interest } \\
\hline \multicolumn{10}{|l|}{ Interactions } \\
\hline ARF $x$ RR & - & - & - & - & - & - & .082 & .507 & .533 \\
\hline ATF x RR & - & - & - & - & - & - & .088 & .489 & .613 \\
\hline
\end{tabular}

$\mathrm{N}=41$. Significance level: $* \mathrm{p}<.05$;** $\mathrm{p}<.01 ; * * * \mathrm{p}<.001$. ARF stands for aggregate relational factors; ATF stands for aggregate transactional factors; RR stands for relational risk.

To establish the mediating effects of relational risk, four steps are required (Judd \& Kenny, 1981; Baron \& Kenny, 1986):

1. The independent variable is correlated with the mediator

2. The independent variable is correlated with the dependent variable

3. The mediator should affect the dependent variable

4. To establish whether the mediator completely mediates the relationship between dependent and independent variables, the effect of the independent variable on the dependent variable controlling for the intervening variable should be zero. 
Model 1 illustrates the mediator (RR) is highly correlated with ARF at a significant level of 0.05, which upholds the first step of establishing mediation. Model 2 further shows ARF is significantly correlated with performance risk $(p<0.05)$, which supports Step 2 of establishing mediation. The results of Model 2 in Table 5.14 also reveal relational risk is significantly correlated with performance risk $(p<0.001)$ implying Step 3 is satisfied. Thus, it is established that first three steps of relational risk being a mediator between relational factors ${ }^{9}$ and performance risk have been supported.

Step 4 determines whether relational risk completely or partially mediates the relationship between relational factors and performance risk. According to Baron and Kenny (1986), a complete mediation is the case when the independent variable (ARF) no longer affects performance risk (dependent variable); the mediator (relational risk) will be significantly related to performance risk. However, the results in Table 5.14 demonstrate a partial mediation effect in which the mediator (relational risk) is significantly related to performance risk (dependent variable), while the independent variable (ARF) is affecting performance risk $(p<0.05)$ as well. To conclude the regression results in this study, relational risk as the mediator played a partial mediation effect on the relationship between relational factors and performance risk (dependent variable), indicating Hypothesis 6b is supported.

\subsection{Control variable (cultural difference)}

It is assumed in Chapter 3 that cultural differences such as language, religion, the way of thinking, and management style would contribute to performance risk and relational risk. Table 5.12 showed that cultural difference had no significant effect on both relational risk and performance risk $(\mathrm{b}=-.023 \sim .101, \mathrm{t}=-.132 \sim .401, p=.691$ .896).

\footnotetext{
${ }^{9}$ Relational factors used to test indirect effects of relational risk are the average score of 6 relational factors from an aggregate measure, which is indicated in 5.3.3.2.1.
} 


\subsubsection{Summary of hypotheses testing results}

Table 5.15 illustrates the hypotheses that were supported or rejected. The survey data shows a significant correlation between the dependent variables (relational risk and performance risk) investigated in this study, which supports Hypothesis 1. Relational risk as the dependent variable shows no significant correlations with six of the relational factors, two of the transitional factors and the control variable (cultural difference). Only two significant relationships are found to exist with performance risk as the dependent variable among six relational factors, two transitional factors and the control variable (cultural difference). The relationship between interdependence and performance risk is fully supported by the survey data, while the other relationship between asset specificity and performance risk reveals an opposite direction to that proposed in Chapter 3. Finally, relational risk is discovered in the study as mediating between an aggregated measure of relational factors and performance risk (dependent variable).

Table 5.15: Summary of hypotheses testing results

\begin{tabular}{l|l|l}
\hline Hypothesis & \multicolumn{1}{c|}{ Factors } & Results \\
\hline H1 & Relational risk and performance risk (+) & Supported \\
\hline H2 & Relational factors and relational risk (-) & Rejected \\
\hline H2a & Trust and relational risk (-) & Rejected \\
\hline H2b & Commitment and relational risk (-) & Rejected \\
\hline H2c & Information exchange and relational risk (-) & Rejected \\
\hline H2d & Communication and relational risk (-) & Rejected \\
\hline H2e & Interdependence and relational risk (-) & Rejected \\
\hline H2f & Guanxi and relational risk (-) & Rejected \\
\hline H3 & Relational factors and performance risk (-) & Partially supported \\
\hline H3a & Trust and performance risk (-) & Rejected \\
\hline H3b & Commitment and performance risk (-) & Rejected \\
\hline H3c & Information exchange and performance risk (-) & Rejected \\
\hline H3d & Communication and performance (-) & Rejected \\
\hline H3e & Interdependence and performance risk (-) & Supported \\
\hline H3f & Guanxi and performance risk (-) & Rejected \\
\hline H4 & Transactional factors and performance risk (-) & Partially supported \\
\hline H4a & Contractual complexity and performance risk (-) & Rejected \\
\hline H4b & Asset specificity and performance risk (-) & Partially supported \\
& & (opposite direction) \\
\hline H5 & Transactional factors and relational risk (+) & Rejected \\
\hline H5a & Contractual complexity and relational risk (+) & Rejected \\
\hline H5b & Asset specificity and relational risk (+) & Rejected \\
\hline H6 & Indirect effect of relational risk & Partially supported \\
\hline H6a & Relational risk as a moderating variable & Rejected \\
\hline H6b & Relational risk as a mediating variable & Supported \\
\hline
\end{tabular}




\subsection{Chapter summary}

The data presented and analysed in this chapter was obtained from responses to an online survey, which was created and designed for the study of managing risks of offshore outsourcing relationships to China. The results of the data analysis showed a significant correlation between performance risk and relational risk. However, no evidence supported the relationships between relational risk and all independent variables including relational factors and transactional factors. On the other hand, performance risk is negatively correlated with interdependence, but positively related to asset specificity. Most importantly, relational risk was found to have a mediating effect on the relationship between aggregate relational factors and performance risk. The results of all hypotheses testing will be discussed at a more in-depth level in Chapter 6. 


\section{Chapter 6: Discussion}

The focus of Chapter 5 was to present the results of the quantitative survey and analyse them for their relevance to the research hypotheses. The purpose of this chapter is to interpret these results and provide a meaningful discussion. This chapter is divided into two sections. The first section summarises the findings of the hypotheses testing from Chapter 5. This section covers two areas of discussion. The first part discusses the results for each research hypothesis presented in Chapter 5. The second part discusses the findings that relate to the conceptual model as revealed in Chapter 3. In addition, a modified research model is presented, based on the findings of the survey. Lastly, the second section of this chapter highlights important contributions this study makes to the literature on risk management in offshore outsourcing relationships.

\subsection{Findings from the survey}

This study is designed to determine whether a relational approach and a transactional approach, guided by social exchange theory and transactional cost theory, can minimise risks in offshore outsourcing relationships. The results illustrated in Chapter 5 have found some support for the hypotheses proposed in Chapter 3. Hypotheses 1 , $3 e$ and $6 \mathrm{~b}$ were fully supported by the survey data. Hypothesis $4 \mathrm{~b}$ was partially supported (although, significantly, in the opposite direction). The findings of the hypotheses testing are discussed below.

\subsubsection{Discussion on hypotheses testing}

To examine the offshore outsourcing supplier risks, this study introduced two types of risks, relational risk and performance risk (dependent variables), that are conceptualised by Das and Teng (1996) see Chapter 2. Based on social exchange theory and transaction cost theory, this study proposed two management approaches to minimise outsourcing supplier risks, the relational approach and the transactional approach. These approaches are translated into two sets of independent variables (relational factors and transactional factors) in Chapter 3 as the critical variables in 
explaining relational risk and performance risk. The analysis of the quantitative data presented in Chapter 5 showed some interesting results.

\subsubsection{Interactions between relational risk and performance risk (H1)}

The survey data has supported the prediction of Hypothesis 1, which confirms a positive relationship between relational and performance risk. In the context of offshore outsourcing relationships, this finding can be understood as a high level of conflict between buyer firms and supplier firms (relational risk is high) that discourages cooperation efforts between supplier firms, which results in a disappointing outsourcing performance (performance risk is high). Correspondingly, a high performance risk is reflected in terms of late delivery, poor quality and longer lead times, causing conflicts (high relational risk). If buyer firms and supplier outsourcing firms are unable to resolve the conflicts, cooperative behaviours between exchange outsourcing firms are reduced. In the situation of a low level of conflict among outsourcing exchange firms (low relational risk), uncooperative behaviour such as opportunism is discouraged, which results in lower performance risk and vice versa.

6.1.1.2 Interactions between relational risk and relational factors $(H 2,2 a, 2 b, 2 c$, 2d, 2e and 2f)

The survey results show there is no evidence for a negative effect between relational risk (dependent variable) and the relational factors (independent variables) of trust, commitment, information sharing, communication quality, interdependence and guanxi. These findings are quite unexpected, but the reliability and validity tests performed on relational risk and relational factors do not appear to have major measurement problems as noted in Chapter 4. All measurement items of the six relational factors have been tested repeatedly in many different papers and confirmed as credible (Mohr \& Spekman, 1994; Lee \& Kim, 1999; Mao et al., 2008; Han et al., 2008). Furthermore, the regression results in Table 5.15 show a negative correlation between aggregate relational factors (ARF) and relational risk (Model 1 without control variable), which illustrates some supports for Hypotheses 2, 2a, 2b, 2c, 2d, 2e and $2 \mathrm{f}$. 
There are several possibilities as to why no significant relationships were found between relational risk and relational factors. Firstly, the number of observations may be too small. A larger number of observations may have helped this study gain more statistical power in SPSS regression analysis. Secondly, there might be too many relational factors involved in this study, which did not work statistically with a small sample size. The six relational factors may need to be aggregated. However, the possibility of re-aggregating the variables may not be conceptually sound. Each individual relational factor is designed to capture different aspect of offshore outsourcing relationships. In future research, concentration on a smaller number of the most crucial relational variables is recommended. Furthermore, future research calls for more accurate measurements of relational risk in the context of offshore outsourcing relationship management. It is recognised that the idea of operationalising relational risk in the context of offshore outsourcing relationship management is still at an exploratory stage. Hence there is room for improvement of the measurement items used to examine relational risk in the future.

\subsubsection{Interactions between performance risk and relational factors $(\mathrm{H} 3,3 \mathrm{a}, 3 \mathrm{~b}$,} 3c, 3d, 3e and 3f)

The only hypothesis supported by the quantitative data in Chapter 5 is Hypothesis 3e, which reveals a negative relationship between interdependence (relational factor) and performance risk (dependent variable). This finding is consistent with social exchange theory, which stresses the importance of interdependence among outsourcing exchange firms. The notion of social exchange theory assumes that an interdependent relationship ensures members of outsourcing exchange parties will work towards a mutually beneficial goal (Homan, 1958; Blau, 1964; Kelly \& Thibaut, 1978). It is argued by Mohr and Spekman (1994) that the advantage of interdependence provides benefits greater than one could achieve alone. Thus a high level of interdependence promotes cooperative behaviour and reduces performance risk subsequently. Accordingly, Hypothesis 3 receives partial support.

The results for Hypotheses 3a, 3b, 3c, 3d and 3f present no evidence to support a high level of trust, commitment, information exchange, communication quality and guanxi 
reducing outsourcing performance risk. The possible answers to these findings are similar to those for relational risk as the dependent variable. Firstly, a larger research sample size may potentially help resolve the issue of insufficient evidence among predicted relationships in SPSS. Secondly, a reduced number of relational factors would help future study to concentrate more on the most important relational factors in managing risks in outsourcing relationships. Lastly, enhanced measurement items of performance risk would offer better statistical power in SPSS.

\subsubsection{Interactions between performance risk and transactional factors $(\mathrm{H} 4,4 \mathrm{a}$,} 4b)

Hypothesis 4b has the only significant correlation found in the survey results, which reveals a positive relationship between performance risk (dependent variable) and asset specificity. It implies that a high level of asset specificity among outsourcing firms leads to higher performance risk. This finding shows a conclusion that works in the opposite direction to what was originally predicted in Chapter 3. There are several justifications for an increase in asset specificity leading to an increase in perceived performance risk. When an offshore outsourcing venture requires significant relationship-specific investments, the related costs of developing these relationshipspecific investments will rise (Williamson, 1983). The escalating cost of managing offshore outsourcing relationships is viewed as a form of performance risk. Secondly, it is noted in Chapter 3 that outsourcing firms tend to safeguard relationship-specific investments, due to mutually high costs of termination and high levels of dependence among exchange firms. According to TCT (Williamson, 1985), when relationshipspecific investments are high, the potential risk of becoming locked-in with an outsourcing supplier tends to be high as well (high performance risk).

Hypothesis 4a predicts a negative relationship between performance risk and contractual complexity. The survey results did not support this hypothesis as outlined in Chapter 5. There are several possibilities as to why Hypothesis 4a is not supported. Firstly, the sample size is too small to detect any statistical significance between performance risk and contractual complexity. Secondly, outsourcing buyer firms may believe it takes more than highly customised contracts to minimise performance risk in outsourcing relationships. It is argued that firms should consider using the 
relational approach and transactional approach as complements to improve exchange performance, thus potentially lowering offshore outsourcing relationship risks (Poppo \& Zenger, 2002; Barthelemy, 2003b). Thirdly, it is emphasised the content of a good contract should vary according to the level of perceived risks (Joskow, 1988; Williamson, 1991). It is possible that the outsourcing firms surveyed for this study may have a low perception of outsourcing performance risk within their relationships, so the need to develop stringent contracts is not as important.

\subsubsection{Interactions between relational risk and transactional factors $(\mathrm{H} 5,5 \mathrm{a}, 5 \mathbf{b})$}

The survey results show no support for Hypotheses 5, 5a and 5b, which predict positive associations between relational risk (dependent variable) and transactional factors including contractual complexity and asset specificity. It is argued in Chapter 2 that social exchange theorists suggest that highly customised contracts (transactional factor) signal distrust of exchange parties and encourage opportunistic behaviours (relational risk) among exchange parties (Macaulay, 1963; Ghoshal and Moran, 1996). In addition, TCT indicates high relationship-specific investments that cannot be transferrable to other activities could encourage exchange firms to behave opportunistically (Williamson, 1981, 1985). These arguments all lead to the predictions of Hypotheses 5, 5a and 5b. The results of the validity, reliability and assumption tests of relational risk, contract complexity and asset specificity are all satisfied. Thus, there are two possible explanations to explain the lack of correlation. Firstly, a larger sample size would help this study achieve better statistical power in establishing sufficient evidence between relational risk and transactional factors. Secondly, refined measurement items of relational risk would offer better understanding of the relationships between relational risk and transactional factors

\subsubsection{Indirect effect of relational risk (H6, 6a and 6b)}

The survey results show that relational risk has a partial mediating effect on the interactions between aggregate relational factors (independent variable) and performance risk (dependent variable). As shown in Table 5.15, the strong negative relationship between aggregate relational factors and relational risk in Model 1 indicates a cooperative relationship based on trust, commitment, information sharing, 
communication quality, interdependence and guanxi is crucial in order to reduce relational risk in offshore outsourcing relationships. Model 2 also revealed a positive relationship between relational risk and performance risk, which indicates that a higher level of relational risk results in a higher level of performance risk. Furthermore, Model 2 showed a negative relationship between aggregate relational factors and performance risk, which suggests relational factors, such as trust and commitment, can be used to minimise performance risk. The implication of these findings demonstrates a relational approach based on factors such as trust, commitment and information sharing reduces relational risk, which may also lead to a reduction in performance risk in offshore outsourcing relationships. Thus, it is important to treat relational risk as a critical element in managing risks in offshore outsourcing relationships.

\subsubsection{The role of cultural difference as control variable}

It is argued that cultural difference contributes to risks in offshore outsourcing relationships including performance risk and relational risk (Dhar et al, 2006; Ellram et al, 2008; Herath \& Kishore, 2009). Cultural differences such as a language barrier can create difficulties and cause misunderstandings between outsourcing supplier and buyer firms. The implication of not managing cultural difference effectively may result in production delay (performance risk), difference in quality expectation (performance risk), or even conflicts (relational risk) due to miscommunication and lack of understanding of cultural behaviours.

The survey result shows no evidence of cultural difference affecting performance and relational risk. There are two possible reasons for these findings. Firstly, the lack of quantitative data support due to small sample size. Secondly, the survey data was returned mainly by outsourcing manufacturing firms. They may not treat cultural difference as a key contributor to the risks of offshore outsourcing relationships. The outsourcing firms that replied may choose to focus more on outsourcing relationshipspecific risks instead of macro-environmental issues such as cultural difference. 


\subsubsection{A modified research model}

Based on the conceptualisation made in Chapter 3, the survey results established four significant relationships. Firstly, a strong and positive correlation was found between relational risk and performance risk. Secondly, there is a negative relationship between interdependence and performance risk. Thirdly, a negative association was found between asset specificity and performance risk. Lastly, it is found that relational risk played a mediating role between aggregate relational factors and performance risk.

Due to insufficient evidence among predicted relationships in the survey results, this study chooses not to include specific relational and transactional factors in the modified model. Thus, the modified model presented in Figure 6.1 drew insights partially from the survey results and partially from some conceptualisation presented in Chapter 3. There are two main differences between the conceptual model presented in Chapter 3 and this modified research model. First, relational risk plays a mediating role in the interactions between relational factors and performance risk. Secondly, the relational factors are not directly affecting performance risk (negative relationship), but through the mediator (relational risk).

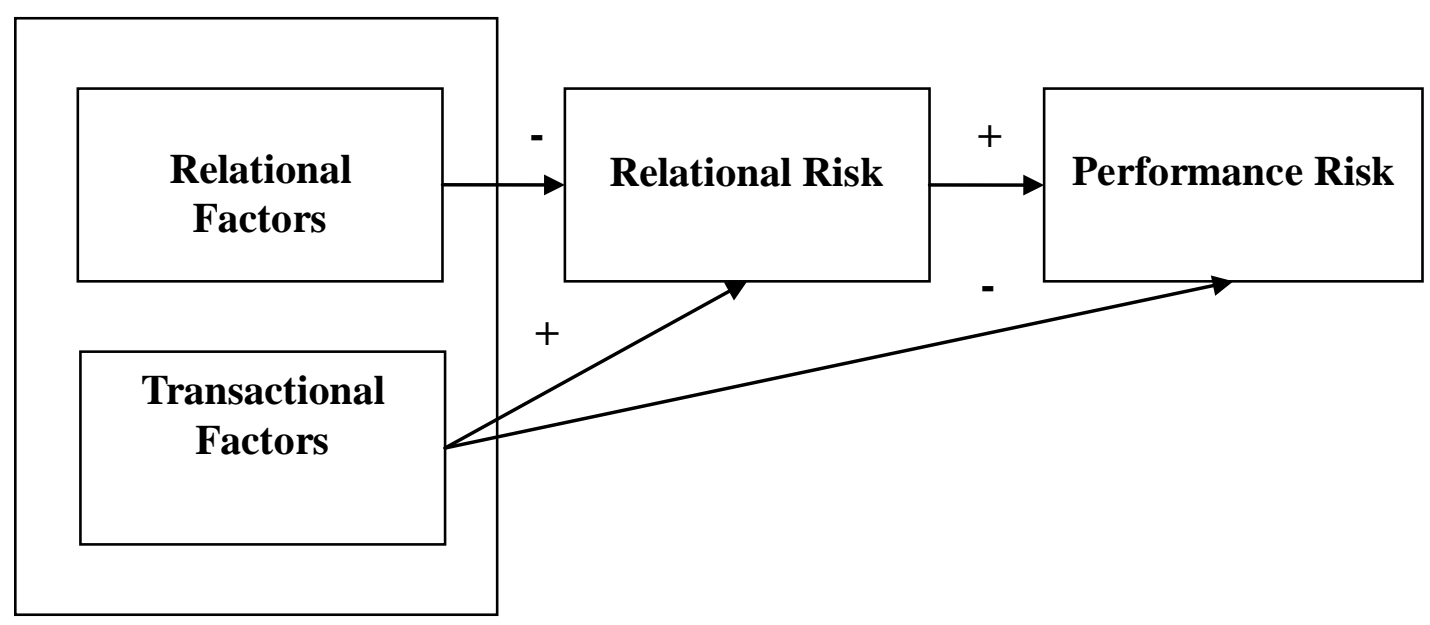

Figure 6.1: The modified research model

The modified research model has kept the conceptualisation related to transactional factors, which suggests a positive correlation with relational risk, but a negative association with performance risk. This study continues with the argument that a transactional approach reflected in transactional factors is likely to be an effective 
management approach in reducing the performance risk in offshore outsourcing relationships. Based on the survey results, the modified research model demonstrates that relational risk is a mediator between relational factors and performance risk. In addition, the model shows that relational risk is positively related to performance risk according to the survey results. Furthermore, the relational factors are negatively associated with performance risk through the mediating effect of relational risk, as revealed by the survey results. It is recommended that testing of this modified research model is carried out in the future.

\subsection{Research contributions}

This section addresses the important contributions of this study to the existing literature. These contributions are made in several ways.

Firstly, research relating to risk management of offshore outsourcing relationships has not been adequately reflected in the literature. Considerable research effort has been focussed on the understanding of areas such as outsourcing decisions and outsourcing outcomes (Chadee \& Raman, 2009). This study expands current literature by addressing this research gap. To effectively address the research problem of this study, it was necessary to source theoretical understandings from various perspectives. In addition, the conceptual model of this study, which incorporated literature from a risk perspective, relational perspective and transactional cost perspective, builds a theoretical foundation for future testing.

Secondly, this study operationalised relational risk and performance risk from a conceptual idea (Das \& Teng, 1996) and applied it in the context of offshore outsourcing. In addition, empirically testing relational risk for a mediating effect in this study is a novel concept in offshore outsourcing literature. Furthermore, this study employed a China-specific factor (guanxi), which adds a cultural characteristic to the investigation of offshore outsourcing relationships.

Thirdly, this study contributes to current literature by discovering new findings. Firstly, the survey results found that relational risk played a critical role as a mediator between aggregate relational factors and performance risk. The implication of this 
finding demonstrates the importance of minimising relational risk when managing offshore outsourcing relationships. It also found relational risk is positively related to performance risk. This finding implies offshore outsourcing firms should not only concentrate on minimising risks associated with outsourcing performance, but also on relational risks due to mismanagement of outsourcing relationships. Finally, the findings of the survey show that the interdependence between outsourcing buyer firms and supplier firms reduces performance.

The final contribution is made to the research context of current literature. In comparison with Europe and North America, less offshore outsourcing research has focussed on outsourcing firms in New Zealand and Australia. It is useful to extend the existing research context by studying risks in offshore outsourcing relationships from New Zealand and Australian perspectives. This study also chooses to focus on China as a research context for two reasons. Firstly, China is one of the fastest growing economies in the world (Buckley, 2007). Secondly, China is an important trading destination for Australian and New Zealand outsourcing firms (Australian Department of Affairs and Trade, 2010; New Zealand Ministry of Foreign Affairs and Trade, 2010). Thus, this study provides useful insights for Australian and New Zealand outsourcing firms into managing supplier risks when outsourcing to China.

\subsection{Chapter summary}

This chapter has provided a detailed discussion of the survey results that were analysed in Chapter 5. A modified conceptual model was presented to reflect the new findings of the quantitative survey. The modified conceptual model provides an important research foundation for future testing of offshore outsourcing supplier risks. This chapter has also described the new insights made into current literature in terms of theoretical contribution, methodological contribution, new research findings and application of different research contexts. The next chapter concludes the research by summarising the key arguments, offering managerial implications, presenting limitations and proposing directions for future research. 


\section{Chapter 7: Conclusions}

As outlined in Chapter 1, the purpose of this empirical study was to examine whether relationship management approaches can minimise risks in offshore outsourcing relationships. In order to achieve this research objective, Chapter 2 of this study drew upon literature from a range of different perspectives, including the risk perspective, the relational perspective and the transactional cost perspective. Based on the literature review of Chapter 2, Chapter 3 presented a conceptual model that incorporated all three perspectives. In Chapter 4, the model and pertinent hypotheses were tested using a quantitative research method involving an online survey of Australian and New Zealand managers. The focus of Chapters 5 and 6 was on solving the effects of management approaches on the risks in offshore outsourcing relationships. The results of survey data showed some support for using the relational approach to minimise performance risk. Moreover, the survey results demonstrated the importance of managing relational risk in offshore outsourcing relationships, as relational risk mediates the association between the relational approach and performance risk.

In order to determine the effects of management approaches on risks in offshore outsourcing relationships, this study proposed three research questions in Chapter 1.

The first research question of this study was in determining the risks relating to offshore outsourcing relationships from the literature. This question has been answered in Chapter 2 of this study. Based on the understanding of risk perspectives, this study categorises offshore outsourcing risks into relational risk and performance risk, which was conceptualised by Das and Teng, (1996). Relational risk focuses on the probability and consequences of outsourcing exchange firms cooperating unsatisfactorily on a joint goal (Das and Teng, 1996). In contrast, performance risk accounts for the probability and consequences of not accomplishing strategic objectives, despite satisfactory cooperation among outsourcing exchange firms (Das and Teng, 1996).

The second research question was to uncover the types of management approaches 
that can diminish risks in the offshore outsourcing relationship. Based on the relational perspective and transaction cost perspective, this study proposed two management approaches to minimising risks in offshore outsourcing relationships. The relational approach is grounded in the SET (relational perspective), which encourages exchange parties to develop outsourcing relationships based on social norms such as trust, commitment, and interdependence, and therefore overcome outsourcing relational risk caused by uncooperative behaviours such as opportunism. The transactional approach is guided by TCT (transaction cost perspective), which supports the enforcement of formal contracts to resolve outsourcing performance risk, such as low quality level and late delivery, caused by not achieving strategic objectives. Hence, the second research question is answered.

The last research question of this study was to draw links between management approaches and risks in offshore outsourcing relationships, based on the development and testing of a research model. The results of hypotheses testing pertinent to the research model indicated four findings. Firstly, the relational approach based on interdependence of outsourcing exchange firms reduces performance risk. Secondly, a high level of asset specificity can cause an increase of performance risk in offshore outsourcing relationships. Thirdly, performance risk is found to be positively and highly associated with relational risk. Most importantly, this study discovers that relational risk has a mediating effect on the association between relational approaches and performance risk. Thus, the third research question of this study is also answered.

\subsection{Managerial implications}

The findings of this study provide several implications for managers of offshore outsourcing buyer firms.

Firstly, the results show that relational risk and performance risk in offshore outsourcing relationships are highly correlated. This finding indicates that when it comes to managing risks in offshore outsourcing relationships, outsourcing managers should not just focus on the obvious performance risk such as late delivery and low quality but also recognise the danger of increasing relational risk, such as conflicts and opportunistic behaviours, since a higher level of relational risk can contribute to a 
higher level of performance risk.

Secondly, the results illustrate that when outsourcing buyer firms and supplier firms are interdependent on each other, the performance risk in offshore outsourcing relationships is reduced. This finding suggests outsourcing managers should develop relationships with supplier firms based on interdependence, as this can result in a stronger focus by the supplier firms on sustaining relationships and achieving mutual benefits. Correspondingly, the performance risk tends to diminish when outsourcing buyer-supplier firms are working towards a mutual objective,

Thirdly, the finding about the negative effect of asset specificity on performance risk implies that the outsourcing manager needs to minimise the level of relationshipspecific investments in offshore outsourcing, because it can lead to a high level of reliance on offshore outsourcing suppliers. Consequently, the suppliers could become less motivated to fulfil outsourcing objectives, which contributes to a higher level of performance risk in offshore outsourcing relationships.

Finally, this study finds a partial mediating effect of relational risk on the interactions between relational factors and performance risk. This suggests outsourcing managers can use a relational approach based on factors such as trust, commitment, and information sharing to minimise relational risks, which may also lead to a reduction in performance risks in offshore outsourcing relationships. In addition, outsourcing managers need to recognise relational risk as an important element when it comes to managing risk in offshore outsourcing activities. It is also vital for outsourcing managers to utilise the relational approach in the design of risk management practices in offshore outsourcing.

\subsection{Limitations}

This study has found some support for managing risk in offshore outsourcing relationships by utilising the relational approach. In addition, the establishment of the mediating role of relational risk between the relational approach and performance risk in offshore outsourcing relationships added a further theoretical contribution to the extant literature. In order to improve research proficiency, it is critical for academic 
scholars to learn from the limitations of their study. This section examines the limitations that have arisen during the process of this study.

The first issue is related to the generalisability of this study. Although the return response of the online survey was excellent (48/117 managers responded), the size of sample is relatively small (41 completed survey). The small sample size clearly impacted on the lack of correlations between relational factors and relational risks. It was discovered during the data collection period that many outsourcing managers were on business trips to China during October and November. Some outsourcing managers suggested during reminder phone calls that the month of May is a more suitable time for collecting survey data.

Secondly, the survey results showed no significant correlations between relational factors and relational risks, which may be caused by the measurement items of relational risk. This study attempted to capture the main factors of relational risk in the context of offshore outsourcing relationships by utilising the conceptual ideas from Das and Teng (1996). By doing so, this study has already made some methodological contributions to the extant literature. However, the conceptualisation from Das and Teng was based in a different research setting, thus repeated measurement validations are required to assure the risk factors in the context of offshore outsourcing relationships are accurately represented. It is acknowledged that there are some imperfections in this study. Nevertheless, the limitations discussed in this study provide a good platform for future research.

\subsection{Recommendations for future research}

On the basis of this study, it is recommended that other scholars fully test the conceptual model by improving the generalisability in future research. With a larger sample size, analysis of the interaction between relational factors and relational risk would generate a higher statistical power in establishing significant correlations. Secondly, an extension of this study is to reduce the number of relational factors for a better representation of the relational approach. In addition, future research may also consider the utilisation of other relational factors such as top management involvement (Lee et al., 2010), relationship stability (Luo, 1997; Lai, 2009), and long 
term orientation (Dong, et al., 2008) to expand the understanding of the outsourcing relational approach. Thirdly, future research contexts of managing risks in offshore outsourcing relationships could involve different countries, different industries and different outsourcing destinations, in order to facilitate the development of theoretical understanding in the research area. Finally, longitudinal research comparing risks and management approaches used by different industries and countries will provide more robust results.

\subsection{Final statement}

The aim of this study is not only to examine the effects of management approaches on risks in offshore outsourcing relationships, but also to re-emphasise offshore outsourcing risk management as an important research topic in offshore outsourcing literature. This study is aware that managing risks in offshore outsourcing relationships is a complex problem. Keeping in mind the complexity of this topic, this study has provided a sound theoretical base from which fellow scholars can carry out future research. 


\section{References}

Anderson, J.C., \& Narus, J.A. 1990. A model of distributor firm and manufacturer firm working partnership. Journal of Marketing 54 (1):54-58.

Anderson, E., \& Weitz, B. 1992. The use of pledges to build and sustain commitment in distribution channels. Journal of Marketing Research, 29: 18-34.

Alder, P. 2001. Market, hierarchy and trust: the knowledge economy and the future of capitalism. Organization Science 12 (2):214-234.

Alreck, P. L., \& Settle, R. B. 1995. The survey research handbook: guidelines and strategies for conducting a survey. 2nd ed. Chicago, IL: Irwin publishing.

Aron, R., Clemons, E.K., \& Reddi, S. 2005a. Just right outsourcing: understanding and managing risk, Proceedings of the 38th Hawaii International Conference on System Sciences. Hawaii.

Aron, R., Clemons, E.K., \& Reddi, S. 2005b. Just right outsourcing: understanding and managing risk. Journal of Management Information Systems, 22(2): 37-55.

Aubert, B. A., Rivard, S., \& Patry, M. 1996. A transaction cost approach to outsourcing behaviour: some empirical evidence. Information and Management, 30(2): 51-64.

Australian Department of Affairs and Trade. 2010. Australia's top 10 two-way trading partners and Australia' top 10 exports, goods and services. http://www.dfat.gov.au/trade/focus/081201_top10_twoway_exports.html Accessed 1 November 2010.

Bahli, B., \& Rivard, S. 2003. The information technology outsourcing risk: a transaction cost and agency theory-based perspective. Journal of Information Technology, 18: 211-21. 
Barney, J. 1991. Firm resources and sustained competitive advantage. Journal of Management, 17(1): 99-120.

Barney, J. 1995. Looking inside for competitive advantage. Academy of Management Executive, 9: 99-120.

Barthelemy, J. 2001. The hidden costs of IT outsourcing. Sloan Management Review 42 (3):60-69.

Barthelemy, J. 2003a. The seven deadly sins of outsourcing. Academy of Management Executive, 17(2): 87-98.

Barthelemy, J. 2003b. The hard and soft sides of IT outsourcing management. European Management Journal 21 (5):539-548.

Baron, R. M., \& Kenny, D.A. 1986. The moderator-mediator distinction in social psychological research: conceptual, strategic, and statistical consideration. Journal of Personality and Social Psychology, 51(6): 1173-82.

Bello, C. D., \& Giilliland, D.I. 1997. The effect of output controls, process controls, and flexibility on export channel performance. Journal of Marketing, 61(1): 2238.

Bensaou, M., \& Venkatraman, N. 1995. Configurations of inter-organisational relationships: a comparison between U.S. and Japanese automakers. Management Science, 41(9): 1471-92.

Blau, P. 1964. Exchange and power in social life. New York: Wiley.

Bryman, A., \& Bell, E. 2003. Business research methods. New York: Oxford University Press.

Buckley, P. J. (2007). The Strategy of multinational enterprises in light of the rise of 
China. Scandinavian Journal of Management, 23: 107-26.

Cannon, J. P., \& William, D.P. 1999. Buyer-seller relationships in business markets. Journal of Marketing Research, 36(4): 439-60.

Cannon, J. P., \& William, D.P. 1999. Buyer-seller relationships in business markets. Journal of Marketing Research, 36(4): 439-60.

Carmines, E., \& Zeller, R. 1990. Reliability and validity assessment. London: Sage.

Cavusgil, S.T., Yaprak, A. \&Yeoh, P. 1993. A decision-making framework for global sourcing. International Business Review 2 (2):143-156.

Chadee, D., \& Raman, R. 2009. International outsourcing of information technology services: review and future directions. International Marketing Review 26 (4/5):411-438.

Coase, R. H. 1937. The nature of firm. Economica, 4(16): 386-405.

Coleman, J. 1990. Social capital in the creation of human capital. American Journal of Sociology, 94: 95-120.

Conner, K. R., \& Prahalad, C.K. 1996. A resource-based theory of the firm: knowledge versus opportunism. Organization Science, 7(477-501).

Cook, K. S. 1977. Exchange and power in networks of inter-organisational relations. Sociological Quarterly, 18: 62-82.

Cook, K. S., \& Emerson, R.M. 1978. Power, equity and commitment in the exchange networks American Sociological Review, 43: 721-39.

Costa, C. 2001. Information technology outsourcing in Australia: a literature review. Information Management and Computer Security, 9(5): 213-24. 
Creswell, J. W. 2009. Research design: qualitative, quantitative, and mixed methods approaches 3rd ed. Thousand Oaks: Sage.

Cronbach, L. J. 2004. My current thoughts on coefficient alpha and successor procedures. Educational and Psychological Measurement, 64 (3): 391-418

Cummings, T. 1984. Transorganizational development. Research in Organizational Behaviour 6:367-422.

Das, T.K., \& Teng, B. 1996. Risk types and inter-firm alliance structures. Journal of Management Studies 33 (6):827-843.

Deci, E. L., Koestner, R., \& Ryan, R.M. 1999. A meta-analytic review of experiments examining the effects of extrinsic rewards on intrinsic motivation. Psychological Bulletin, 125: 627-68.

Dhar, S., \& Balakrishnan, B. 2006. Risks, benefits, and challenges in global IT outsourcing: perspectives and practices. Journal of Global Information Management, 14(3): 59-89.

Di Gregorio, D., Musteen, M. \& Thomas, D.E. 2009. Offshore outsourcing as a source of international competitiveness for SMEs. Journal of International Business Studies 40:969-988.

Doh, J.P. 2005. Offshore outsourcing: Implications for international business and strategic management theory and practice. Journal of Management Studies 42 (3):695-704.

Doney, P. M. \& Cannon., J.P. 1997. An examination of the nature of trust in buyerseller relationships. Journal of Marketing, 61: 35-51.

Dong, M. C., Tse, D.K., \& Cavasgil, S.T. 2008. Efficiency of governance mechanisms in China's distribution channels. International Business Review, 17: 509-19. 
Doz, H. G., \& Prahalad, C.K. 1991. Managing DMNCs: a search for a new paradigm. Strategic Management Journal, 12(4): 145-64.

Dun \& Bradstreet. 2010. About us. http://dnb.co.nz/Header/About_Us/index.aspx. Accessed 1 November 2010.

Duncan, N. B. 1998. Beyond opportunism: a resource-based view of outsourcing risk, Proceedings of the HCISS-31. Hawaii.

Dunning, J.H. 1980. Towards an eclectic theory of international production: some empirical tests. Journal of International Business Studies 11:9-31.

Dunning, J.H. 1998. Location and the multinational enterprise: A neglected factor? Journal of International Business Studies 29 (1):45-66.

Durbin, J., \& Watson, G.S. 1952. Testing for serial correlation in least squares regression, II. Biometrika, 30: 159-78.

Dryer, J.H. \& Singh, H. 1998. The relational view: cooperative strategy and sources of inter-organizational competitive advantages. The Academy of Management Review 23 (4):660-79.

Dyer, J.H., Cho, D.S. \& Chu, W. 1998. Strategic supplier segmentation: The next "best practice" in supply chain management. California Management Review 40 (2):57-77.

Earl, M. J. 1996. The risks of outsourcing IT Sloan Management Review, 37(3): 26-32.

Enderwick, P. (2008). Quality Assurance and Upgrading in Global Supply Chains: Implications for Management in a Transition Economy. Thunderbird International Business Review, 50(4): 217-30.

Ellram, L. M., Tate, W.L. \& Billington, C. 2008. Offshore outsourcing of professional 
service: A transaction cost economics perspective. Journal of Operations Management, 26: 148-63.

Emerson, R. M. 1976. Social exchange theory. American Review of Sociology, 2: 335362.

Emerson, R. M. 1981. Social exchange theory. In Rosenberg, M., \& Turner, R.H., (Ed.), Social psychology: sociological perspective. New York: Basic Books.

Farrell, D. 2005. Offshoring value creation through economic change. Journal of Management Studies 42 (3):675-683.

Feeny, D., Lacity, M. \& Willcocks, L.P. 2005. Taking the measure of outsourcing providers. MIT Sloan Management Review 46 (3):40-48.

Field, A. 2005. Discovering statistics using SPSS. Second ed. London: Sage publications.

Fowler, F. J. 1993. Survey research methods. Newbury Park: Sage.

Frosdick, M. 1997. The techniques of risk management are insufficient in themselves. Disaster Prevention and Management, 6(3): 165-77.

Ghoshal, S. 1987. Global strategy: An organizing framework. Strategic Management Journal 8:425-440.

Ghoshal, S. \& Moran, P. 1996. Bad for practice: a critique of the transaction cost theory. Academy of Management Review 21 (1):13-47.

Goo, J., Kishore, R., Rao, H.R. and Song, Y. 2007. The role of service level agreements in relational management of information technology outsourcing: an empirical study. MIS Quarterly, 33(1): 119-45.

Gottschalk, P. \& Solli-Sæther, H. 2005. Critical success factor from IT outsourcing 
theories: An empirical study. Industrial Management and Data Systems 105 (6):685-702.

Graf, M., \& Mudambi, S.M. 2005. The outsourcing of IT-enabled business processes: A conceptual model of the location decision. Journal of International Management, 11(2): 253-68.

Granovetter, M. 1985. Economic action and social structure: the problem of embeddedness. American Journal of Sociology 91 (3):481-510.

Granovetter, M. 2005. The impact of social structure on economic outcomes. The Journal of Economic Perspectives 19 (1):33-50.

Grover, V., Cheon, M., \& Teng, J. 1996. The effect of service quality and partnership on the outsourcing of information systems functions. Journal of Management Information Systems 12 (4):89-116.

Gu, F. F., Hung, K., \& Tse, D.K. 2008. When does guanxi matter? Issues of capitalisation and its dark sides. Journal of Marketing, 72: 12-28.

Gulati, R. 1995a. Does familiarity breed trust? Academy of Management Journal, 38: 85-112.

Gulati, R. 1995b. Social structure and alliance formation patterns: a longitudinal analysis. Administrative Science Quarterly, 40: 619-52.

Gupta, U. G., \& Gupta, A. 1992. Outsourcing the IS function: is it necessary for your organization? Information System Management 9(2): 44-50.

Hair, J. F., Bush, R.P., \& Ortinau, D. J. 2009. Marketing research: in a digital information environment. 4th ed. New York: McGraw-Hill/Irwin.

Han, H., Lee, J. \& Seo, Y. 2008. Analyzing the impact of a firm's capability on outsourcing success: A process perspective. Information \& Management 45:31- 
42.

Haried, P. \& Ramamurthy, K. 2009. Evaluating the success in international sourcing of information technology projects: the need for a relational client-vendor approach. Project Management Journal 40 (3):56-71.

Heide, J.B. \& John, G. 1992. Do norms matter in marketing relationships. Journal of Marketing 56: 32-44.

Heide, J., Wathne, K.H., \& Rokkan, A.I. 2007. Interfirm monitoring, social contracts, and relationship outcomes. Journal of Marketing Research, 44(3): 425-33.

Henderson, J.C. 1990. Plugging into strategic partnerships: the critical IS connection. Sloan Management Review 30 (3):7-18.

Herath, T., \& Kishore, R. 2009. Offshore outsourcing: risks, challenges, and potential solutions. Information Systems Management, 26(4): 312-26.

Homans, G. C. 1958. Social behaviour as exchange. The American Journal of Sociology, 63(5): 597-606.

Hwang, K. 1987. Face and favour: the Chinese power game. American Journal of Sociology, 92: 944-74.

Johnson, D. \& Grayson, K. 2005. Cognitive and affective trust in service relationships. Journal of Business Research 58:500-507.

Joskow, P. 1988. Asset specificity and the structure of critical relationships: empirical evidence. Journal of Law, Economics and Organisation, 4(1): 95-117.

Judd, C. M., \& Kenny, D.A. 1981. Process analysis: estimating mediation in treatment evaluations. Evaluation Review, 5: 602-19.

Kakabadse, A. \& Kakabadse, N. 2005. Outsourcing: current and future. Thunderbird 
International Business Review 47 (2):183-204.

Kale, P., Singh, H., \& Perlmutter, F. 2000. Learning and protection of proprietary assets in strategic alliances: Building relational capital Strategic Management Journal 21:217-237.

Kalwani, M. U., \& Narayandas, N. 1995. Long-term manufacturer-supplier relationships: do they pay off for supplier firms. Journal of Marketing, 59: 1-16.

Kakumanu, P., \& Portanova, A. 2006. Outsourcing: its benefits, drawbacks and other related issues. Journal of American Academy of Business, 9(2): 1-7.

Kelley, H. H., \& Thibaut, J. 1978. Interpersonal relations: a theory of interdependence. New York: Wiley.

Kern, T., \& Bloi, K. 2002. Norm development in outsourcing relationship. Journal of Information Technology, 17(1): 32-42.

Kern, T., \& Willcocks, L. 2000. Exploring information technology outsourcing relationships: theory and practice. Journal of Strategic Information System, 9: 321-50.

Kern, B., Willcocks, L. \& van Heck, E. 2002. The winner's curse in IT outsourcing: strategies for avoiding relational trauma. California Management Review 44 (2):17-69.

Klein, B., Crawford, R., \& Alchian, A. 1987. Vertical integration, appropriate rents and the competitive contracting process. Journal of Law and Economics, 21: 297326.

Kliem, R. 2004. Managing the risks of offshore IT development projects. Information Systems Management, 21(3): 22-27.

Kotabe, M. 1992. Global sourcing strategy: $R \& D$, manufacturing, and marketing 
interfaces. New York: Quorum Books.

Kotabe, M. 1998. Efficiency vs. effectiveness orientation of global sourcing strategy: A comparison of US and Japanese multinational companies. Academy of Management Executive 12 (4):107-119.

Kotabe, M. \& Murray, J.Y. 2004. Global sourcing strategy and sustainable competitive advantage. Industrial Marketing Management 33:7-14.

Kremic, T., Tukel, O.I., \& Rom, W. O. 2006. Outsourcing decision support: a survey of benefits, risks, and decision factors. Supply Chain Management: An International Journal, 11(6): 467-82.

Kwon, Y. 2008. Antecedents and consequences of international joint venture partnerships: A social exchange perspective. International Business Review 17:559-573.

Lacity, M., \& Willcocks, L. 1998. An empirical investigation of information technology sourcing practices: Lessons from experience. MIS Quarterly 22 (3):363-409.

Lai, K. 2009. Linking exchange governance with supplier cooperation and commitment: A case of container terminal operations. Journal of Business Logistics 30 (1):243-265.

Larson, P. D. 1992. Network dyads in entrepreneurial settings: a study of governance of exchange relationships. Administrative Science Quarterly, 37: 76-104.

Larson, P. D. 1994. Buyer-supplier cooperation, product quality and total cost. International Journal of Physical Distribution and Logistics Management, 24(6): 4-10.

Lee, J. 2001. The impact of knowledge sharing, organizational capability and partnership quality on IS outsourcing success. Information \& Management 38 
(5):323-335.

Lee, D. Y., \& Dawes, P.L. 2005. Guanxi, trust, and long-term orientation in Chinese business markets. Journal of International Marketing, 13(2): 28-56.

Lee, J., \& Kim, Y. 1999. Effect of partnership quality on IS outsourcing success: Conceptual framework and empirical validation. Journal of Management Information Systems 15 (4):29-61.

Lee, J., \& Kim, Y. 2005. Understanding outsourcing partnership: A comparison of three theoretical perspectives. IEEE Transactions on Engineering Management 52 (1):43-58.

Lee, J. W., Mohamad, O., \& Ramayah, T. 2010. Outsourcing: is the social exchange theory still relevant in developing countries? Journal of Research in Interactive Marketing, 4(4): 316-45.

Leiblein, M.J., \& Miller, D.J. 2003. An empirical examination of transaction - and firm-level influences on vertical boundaries of the firm. Strategic Management Journal, 24(9): 839-859.

Levine, M., \& Schneider, M. 1997. Making the distinction: risk management, risk exposure. Risk Management, 44(8): 36-42.

Lewin, A.Y., Massini, S., \& Peeters, C. 2009. Why are companies offshoring innovation? The emerging global race for talent. Journal of International Business Studies 40:901-925.

Lewin, A.Y., \& Furlong, S. 2005. Second bi-annual offshore survey result. Duke University CIBER/Archstone Consulting, December.

Li, X., \& Barnes, I. 2008. Proactive supply risk management methods for building a robust supply selection process when sourcing from emerging markets. Strategic Outsourcing: An International Journal 1 (3):252-267. 
Li, Y., Liu, Y., Li, M., \& Wu, H. 2008. Transformational offshore outsourcing: empirical evidence from alliances in China. Journal of Operations Management, 26: 257-74.

Luo, Y. 1997. Guanxi and performance of foreign-invested enterprises in China: an empirical inquiry. Management International Review, 37(1): 57-70.

Macaulay, S. 1963. Non-contractual relations in business: a preliminary study. American Sociological Review, 28(1): 55-67.

Macneil, I.R. 1978. Contracts: adjustment of long-term economic relations under classical, neoclassical and relational contract lay. Northwestern University Law Review 72:845-905.

Madhuchhanda, A. D., \& Saji, M. K. 2009. Risks in offshore IT outsourcing: A service provider perspective. European Management Journal 27:418-428.

Mahnke, V., Lucas, M. \& Vang, J. 2005. Strategic Outsourcing of IT Services: Theoretical Stocktaking and Empirical Challenges. Industry and Innovation 12 (2):205-253.

Mao, J., Lee, J., \& Deng, C. 2008. Vendors' perspectives on trust and control in offshore information systems outsourcing. Information and Management, 45: 482-92.

McAllister, D.J. 1995. Affect - and cognition - based trust as foundations for interpersonal cooperation in organizations. Academy of Management Journal 38 (1):24-59.

McFarlan, F. W., \& Nolan, R.L. 1995. How to manage an IT outsourcing alliance. Sloan Management Review, 36(2): 9-23.

McIvor, R. 2005. The outsourcing process: strategies for evaluation and management. 
Cambridge: Cambridge University Press.

McIvor, R. 2009. How the transaction cost and resource-based theories of the firm inform outsourcing evaluation. Journal of Operations Management 27: 45-63.

Mehta, R., Larsen, T., Rosenbloom, B., \& Ganistky, J. 2006. The impact of cultural differences in US business-to-business export marketing channel strategic alliances. Industrial Marketing Management, 35: 156-65.

Miller, K.D. 1992. A framework for integrated risk management in international business. Journal of International Business Studies 23 (2):311-331.

Mohr, J., \& Spekman, R. 1994. Characteristics of partnership success: partnership attributes, communication behaviour and conflict resolution techniques. Strategic Management Journal 15:135-152.

Mol, M.J., Van Tulder, R.J.M., \& Beije, P.R. (2005). Antecedents and performance consequences of international outsourcing International Business Review 14:599617.

Molm, L.D. 1997. Risk and power use: Constraints on the use of coercion in exchange. American Sociological Review 62 (1):113-133.

Morgan, R.M., \& Hunt, S.D. 1994. The commitment-trust theory of relationship marketing. Journal of Marketing 58 (3):20-38.

Murray, J.Y., \& Kotabe, M. 1999. Sourcing strategies of US service companies: a modified transaction-cost analysis. Strategic Management Journal 20 (9):791809.

Murry, J. P., \& Heide, J.B. 1998. Managing promotion program participation within manufacturer-retailer relationships. Journal of Marketing 6: 58-68.

Myer, R. 1990. Classical and modern regression with applications. 2nd edition ed. 
Boston, MA: Duxbury.

New Zealand Ministry of Foreign Affairs \& Trade. 2010. NZ Inc country and regional strategies. http://mfat.govt.nz/Trade-and-Economic-Relations/4-NZ-Inc-Countryand-Regional-Strategies/4-Strategies-list.php. Accessed 2 November 2010.

Oliver, C. 1990. Determinants of inter-organisational relationships: integration and future directions. Academy of Management Review, 15(2): 241-65.

Oza, N.V., \& Hall, T. 2005. Difficulties in managing offshore software outsourcing relationships: an empirical analysis of 18 high maturity Indian software companies. Journal of Information and Software Technology 48: 345-354.

Park, S., \& Luo, Y. 2001. Guanxi and organisational dynamics: organisational networking in Chinese firms. Strategic Management Journal, 22(5): 455-77.

Parkhe, A. 1998. Understanding trust in international alliances. Journal of World Business, 33(4): 219-40.

Penrose, E. 1959. The theory of growth of the firm. Oxford: Oxford University Press.

Pinnington, A., \& Woolcock, P. 1995. How far is IS/IT outsourcing enabling new organizational structure and competences. International Journal of Information Management, 15(5): 353-65.

Poppo, L., \& Zenger, T. 2002. Do formal contracts and relational governance function as substitutes or complements? Strategic Management Journal 23 (8):707-725.

Porter, M.E. 1990. The competitive advantage of nations. New York: Free Press.

Prahalad, C.K. \& Hamel, G. 1990. The core competence of the corporation. Harvard Business Review 68 (3):79-91.

Quelin, B., \& Duhamel, F. 2003. Bring together strategic outsourcing and corporate 
strategy: outsourcing motives and risks. European Management Journal, 21(5): 647-61.

Quinn, J. B. 1999. Strategic outsourcing: leverage knowledge capabilities. Sloan Management Review, 40(4): 9-21.

Quinn, J.B. \& Hilmer, F.G. 1994. Strategic outsourcing. Sloan Management Review 35 (4):43-55.

Ritchie, R. L., \& Marshall, D.V. 1993. Business risk management. London: Chapman Hall.

Ritchie, R. L., \& Brindley, C. 2007. Supply chain risk management and performance: a guiding framework for future development. International Journal of Operations \& Production Management, 27(3): 303-22.

Ring, P.S.,\&Van de Ven, A.H. 1994. Developmental processes of cooperative interorganizational relationships. Academy of Management Review 19:90-118.

Rubin, H. 2009. Outsourcing to China: risk management and strategies. The Licensing Journal, 29(10): 7-19.

Sako, M. 2005. Outsourcing and Offshoring: Key trends and issues. Background Paper for Emerging Market Forum. Said Business School, Oxford.

Sarkar, M., Cavusigil, S.T., \& Evirgen, C. 1997. A commitment-trust mediated framework of international collaborative venture performance. San Francisco: The New Lexington Press.

Saunders, C., Gebelt, M., \& Hu, Q. 1997. Achieving success in information systems outsourcing. California Management Review 39:63-79.

Schniederjans, M. J., \& Zuckweiler, K.M. 2004. A quantitative approach to the outsourcing-insourcing decision in an international context. Management 
Decision, 42(8): 974-86.

Skarmeas, D. A., \& Katsikeas, C.S. 2001. Drivers of superior importer performance in cross-cultural supplier-reseller relationships. Industrial Marketing Management, 30(2): 227-41.

Statistics New Zealand. 2010. Industry classification. http://www.stats.govt.nz/browse_for_stats/industry_sectors/anzsic06-industryclassification.aspx. Accessed 1 November 2010.

Su, C., Yang, Z., Zhuang, G., Zhou, N., \& Dou, W. 2009. Interpersonal influence as an alternative channel communication behaviour in emerging markets: the case of China. Journal of International Business Studies, 40: 668-489.

Subhankar, D., \& Balakrishnan, B. 2006. Risks, benefits and challenges in Global IT outsourcing: Perspectives and practices. Journal of Global Information Management 14 (3):59-89.

Tate, W.L., \& Ellram, L.M. 2009. Offshore outsourcing: a managerial framework. Journal of Business \& Industrial Marketing 24 (3/4):256-268.

Tate, W.L., Ellram, L.M., \& Billington, C. 2008. Offshore outsourcing of professional services: A transaction cost economics perspective. Journal of Operations Management 26:148-163.

Tate, W.L., Ellram, L.M., Bals, L., \& Hartmann, E. 2009. Offshoring outsourcing of services: an evolutionary perspective. International Journal of Production Economics 120:512-524.

Teece, D. J., Pisano, G. \& Shuen, A. 1997. Dynamic capabilities and strategic management. Strategic Management Journal, 18(7): 509-33.

Tihanyi, L., Griffith, D.A., \& Russell, C. 2005. The effect of cultural distance on entry mode choice, international diversification, and MNE performance: a meta- 
analysis. Journal of International Business Studies, 36: 270-83.

Thibaut, J. W., \& Kelley, H. H. 1959. The social psychology of groups. New York: Wiley.

Uzzi, B. 1997. Social structure and competition in inter-firm networks: the paradox of embeddedness. Administrative Science Quarterly 42:35-67.

Walker, G., \& Weber, D. 1984. A transaction cost approach to make-buy decisions. Administrative Science Quarterly, 29(3): 66-87.

Wernerfelt, B. 1984. A resource-based view of the firm. Strategic Management Journal, 5(2): 171-80.

Willcocks, L., Feeny, D., \& Lacity, M. 2004. IT and business process outsourcing: the knowledge potential. Information Systems Management, 21(3): 7-15.

Williamson, O.E. 1971. The vertical integration of production: Market failure considerations. American Economic Review 61 (2):112-123.

Williamson, O.E. 1975. Markets and Hierarchies: Analysis and Antitrust Implications. New York: Free Press.

Williamson, O.E. 1981. The modern corporation: origins, evolution, attributes. Journal of Economic Literature 20: 691-706.

Williamson, O.E. 1983. Credible commitments: Using hostages to support exchange. American Economic Review 73:519-540.

Williamson, O.E. 1985. The economic institutions of capitalism. New York: Free Press.

Williamson, O.E. 1991. Comparative economic organisation: the analysis of discrete structural alternatives. Administrative Science Quarterly, 36: 269-96. 
Williamson, O.E. 1993. Calculativeness, trust, and economic organization. Journal of Law and Economics 36:453-486.

Wu, F., \& Cavusgil, S.T. 2006. Organizational learning, commitment, and joint venture creation in interfirm relationships. Journal of Business Research, 59(1): 81-89.

Yang, M. 1994. Gifts, favours and banquets: the art of social relationships in China. Ithaca, NY: Cornell University Press.

Zaheer, A., \& Venkatraman, N. 1995. Relational governance as an interorganizational strategy: an empirical test of the role of trust in economic exchange. Strategic Management Journal 16(5):373-392.

Zhang, C., Cavusgil, S.T., \& Roath, A.S. 2003. Manufacturer governance of foreign distributor relationships: do relationship norms enhance competitiveness in the export market? Journal of International Business Studies, 34: 550-66. 


\section{Appendix A: P-P Plot and Scatterplot of Equation 1}

\section{Relational risk as dependent variable}

Normal P-P Plot of Regression Standardized Residual

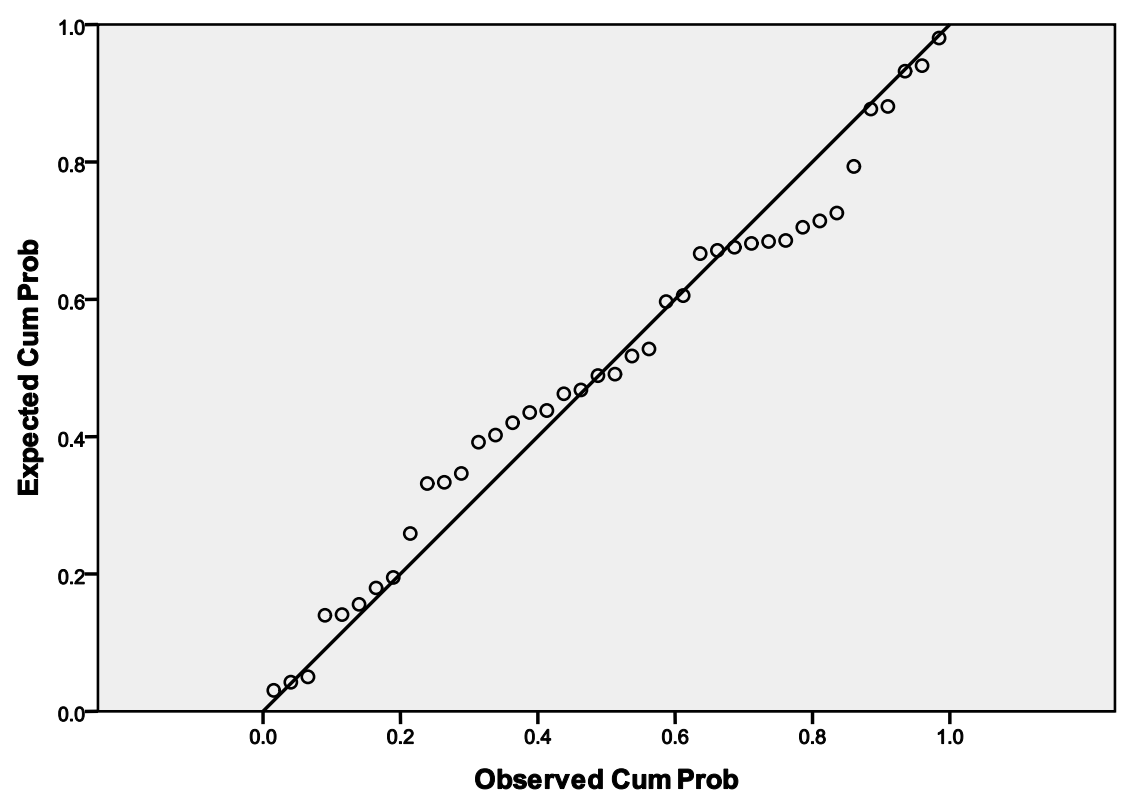

Scatterplot

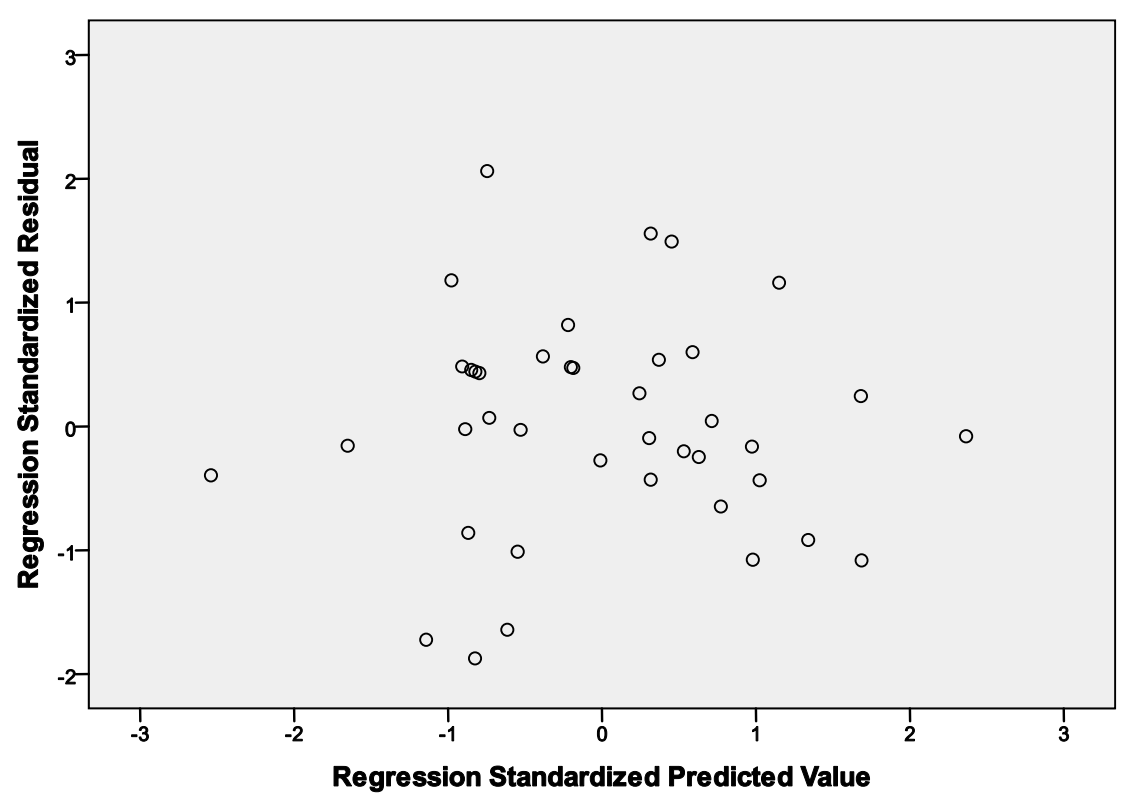




\section{Appendix B: P-P Plot and Scatterplot of Equation 2}

Performance risk as dependent variable

Normal P-P Plot of Regression Standardized Residual

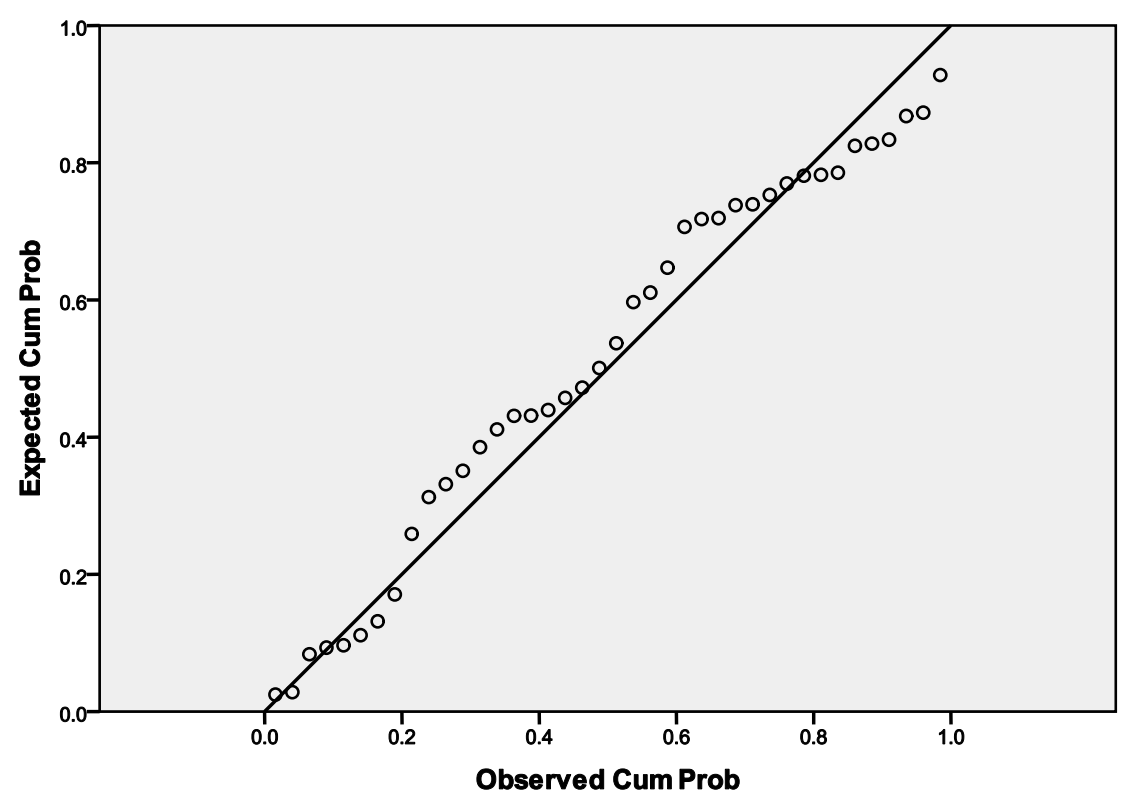

Scatterplot

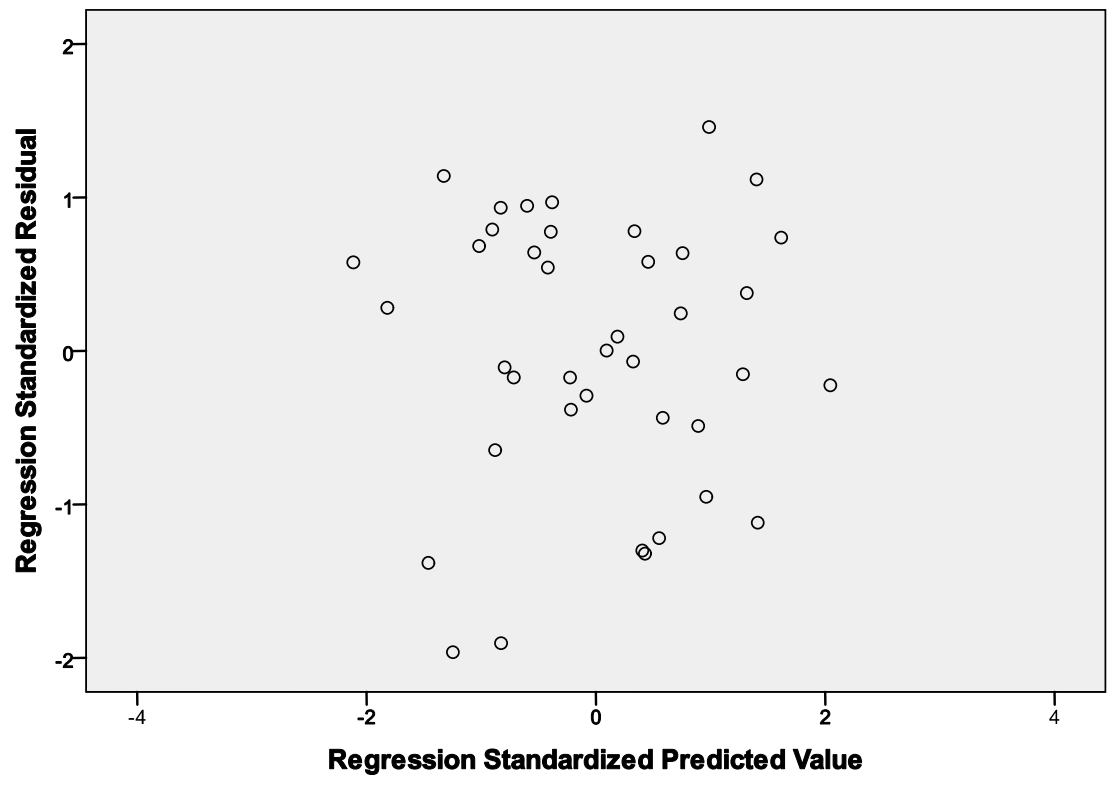




\section{Appendix C: Invitation letter}

Dear

My name is Cindy Zhang, and I am a Masters student in International Business at Victoria University of Wellington. As part of my degree I am undertaking a research project which will be used in my final thesis. By undertaking this project I am hoping to gain insight and understanding into how New Zealand and Australian firms manage relationships with their foreign suppliers in emerging economies, particularly China, with the intention to reduce outsourcing hazards.

I would like to invite a senior manager who is responsible for making decisions on your firm's international outsourcing activities to participate in an online questionnaire. The survey should take no more than 30 minutes of their time. I would be extremely grateful if you would complete the online survey. The link to the survey is: INSERT LINK.

Following strict procedures, for research involve human subject at Victoria University of Wellington, this study has been assessed and approved by Faculty of Commerce and Administration's Human Ethics Committee. Your responses will be kept confidential and will in no way be linked to you. All information you provide will be aggregated and used for research purposes only and will not be released or distributed to third parties. The data collected will be used for this research and may also be used for academic publications. However, the research data will be destroyed three years after the conclusion of the research

For additional information about this research, please do not hesitate to contact me or my supervisors Dr Audra Mockaitis and Dr Hongzhi Gao.

Warm regards,

Cindy Zhang Masters Student, School of Marketing and International Business, Victoria University of Wellington, New Zealand 


\section{Appendix D: Online survey in text format}

Thank you for agreeing to participate in my study by completing this questionnaire. This questionnaire will take no more than 30 minutes to complete. Your participation is entirely voluntary, and you may withdraw at any time simply by exiting the survey. Please be assured that the data you provided will remain confidential.

\section{A. Company Information}

The next few questions ask for some information about your company. Simply put a checkmark $(\bigotimes)$ in the shaded field(s), or type your answers on the line provided (_).

1. Where is your company's headquarter (HQ) located?

$\square$ In New Zealand
$\square$ In Australia
$\square$ Elsewhere, please specify:

2. In which year was your company first established in New Zealand or Australia?

Year

3. What is the percentage of foreign ownership of your company? (Note: please write $0 \%$ for domestic owned company)

$\square$ Approximately __ \% of foreign ownership $\quad \square$ Not sure

4. What is the primary industry in which your organization operates (e.g. apparel, banking)?

5. Company data: Please complete the following table concerning your company using end-of-year data for the years indicated. (Note: please write $\underline{0 \%}$ if your company only operate domestically)

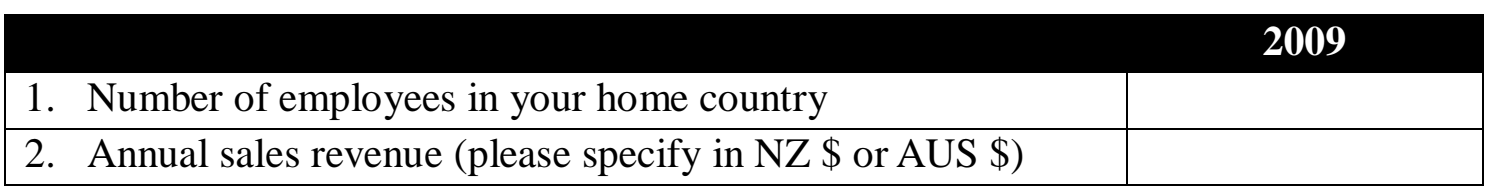




\section{B. Offshore Outsourcing Activities}

In this section, we are interested in your company's overall outsourcing experience in all countries. Most of the questions ask for your opinion. There are no correct or incorrect answers. Please answer each question to the best of your knowledge.

6. How long has your company been involved in outsourcing activities to foreign countries? (in years)

7. What percentage of your total business activities (manufacturing or services) is comprised of outsourcing activities?

Approximately _ $\%$

8. How would you characterize your primary outsourcing activities?

$\square$ Manufacturing $\quad \square$ Service $\quad \square$ Other

9. What is your primary outsourced product or service?

(Please specify)

10. Please list the top three most important countries in which you conduct most of your outsourcing activities other than your home country. Please write the name of each country (A-B) in the first row, and answer the questions beneath each country (please use 2010 data).

\begin{tabular}{|l|l|l|}
\hline Country names: & Country A: & Country B: \\
\hline Year entered & & \\
\hline
\end{tabular}

11. What are your motives for outsourcing? Please rate each of the following items on a scale from 1 to 7 , where $\mathbf{1}=$ completely unimportant and $\mathbf{7}$ = extremely important. 


\begin{tabular}{|c|c|c|c|c|c|c|c|}
\hline & \multicolumn{3}{|c|}{$\begin{array}{r}\text { Completely } \\
\text { unimportant }\end{array}$} & \multirow[b]{2}{*}{4} & \multicolumn{3}{|c|}{$\begin{array}{l}\text { Extremely } \\
\text { important }\end{array}$} \\
\hline & 1 & 2 & 3 & & 5 & 6 & 7 \\
\hline 1. Exploiting technological capabilities & $\square$ & $\square$ & 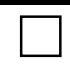 & $\square$ & & $\square$ & \\
\hline 2. Seeking lower cost (e.g. lower labour and production costs) & $\square$ & $\square$ & $\square$ & $\square$ & $\square$ & $\square$ & $\square$ \\
\hline $\begin{array}{l}\text { 3. Access to new skills and technologies from foreign } \\
\text { suppliers }\end{array}$ & $\square$ & $\square$ & & $\square$ & $\square$ & $\square$ & $\square$ \\
\hline 4. Focusing on core business & $\square$ & $\square$ & $\square$ & $\square$ & $\square$ & $\square$ & $\square$ \\
\hline 5. Seeking skilled labour overseas & $\square$ & $\square$ & $\square$ & $\square$ & $\square$ & $\square$ & $\square$ \\
\hline 6. $\quad$ Following industry competitors & $\square$ & $\square$ & $\square$ & $\square$ & $\square$ & $\square$ & $\square$ \\
\hline 7. Servicing customers' needs more effectively & $\square$ & $\square$ & $\square$ & $\square$ & $\square$ & $\square$ & $\square$ \\
\hline 8. Improving production flow & $\square$ & $\square$ & $\square$ & $\square$ & $\square$ & $\square$ & $\square$ \\
\hline
\end{tabular}

\section{How does your company conduct outsourcing activities?}

Directly from a foreign country

$\square$ Through an intermediate party (e.g. agent) based at home country or foreign country

$\square$ In combination of above (please indicate percentage of each):

Direct outsourcing _ _ $\%$; through an agent__ $\%$;

13. If your company conducts outsourcing activities through intermediate parties, where are they located?

$\square$ In the home country (e.g. Australia or New Zealand)

$\square$ In the foreign country where your company conduct its outsourcing activities

$\square$ A combination of two answers above

$\square$ Other (please specify):

14. How many outsourcing suppliers do you have internationally?

(in numbers) suppliers 


\section{Outsourcing Activities in China}

In this section, we are interested specifically in your company's overall outsourcing experience in China. Most of the questions ask for your opinion. There are no correct or incorrect answers. Please answer each question to the best of your knowledge.

15. In which year did you commence your outsourcing activities in China?

Year

16. In this section, we are interested in your opinion regarding your main supplier relationship in China.

\section{Main supplier for China}

1. Number of suppliers

2. How long has your company been working with this party? (in month)

17. Please rate how important the main Chinese supplier is relative to your company's overall activities in China on a scale from 1 to 7 , where 1 = completely unimportant and 7 = utmost importance.

1. Main Chinese supplier

18. Please rate how important the main Chinese suppliers is relative to your company's overall activities worldwide on a scale from 1 to 7 , where 1 = completely unimportant and 7 = utmost importance.

\begin{tabular}{|lllll|llll|} 
& $\begin{array}{c}\text { Completely } \\
\text { unimportant }\end{array}$ & \multicolumn{4}{c}{$\begin{array}{c}\text { Utmost } \\
\text { importance }\end{array}$} \\
1. Main Chinese supplier & $\mathbf{1}$ & $\mathbf{2}$ & $\mathbf{3}$ & $\mathbf{4}$ & $\mathbf{5}$ & $\mathbf{6}$ & $\mathbf{7}$ & $\mathbf{n} / \mathbf{a}$ \\
\hline
\end{tabular}

19. Please indicate how similar you feel that China is to your own country on a scale from 1 to 7, where 1 = completely the same, 4 = moderately similar, and 7 = completely different. 


\begin{tabular}{|c|c|c|c|c|c|c|c|}
\hline & $\begin{array}{c}\text { Completely } \\
\text { the same }\end{array}$ & & & & & Com & $\begin{array}{l}\text { etely } \\
\text { rent }\end{array}$ \\
\hline & 1 & 2 & 3 & 4 & 5 & 6 & 7 \\
\hline 1. Culture & $\square$ & $\square$ & $\square$ & $\square$ & $\square$ & $\square$ & $\square$ \\
\hline 2. Religion & $\square$ & $\square$ & $\square$ & $\square$ & $\square$ & $\square$ & $\square$ \\
\hline 3. People's thinking & $\square$ & $\square$ & $\square$ & $\square$ & $\square$ & $\square$ & $\square$ \\
\hline 4. The way of doing business & $\square$ & $\square$ & $\square$ & $\square$ & $\square$ & $\square$ & $\square$ \\
\hline 5. Language & $\square$ & $\square$ & $\square$ & $\square$ & $\square$ & $\square$ & $\square$ \\
\hline 6. Legal environment & $\square$ & $\square$ & $\square$ & $\square$ & $\square$ & $\square$ & $\square$ \\
\hline 7. The economic environment & $\square$ & $\square$ & $\square$ & $\square$ & $\square$ & $\square$ & $\square$ \\
\hline 8. The political environment & $\square$ & $\square$ & $\square$ & $\square$ & $\square$ & $\square$ & $\square$ \\
\hline
\end{tabular}

20. Please indicate your familiarity about China as a country on a scale from 1 to 7 , where $\mathbf{1}$ = completely unfamiliar, $\mathbf{4}=$ moderately familiar, and $\mathbf{7}=$ completely familiar.

\begin{tabular}{|c|c|c|c|c|c|c|c|}
\hline & $\begin{array}{c}\text { Completely } \\
\text { unfamiliar }\end{array}$ & & & & & $\begin{array}{r}\text { Comp } \\
\text { fa }\end{array}$ & $\begin{array}{l}\text { etely } \\
\text { iliar }\end{array}$ \\
\hline & 1 & 2 & 3 & 4 & 5 & 6 & 7 \\
\hline 1. Culture & $\square$ & $\square$ & $\square$ & $\square$ & $\square$ & $\square$ & $\downarrow$ \\
\hline 2. Religion & $\square$ & $\square$ & $\square$ & $\square$ & $\square$ & $\square$ & $\square$ \\
\hline 3. People's thinking & $\square$ & $\square$ & $\square$ & $\square$ & $\square$ & $\square$ & $\square$ \\
\hline 4. The way of doing business & $\square$ & $\square$ & $\square$ & $\square$ & $\square$ & $\square$ & $\square$ \\
\hline 5. Language & $\square$ & $\square$ & $\square$ & $\square$ & $\square$ & $\square$ & $\square$ \\
\hline 6. Legal environment & $\square$ & $\square$ & $\square$ & $\square$ & $\square$ & $\square$ & $\square$ \\
\hline 7. The economic environment & $\square$ & $\square$ & $\square$ & $\square$ & $\square$ & $\square$ & $\square$ \\
\hline 8. The political environment & $\square$ & $\square$ & $\square$ & $\square$ & $\square$ & $\square$ & $\square$ \\
\hline
\end{tabular}




\section{Outsourcing Relations}

In this section, we are interested in your company's outsourcing relations you're your main Chinese supplier.

21. Based upon your experience with you main Chinese supplier, please indicate the extent of your agreement with the following statements about each on a scale from 1 to 7 .

$\mathbf{1}=$ completely disagree, $\mathbf{2}=$ disagree, $\mathbf{3}=$ somehow disagree, $\mathbf{4}=$ neither agree nor disagree, $\mathbf{5}$ = somehow agree, $\mathbf{6}=$ agree, $\mathbf{7}=$ completely agree. If any of the statement does not apply to your company, please put $\underline{\mathbf{N} / \mathbf{A}}$ instead.

\section{Main Chinese Supplier}

1. We trust that this supplier makes beneficial decisions for us under any circumstances.

2. This supplier is willing to provide assistance to us without exception.

3. We are generally sceptical of the information provided to us by this foreign supplier.

4. Without monitoring, this foreign supplier would fulfil his obligations.

5. We and this supplier are willing to devote all resources needed for the relationship.

6. We would not drop this supplier even if another supplier offers us better terms.

7. We are fully committed to helping this supplier in the long term.

8. We share mutual information with this supplier regarding the business environment and technical change that affects each other's businesses.

9. We mutually share proprietary information with this supplier.

10. We only provide information to this supplier according to a prespecified agreement.

11. This supplier lets us know as soon as possible about any unexpected 
Main Chinese Supplier

problems (e.g. late delivery, financial problems).

12. The communication between us and this supplier is complete and thorough.

13. There is no language barrier between us and this supplier.

14. We have made significant investments for this supplier (e.g. upgraded production systems).

15. If we wanted to, we could switch to another supplier quite easily.

16. If this supplier wanted to, they could easily switch to another client.

17. Our senior manager has extensive personal relationships with this supplier.

18. Based upon our senior manager's personal relationship with this supplier, our company was able to gain privileges.

19. Our senior manager was able to obtain valuable and important information based on his/her personal relationship with this supplier.

20. When problem arises, our senior manager contact this supplier for resolutions based on their personal relationship.

21. Our outsourcing contract with this supplier is highly customised and required considerable legal work.

22. We believe a detailed contract is the most important tool for regulating the behaviour of this supplier.

23. When it comes to disputes and arbitration concerning the products and services with this supplier, we always follow the terms of the contract.

24. Our company-specific routines and workflows are customised to this supplier.

25. We invested a significant amount of time in developing the skill level of our employees to suit this supplier.

26. It's very costly for us to switch from this supplier. 


\section{E. Outsourcing Challenges}

In this section, we are interested in your company's opinion on outsourcing challenges.

22. What do you consider to be the main challenges for your company in developing a working relationship with your main Chinese suppliers? Please rate your opinions next to each statement on a scale from 1 to 7.

$\mathbf{1}=$ completely $\underline{\text { disagree, }} \mathbf{4}=$ neither agree nor disagree, $\mathbf{7}=$ completely agree. If any of the statements does not apply to your company, please put $\underline{\mathbf{N} / \mathbf{A}}$ instead.

Main Chinese Supplier

1. The probability of this supplier acting opportunistically is high.

2. The potential for conflicts regarding the way we do business with this supplier is high.

3. The likelihood of this supplier acquiring useful technological information from us for their own benefit is high.

4. The likelihood of unexpected costs in this working relationship is high.

5. This supplier has a tendency of requiring longer lead time than others in the past.

6. This supplier has a tendency of late delivery issues in the past.

7. This supplier has a tendency of quality issues in the past.

8. Our contract with this supplier suffers from lack of detail about project scope.

9. Our contract with this supplier suffers from lack of detail about the project compliance.

10. Our contract with this supplier suffers from lack of detail about penalty clauses. 


\section{Respondent Information}

23. Are you: $\square$ Female $\square$ Male

24. What is your current position?

$\square$ Owner/CEO

$\square$ Management team

$\square$ Employee

$\square$ Assistant personnel, administrative, secretarial

$\square$ Other (please specify):

25. Specifically, what is your job title? (e.g. operation manager)

26. Are you the person responsible for decisions made on outsourcing activities in your company?

$\square$ Yes $\quad \square$ No (please specify your responsibility):

27. Please indicate your work experience:

Your overall outsourcing experience (in years):

28. Are there any other comments you would like to share with us? 